FORMAL ASSESSMENT AND MEASUREMENT OF DATA UTILIZATION AND VALUE FOR MINES

By

William Pratt Rogers

Copyright $($ ) William Pratt Rogers 2015

\begin{abstract}
A Dissertation Submitted to the Faculty of the
DEPARTMENT OF MINING AND GEOLOGICAL ENGINEERING
\end{abstract}

In Partial Fulfillment of the Requirements

For the Degree of

DOCTOR OF PHILOSOPHY

WITH A MAJOR IN MINING, GEOLOGICAL AND GEOPHYSICAL ENGINEERING

In the Graduate College

THE UNIVERSITY OF ARIZONA 


\section{THE UNIVERSITY OF ARIZONA}

\section{GRADUATE COLLEGE}

As members of the Dissertation Committee, we certify that we have read the dissertation prepared by William Pratt Rogers, titled “ Formal Assessment and Measurement of Data Utilization and Value for Mines" and recommend that it be accepted as fulfilling the dissertation requirement for the Degree of Doctor of Philosophy.

Date: $(11 / 24 / 2015)$

Sean Dessureault

Date: (11/24/2015)

Mary Poulton

Date: (11/24/2015)

John Kemeny

Date: (11/24/2015)

Moe Momayez 


\section{STATEMENT BY AUTHOR}

This dissertation has been submitted in partial fulfillment of the requirements for an advanced degree at the University of Arizona and is deposited in the University Library to be made available to borrowers under rules of the Library.

Brief quotations from this dissertation are allowable without special permission, provided that an accurate acknowledgement of the source is made. Requests for permission for extended quotation from or reproduction of this manuscript in whole or in part may be granted by the copyright holder.

SIGNED: William Pratt Rogers 


\section{ACKNOWLEDGEMENTS}

First, I would like to thank Dr. Sean Dessureault for the opportunity to pursue graduate studies. The people I have been able to meet, new concepts explored, and hard work have been life changing. Thanks for the challenge, mentoring, and support. Dr. Mary Poulton has been a great mentor and inspiration. Thanks for getting me exciting about the mining industry. The remaining members of my committee Dr. John Kemeny and Dr. Moe Momayez have been great supporters and their feedback enhanced my studies and career.

Dr. Dave Hammond's advice and mentoring will always be appreciated.

The MISOM and MIRG lab students I consider some of my best friends. Mustafa Kahraman was a great sounding board for ideas and exploring concepts. I highly value his friendship.

My mother, Debbie Rogers, for her editing services. It would have been impossible to finish without your help.

Kortney, my wife, thank you for supporting and encouraging me never to give up.

I truly feel God is involved in the details of our lives. I have felt His calming and encouraging influence throughout my life as I have sought it. I acknowledge His hand in all my accomplishments. 


\section{DEDICATION}

To my wonderful wife Kortney and my children. 


\section{Contents}

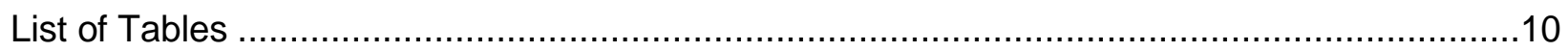

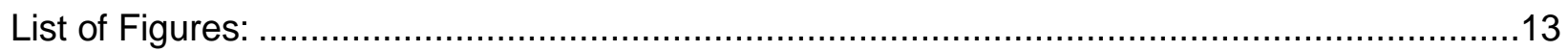

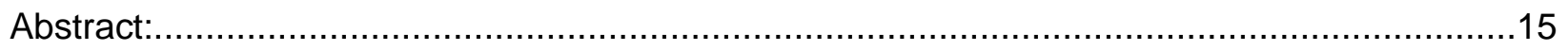

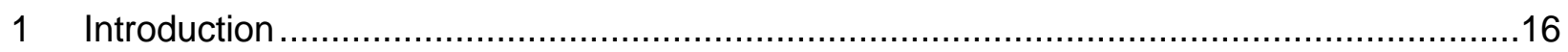

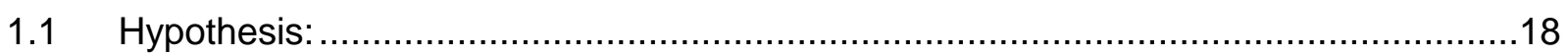

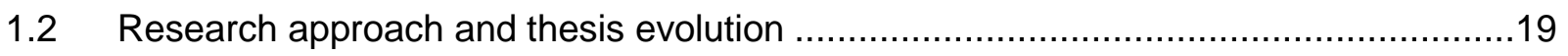

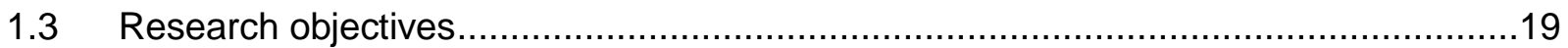

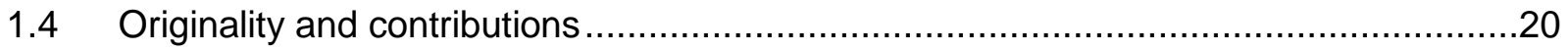

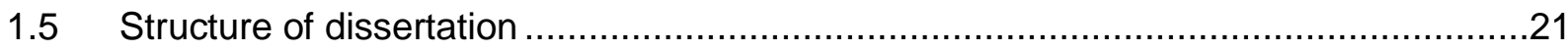

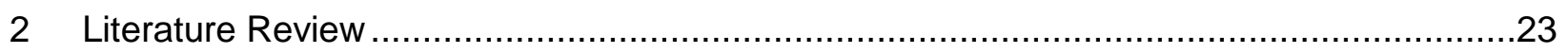

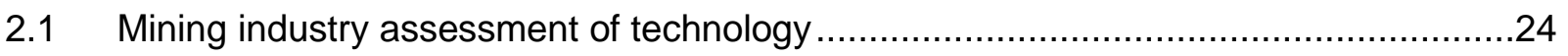

2.2 Technology system deployment assessment: and Management of Information System

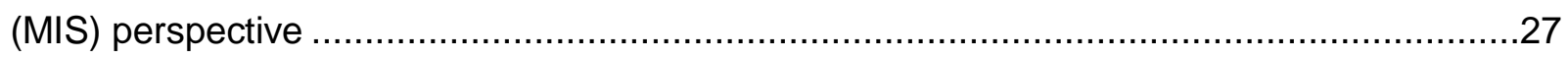

2.3 Measuring and assessing value of information/data...............................................

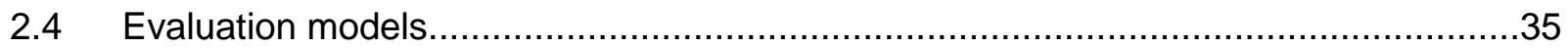

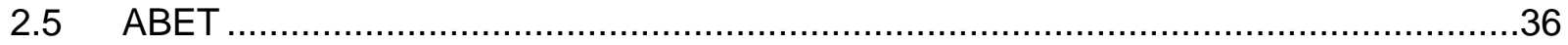

$2.6 \quad$ Literature review conclusions:

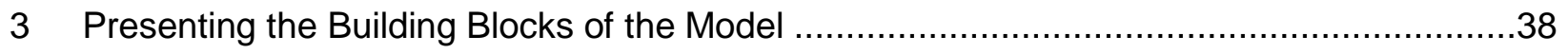

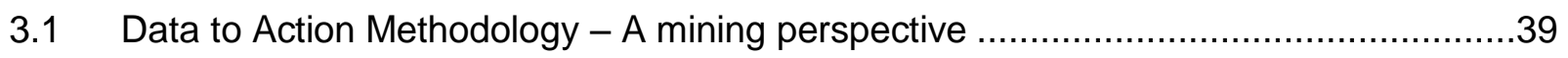

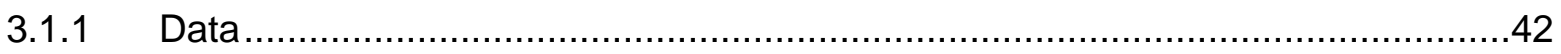




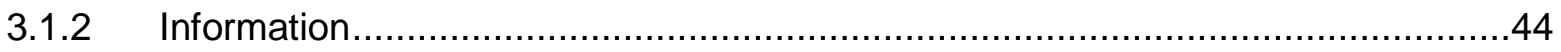

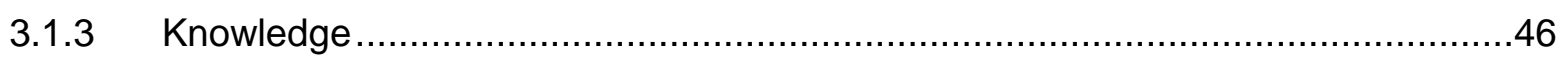

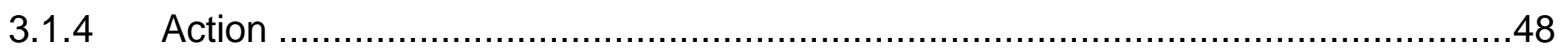

3.2 Measuring utilization as a means of motivation ...................................................

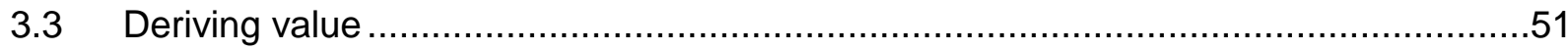

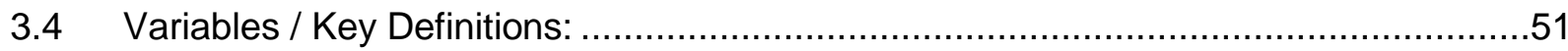

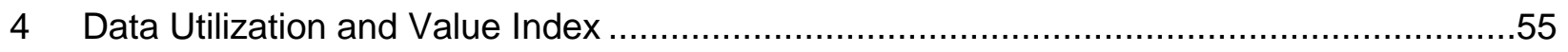

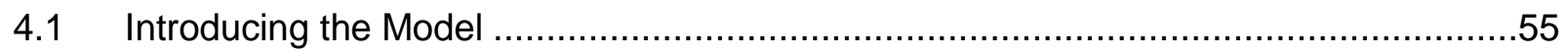

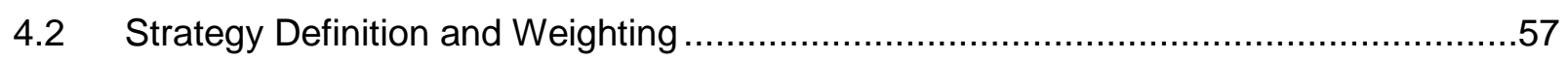

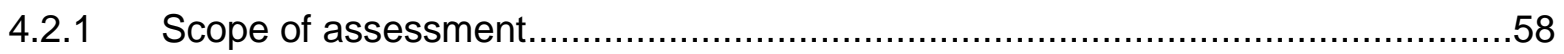

4.2.2 Define BI strategy and factor variables........................................................6

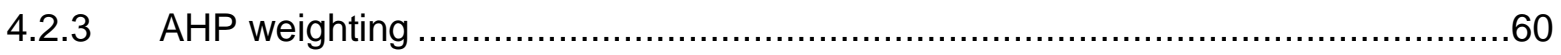

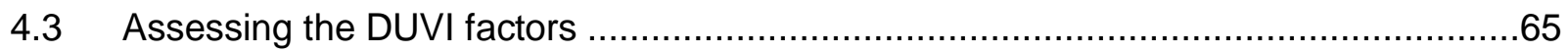

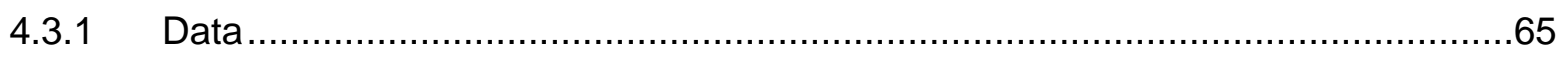

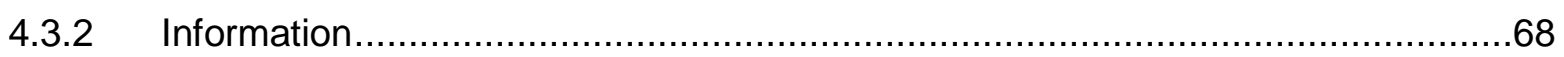

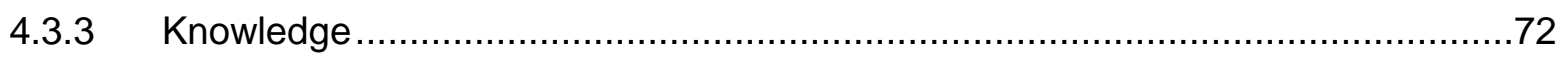

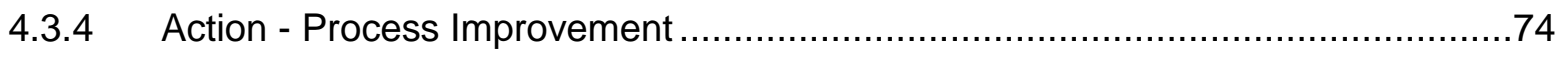

4.4 Visualizing and Managing Data Utilization .........................................................

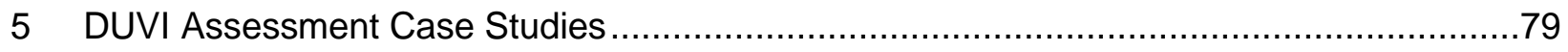

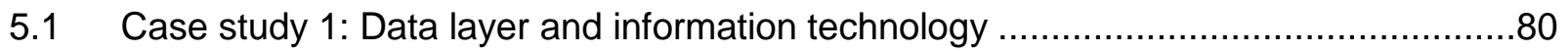

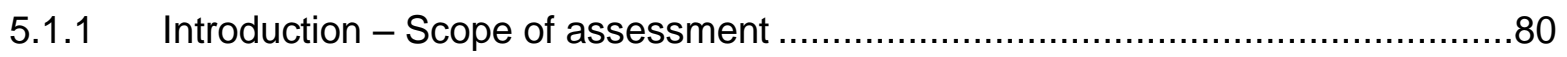




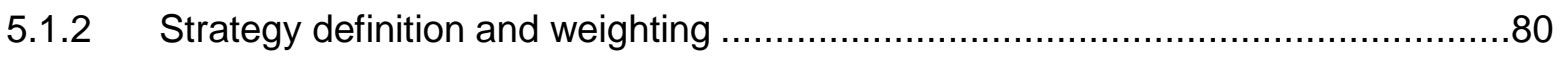

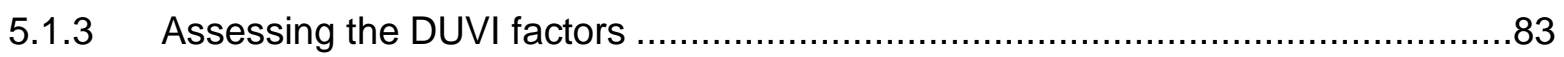

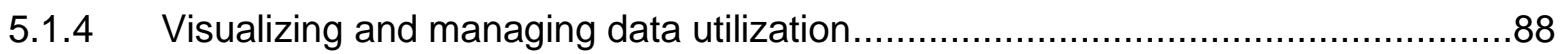

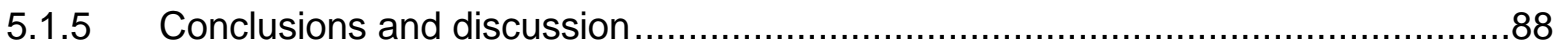

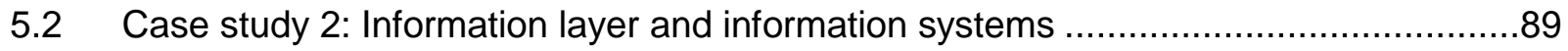

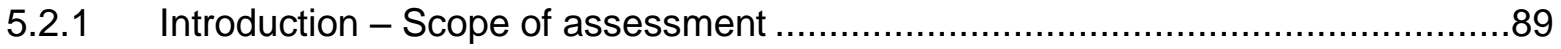

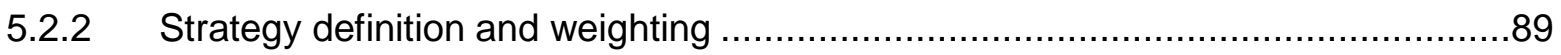

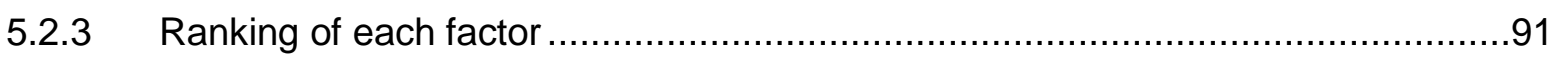

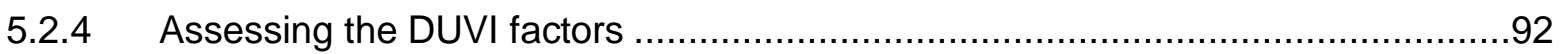

5.2.5 Visualizing and managing data utilization.................................................

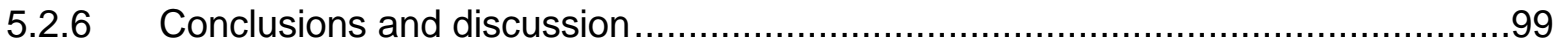

5.3 Case study 3: Knowledge layer and business insight .....................................100

5.3.1 Introduction - Scope of assessment .................................................... 100

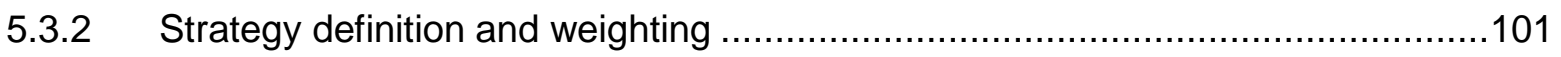

5.3.3 Assessing the knowledge layer factors DUVI ....................................... 104

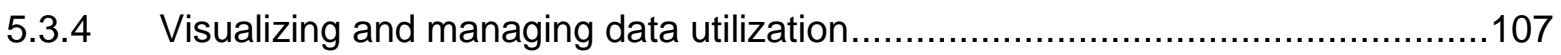

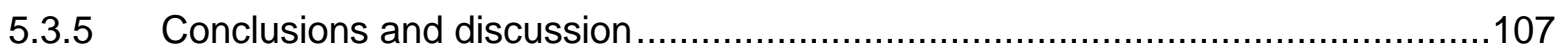

5.4 Case study 4: Action layer and process improvement ........................................109

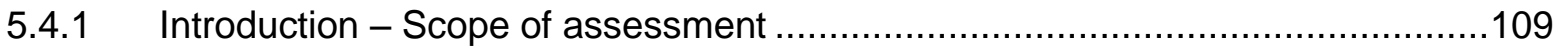

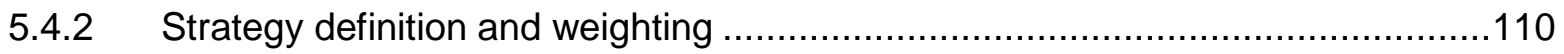

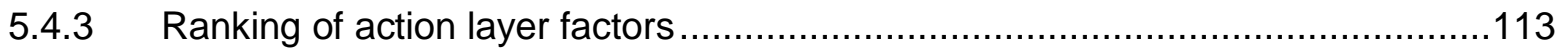


5.4.4 Assessing the DUVI factors DUVI ...........................................................114

5.4.5 Visualizing and managing data utilization.................................................119

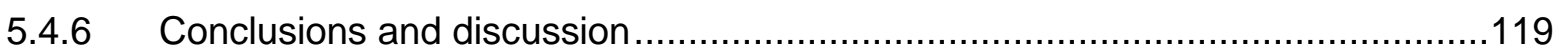

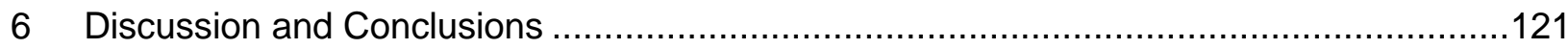

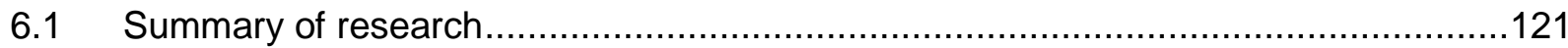

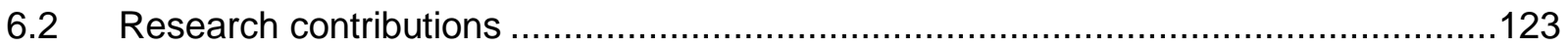

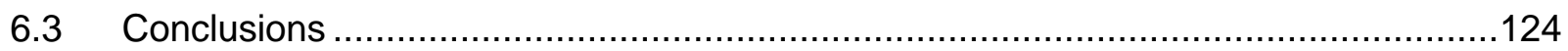

6.4 Methodology review and recommendations for future research: ...........................124

$7 \quad$ Appendix:

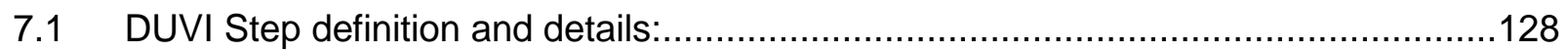

7.2 Analytical Hierarchy Process Calculations ………...........................................129

7.3 Excel calculations of DUVI showing sum product.............................................132

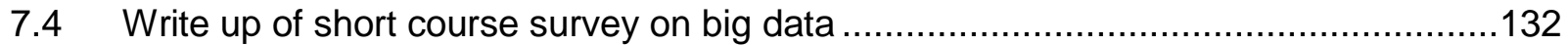

7.5 Justification NPV and Real Options Analysis ..................................................132

7.5.1 Conceptual Justification Model Introduction: ...............................................133

7.5.2 NPV and IT Investment classification and schedule ....................................135

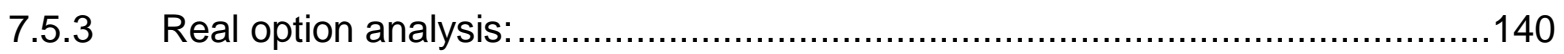

7.5.4 Option and Scenario Modeling …………..............................................140

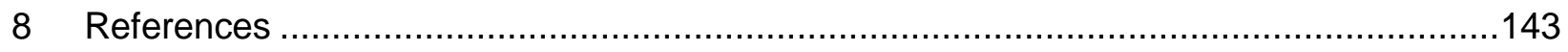




\section{List of Tables}

Table 2-1: Key contributions of literature concepts ....................................................23

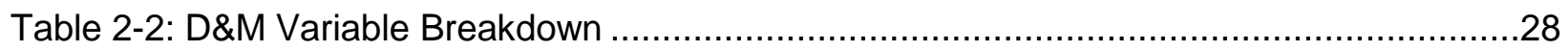

Table 2-3: Description of performance expectancy model independent variables ...................30

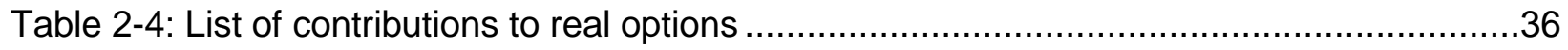

Table 3-1: Common systems used in the mining industry ...........................................42

Table 3-2: Proposed data layer best practices and modeling factors................................44

Table 3-3: Proposed information layer best practices and modeling factors .........................46

Table 3-4: Proposed knowledge layer best practices and modeling factors..........................47

Table 3-5: Proposed action layer best practices and modeling factors ...............................49

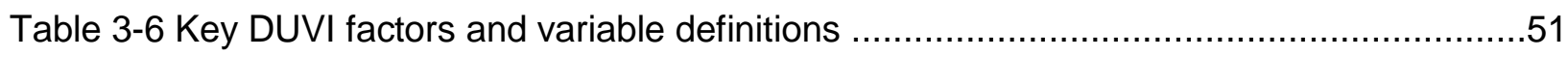

Table 4-1: Pairwise comparisons among BI Layers...................................................61

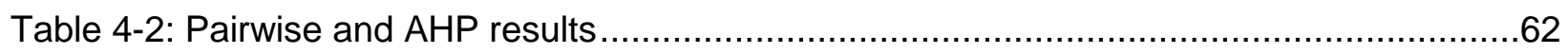

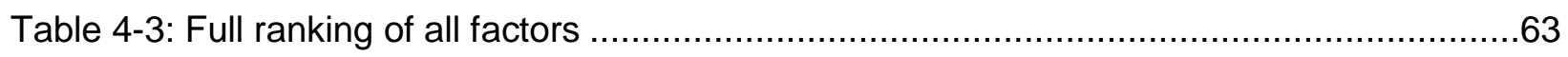

Table 4-4: Sample DUVI with AHP weights and scores example. ..................................64

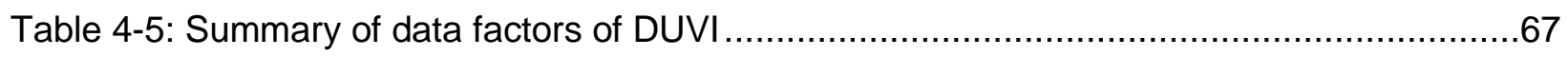

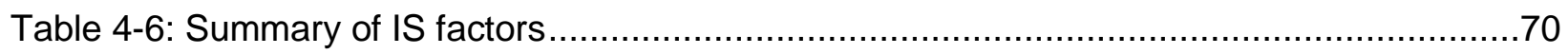

Table 4-7: Summary of factors for the knowledge layer............................................73

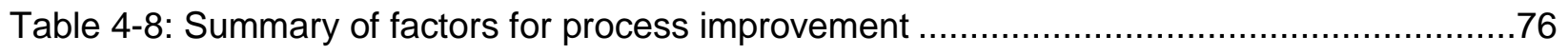

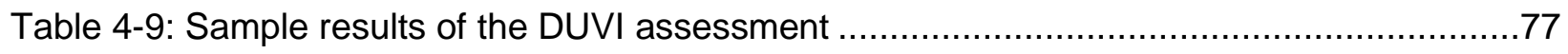

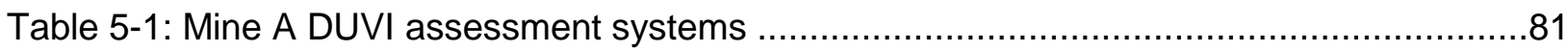

Table 5-2: Pairwise comparisons among BI Layers for Mine A ........................................ 82

Table 5-3: Pairwise comparison the key DUVI factors grouped by BI layers. .........................83

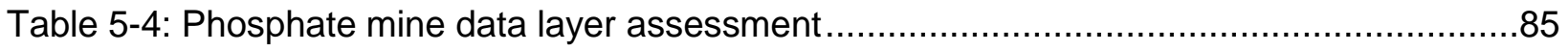

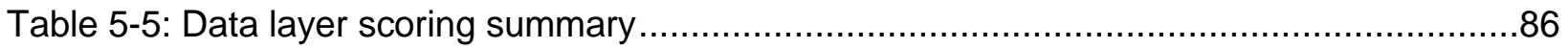




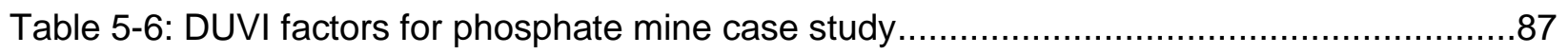

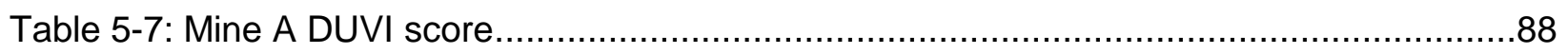

Table 5-8: Mine B assessment systems scope .............................................................90

Table 5-9: Pairwise comparisons among BI layers for medium sized coal mine. .....................91

Table 5-10: Pairwise comparison of the key DUVI factors grouped by BI layers.....................91

Table 5-11: Mine B information layer assessment ....................................................93

Table 5-12: Sample data set of OLAP use metadata...................................................96

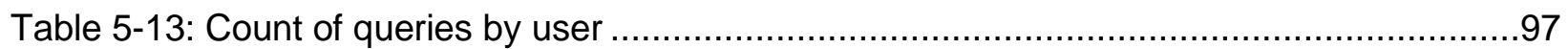

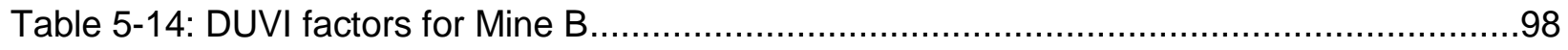

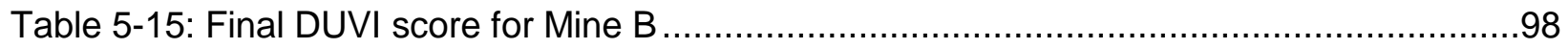

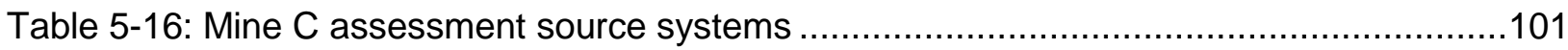

Table 5-17: Pairwise comparisons among BI Layers for Mine C .....................................103

Table 5-18: Pairwise comparison of the key DUVI factors grouped by BI layers....................104

Table 5-19: Mine C knowledge layer assessment .................................................... 105

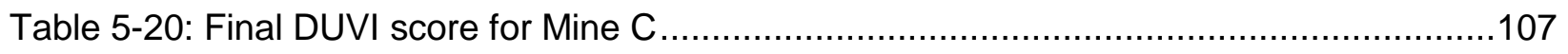

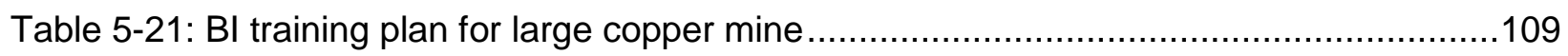

Table 5-22: Mine D mine assessment systems scope ............................................110

Table 5-23: Pairwise comparisons among BI Layers for Mine D. ..................................113

Table 5-24: Mine D pairwise comparison for action layer. ........................................114

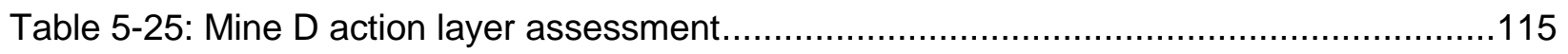

Table 5-26: Mine D scorecard statistics for comparing KPI's to leading indicators.................116

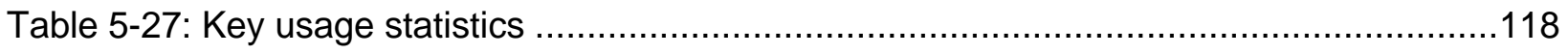

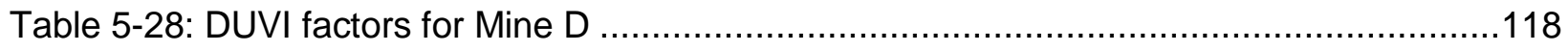

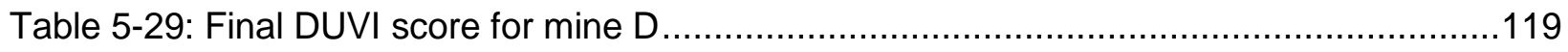

Table 7-1: Definition and details of the DUVI assessment ...........................................128

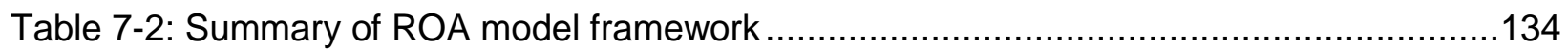




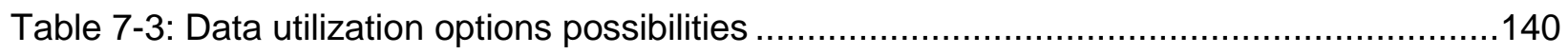

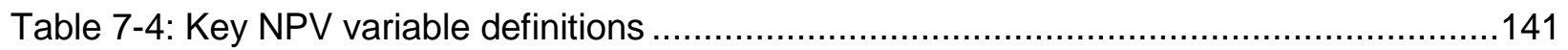




\section{List of Figures:}

Figure 1-1: Data utilization measurement process ……….............................................17

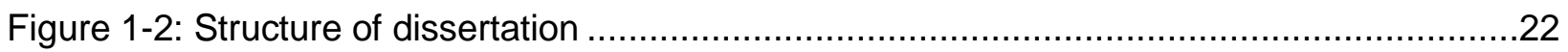

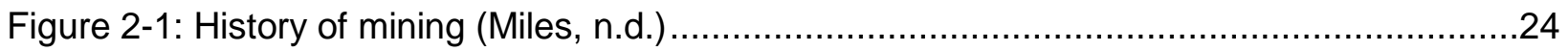

Figure 2-2: History of Dr. Dessureault's research and business (Dessureault, 2015) ...............27

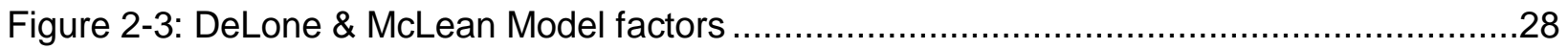

Figure 2-4: Performance expectancy model of factors driving usage behavior ........................29

Figure 2-5: Example scorecard used by Kaplan \& Norton in measuring intangible assets.........33

Figure 2-6: Lavelle et al., visualization of the constant flux of the pathway of value of data .......34

Figure 2-7: The three pillars of data quality presented by Sadiq ............................................35

Figure 3-1. Three Pillars of Sustaining Data-Driven Technology (Mottola \& Payton, n.d.),

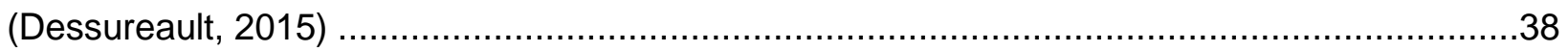

Figure 3-2. Data-Driven Process Change (Dessureault, 2015) .............................................39

Figure 3-3: Data to Action technical architecture …................................................................

Figure 3-4: Connecting literature to the data - action methodology .........................................4

Figure 3-5: Scorecard Prioritization Process (Dessureault, 2015) …………………….......48

Figure 4-1: Data to action methodology with a set of best practice factors ..............................55

Figure 4-2: Data Value Index and assessment process map...........................................57

Figure 4-3: Defining strategy through business process mapping …….................................59

Figure 4-4 Pairwise weighting score assumptions .........................................................61

Figure 4-5: Key system isolation process mapping. .......................................................6

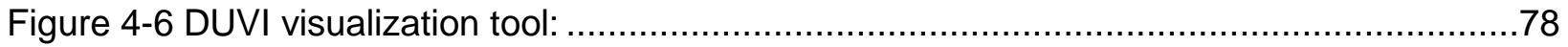

Figure 5-1: Web based drill and blast production report (Dessureault, 2015) ...........................94

Figure 5-2: Steps to update engineering reports ……..........................................................95

Figure 5-3: Frontline supervisor and operator engagement platform (Dessureault, 2015) .........99 


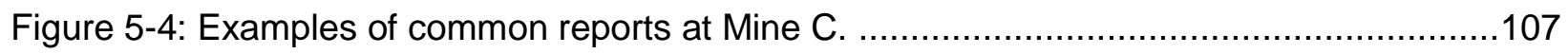

Figure 5-5: Business intelligence tool process maps (Dessureault, 2015) ..........................108

Figure 5-6: Mine D histogram of query duration of key knowledge modules ........................117

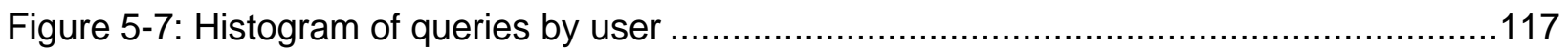

Figure 6-1: Comparisons of the DUVI of the case studies ............................................ 122

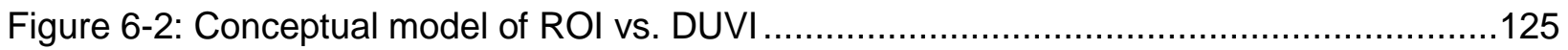

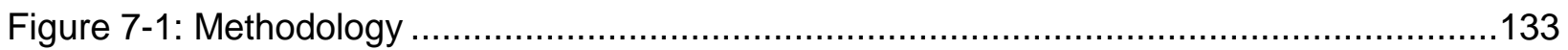

Figure 7-2: A typical investment assumptions and schedule ......................................137

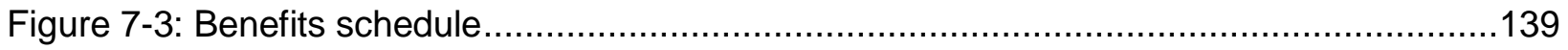

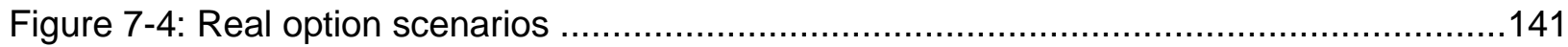




\begin{abstract}
:
Most large contemporary mines already have considerable amounts of data, much of which goes largely unused. The key challenge in big data is increasing data utilization. Much of the data in the mine (not plant) come from a variety of systems, each with different databases and reporting environments. Standard technology deployments create a "silo-ification" of data leading to poor system usage. Through modern server monitoring, data utilization can quantifiably be measured. A host of other quantifiable, often automated approaches, to measuring data use and value can also be incorporated as a means of monitoring value generation. A data valuation tool is presented to measure the data assets at an operation. The Data Value Index (DVI) quantifies business intelligence best practices and user interaction considering managerial flexibility and data utilization rates. The DVI is built considering many case studies of data warehousing at various mining companies, some of which will be presented.
\end{abstract}




\section{Introduction}

Sustained data utilization can fundamentally change the trajectory of a company or industry. Informed decisions made in a more data-centric manner through advances in technology and business processes impact all levels of the value chain. Purchasing and deploying technology does not inherently lead to these data driven decisions. Mining technology must be purposefully integrated into the culture of an organization. To assist an organization in making informed technological requisitions, the management team needs to ask specific questions, such as:

- What does sustained data utilization look like?

- What separates our company from another?

- What best practices can be followed?

- How can our company know the best investment strategy for technology adoption and maximizing the efficiency of our data assets?

These questions are examined within this dissertation and a process is presented to answer them. Technology and innovation have always been a defining feature of man and extraction of resources (Coulson, 2012). Companies that maximize the use of their technology can extract resources more efficiently.

Modern database technology has changed the paradigm of innovation (Davis, 1989). The MIS industry has been studying technology adoption for decades (Bradley, et al., 2006). Many models have been developed and used to improve and increase the likelihood of successful deployments. (DeLone \& McLean, 2003). More recently, research and models have been developed on how organizations can derive value from their data assets (LaValle, et al., 2013), (Kaplan \& Norton, 2004). Many of these models focus on defining the variables and determining which are independent or dependent. All models find that system usage is critical but lack a clear and sustainable measurement process of system and data usage. 
Technology innovation continues to push the limits of intelligence systems (Burrus, 2014). The "internet of things", big data analytics, and data integration will shape the modern world (Nusca, 2015), (Dutton \& Afuang, 2015), (Witchalls, 2013). The mining industry can also be transformed by these innovative tools. However, the industry must be able to increase their utilization of current technology systems. The area of mining innovation and technology has long been researched (Bartos, 2007) and (Tilton \& Landsburg, 1999). The role of database technology, particularly data integration, in mine management has also been thoroughly researched (Dessureault, 2002) \& (Kahraman, 2015). Many innovative "updates" to mine management methods have resulted from these lines of research.

The author proposes that the MIS industry as well as the mining industry, need a method to assess data utilization. This notion will be established by case-studies showing the mining industry to be high-tech and needful of a management tool to assist in increasing data utilization. Technology adoption requires a multi-pronged approach and the current methods and models are insufficient to manage data utilization within an organization.

The research presented herein determines the factors to assess along with a method to quantify data utilization. A three-phase process is required and is illustrated in Figure 1-1. A technology adoption strategy must be clearly defined. A strategy will consider how technology will interact with people through a series of management processes.

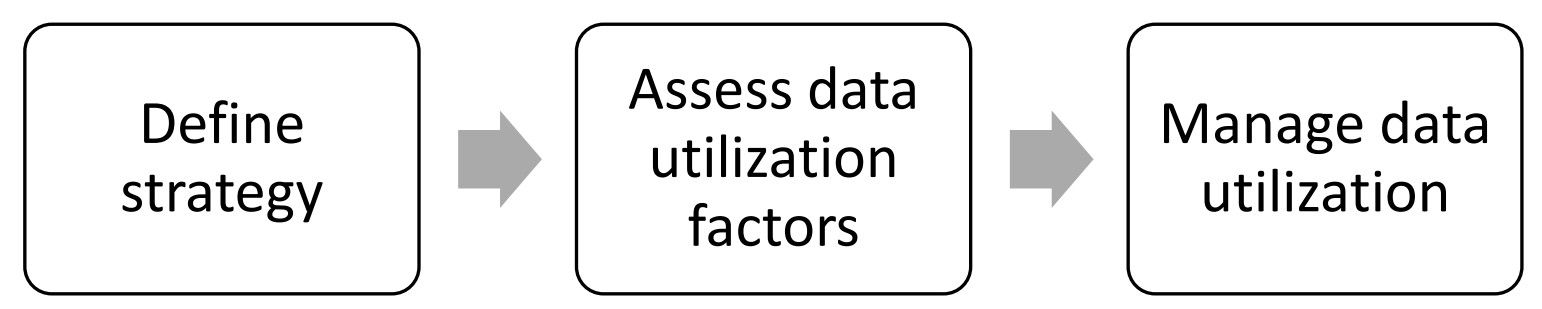

Figure 1-1: Data utilization measurement process 
Next, a set of data utilization best practices are assessed through quantitative variables. These factors fit in each layer of the business intelligence layers; data, information, knowledge, action. Finally the assessment can act as a management tool to manage data utilization and subsequently technology usage and innovation.

\subsection{Hypothesis:}

The hypotheses of the dissertation is as follows:

Data utilization and value can be measured. The variables that comprise utilization include:

- System health: system uptime and configuration

- Information quality: accuracy and applicability of the information

- System use: data utilization is proportional to technology usage and innovation

- Business insight: the potential value of the data versus what is being created from the data

- Process improvement: the action impacts induced by the data (and associated utilization processes).

Why - Measuring data use, as with measuring the use of hard capital assets, will induce an increase in utilization. A key assumption is that increased use results in greater operational and technical efficiencies.

What - Use constitutes acting on knowledge delivered through information, not simply the act of viewing a report.

How - Identifying the best practices for data management, continuous improvement, and business intelligence delivery can identify the utilization variables. Modern IT can track user activities and hence identify the means of delivering information that maximizes utilization. Mining systems are unique in their variance of data types; relational (transactional, event, and 
dimensional) signal based process data, and to a limited extent, unstructured information bound by forms and paper-bound information.

Consistent use and access to data improves operational outcomes through business insight \& predefined processes.

\subsection{Research approach and thesis evolution}

When first examining this research topic, a real options approach to justifying investment in technology, particularly data warehousing, was taken. After realizing the complexity and importance of the Data Utilization and Value Index as a standalone concept, the author determined a greater focus was needed on the measuring of utilization and value (as a key factor for future application of real options pricing).

There are many factors that make up the technology and cultural aspects of data utilization. The author attempted to encapsulate these into a management assessment of best practices. The viability of these factors are tested extensively in four case studies.

\subsection{Research objectives}

The research objectives are as follows:

- Determine quantifiable variables of information system health, technology acceptance, and usage

- Identify variables and methods used to measure technology and data value and adapt them to the mining context

- Link variables and best practices to the business intelligence data to action methodology

- Assess and measure data utilization of data warehouses and information systems

- Deliver a management tool used to drive culture change and integrate technology into mining 
- Investigate the role of academia in promoting data utilization and culture change

\subsection{Originality and contributions}

This dissertation is focused on developing a framework to measure data utilization and estimate the value of data to a mining business. The author will approach the following concepts in the literature:

1. The first concept is an assessment of the literature related to operational information technology in the mining industry. The knowledge models where data assets are used in mine management and performance improvement are defined. A lack of a formal method to assess technology adoption and data utilization is shown.

2. Next, is a review of MIS standards to measure and assess successful information technology adoption. Technology adoption theories are made up of many independent and dependent variables. The literature review will reveal a lack of formal data utilization assessment of current models.

3. The third main area of literature review will focus on past attempts to quantify the value of information and data. The author postulates that data can generate value for organizations and therefore must be treated like an asset which requires investment.

4. A very brief review of $A B E T$ requirements will be given as a means of structuring the role of academia in propagating data utilization in curriculum as seed stock to the industry's need for knowledge workers.

The key contributions:

- A thorough literature review of technology acceptance models

- Identification of key variables used to assess data utilization 
- Data utilization best practices aligned with the business intelligence data to action methodology

- Quantifying the strategy of an organization related to people, process and technology

- Data utilization and value assessment process

- Appling the process to four cases studies of the adoption, then use, of data in various mining processes

- The first measurement tool for data utilization in mining

- Justification for introducing information technology in mining curriculum

\subsection{Structure of dissertation}

The research consists of six chapters:

Chapter 1: General introduction, hypothesis, description of research objectives, contributions, and structure

Chapter 2: Literature review on the key concepts of: technology acceptance models, value of data, mining technology practices, evaluation models, and ABET curriculum for mining engineering and data

Chapter 3: Presentation of the foundational concepts of the Data Utilization and Value Index (DUIV) framework and the data to action methodology. Here, the key variables used to assess each layer are introduced with an analysis of the importance of measuring utilization, assessing the value from the data to action process, and finally a list of key definitions.

Chapter 4: Provides the methodology used for the Data Utilization and Value Index (DUVI)

Chapter 5: Describes how the DUVI was used to assess four mines and the methodology used

Chapter 6: Summary of the research, key findings, next steps, and conclusions

Figure 1-2 represents the structure of the dissertation. 


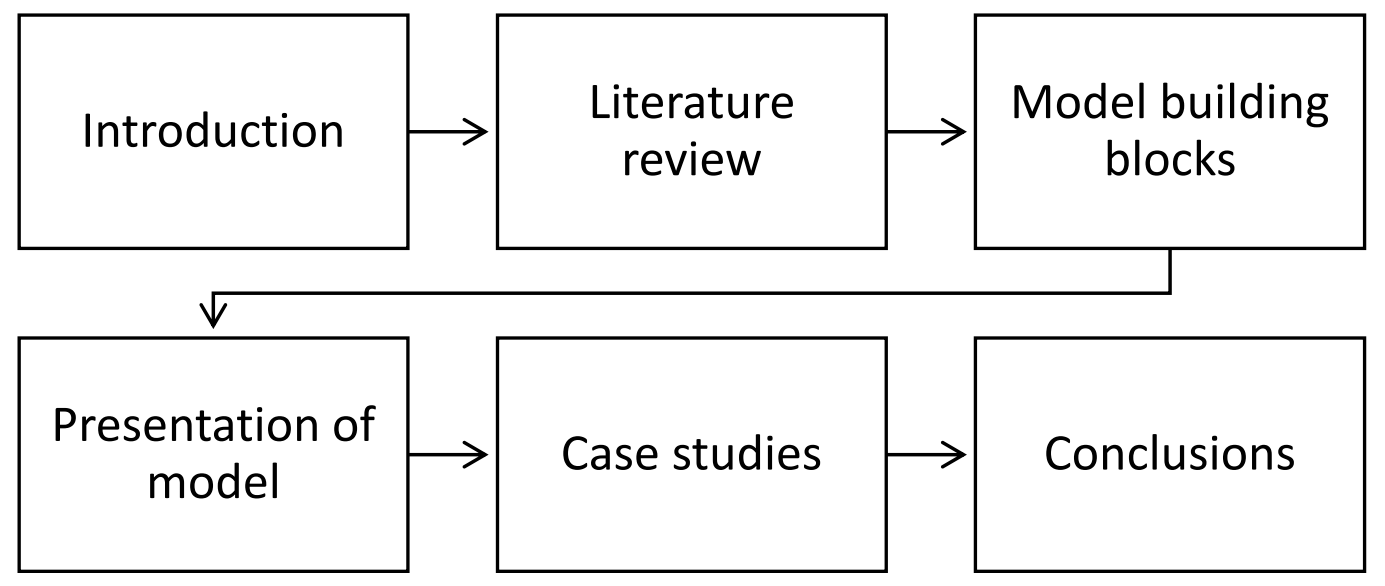

Figure 1-2: Structure of dissertation 


\section{Literature Review}

The literature related to technology adoption, value of information, and mining technology is broad and well researched. Table 2-1 provides the key contributions for each subject. More details follow.

Table 2-1: Key contributions of literature concepts

\begin{tabular}{|c|c|c|}
\hline Key Concept & Contributions & Main Points \\
\hline \multirow[t]{3}{*}{ Mining Industry \& Technology } & (Bartos, 2007) & $\begin{array}{l}\text { Investigation of role of technology } \\
\text { and innovation in productivity rates }\end{array}$ \\
\hline & (Tilton, 2003) & $\begin{array}{l}\text { Economics of technology and } \\
\text { innovation }\end{array}$ \\
\hline & (Dessureault \& Scoble, 2003) & Data and mine management \\
\hline $\begin{array}{l}\text { Modeling Technology } \\
\text { Deployments }\end{array}$ & (Davis, 1989) & $\begin{array}{l}\text { Defining user acceptance of } \\
\text { Information Technology (IT) }\end{array}$ \\
\hline \multirow{4}{*}{ Deployments } & (DeLone \& McLean, 1992) & $\begin{array}{l}\text { Modeling the variables of } \\
\text { successful IT deployments }\end{array}$ \\
\hline & (Bradley, et al., 2006) & $\begin{array}{l}\text { Connecting IT to corporate culture } \\
\text { to ensure technology adoption }\end{array}$ \\
\hline & (Venkatesh, et al., 2003) & $\begin{array}{l}\text { Technology usage and corporate } \\
\text { culture }\end{array}$ \\
\hline & (Nelson, et al., 2005) & $\begin{array}{l}\text { System quality of Data Warehouse } \\
\text { (DW) }\end{array}$ \\
\hline Value of Information & (LaValle, et al., 2013) & $\begin{array}{l}\text { Deriving value from big data and } \\
\text { analytics }\end{array}$ \\
\hline
\end{tabular}



(Kaplan \& Norton, 2004) Method for measuring value of intangible assets.

(Williams \& Williams, 2010) Value/profit of business

intelligence

\subsection{Mining industry assessment of technology}

In 2007 P.J. Bartos asked the question: "Is mining a high tech industry?" His investigation examined and compared mining productivity rates to other sectors. From this analysis he made inferences on the lack of innovation in the industry and concluded that mining was not "high tech" under the standard economic definition. He was building upon the research by John E. Tilton and his ongoing assessment of innovation and productivity increases in mining (Tilton \& Landsburg, 1999), (Tilton, 2003). Technology has always defined mining as shown in Figure 2-1.

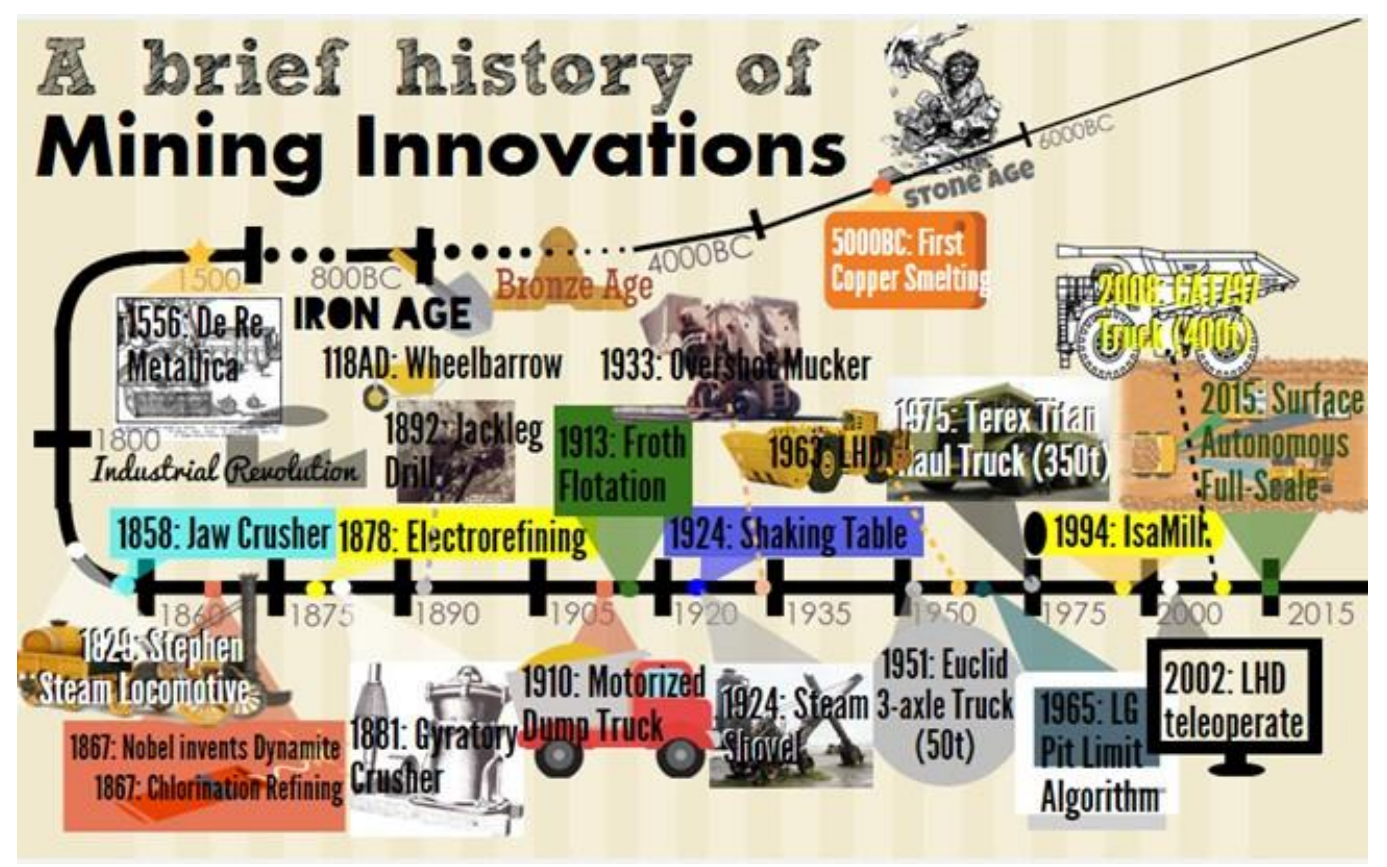

Figure 2-1: History of mining (Miles, n.d.) 
A common theme from the papers cited previously, along with Hitzman, is the role of research and development (R \& D) in technological innovation (Hitzman, 2002). Each discuss the headwinds facing the mining industry due to the lack of $R$ \& $D$ investment. More recently, Filippou and King continue exploring the preceding research and find that the levels of investment in $R$ \& $D$ are not sufficient to thwart the heavy headwinds crippling mining innovation. Managing a mine in a globalized market presents many challenges where technology and innovation provide the critical elements to be competitive and successful (Klippel, et al., 2008).

Another line of research by Upstill \& Hall explores how technology differs through the continued globalization of mining through international mergers and how it affects individual regions. Farooki explores the flow of equipment through the industry and the end destination of mining equipment. Research from Boudreau et el., on equipment innovation and productivity, exhibits that many productivity metrics actually decrease with new equipment deployments. They conclude that technology and innovative equipment does not inherently lead to improvements, but the condition of how the equipment is used is the deciding factor. A continuation of research on the use of technology is a significant conclusion to their work. The role of equipment and technology on occupational health and safety has been explored by several authors (BoudreauTrudel, et al., 2014).

Considering the amount of research done on technology, innovation and productivity, there has also been research on using technology in becoming more efficient to execute step change levels of growth (Bearman, 2013). There are also lines of research on technology assessments. Nikulin et al., provide a nine step process to study the evolution of technical systems.

Dessureault in his dissertation in 2001 examined the role of adopting mine management approaches with new technology. Dessureault \& Scoble 2003 demonstrated that other industries remained profitable and successful during globalization and other related pressures 
because of their operation management's incorporation of using systems and data-driven management. A common theme of Dessureault's approach has been the role of using data warehousing to revolutionize mining operations. Examples of the use of Data Warehouse and Business Intelligence (DWBI) systems in mining often revolve around dimensional analyses related to improving the production systems such as: optimal pit analysis (Benito \& Dessureault, 2008), energy consumption modeling (Dessureault, 2007), and safety (Dessurealt, et al., 2007).

Many improvements in mining engineering and data management have been advanced in Dessureault's lab. A series of theses and dissertations from Dessureault's graduate students:

- Front line management reengineering with data visualization tools (Espinoza, 2013)

- Mine-to-Mill management through data warehousing technology (Erkayauglu, 2015)

- Investigation of role of data integration for drill to leach optimization (Gutierrez, 2008)

- Finding data management opportunities in production management systems (Yildirim, 2005)

- Improvement block caving planning through data warehousing of tech systems (Sinuhaji, 2007)

- Using cost management technology for equipment cost estimations (Salcedo, 2012)

- $\quad$ Managing equipment life using activity based costing (Lopez, 2008)

- Assessing effectiveness of decision support systems and control rooms (Tenorio, 2012)

- Real time adherence to mine plant for integrated control rooms - (Kahraman, 2011)

- Real time bottleneck tracking and holistic mine management - (Kahraman, 2015)

The common theme of each research work is increasing the role of technology in operations management, mine planning, and asset management through data warehousing. An additional contribution by the works cited is that in order for technology to be successful, it must be 
integrated into management through data, process change, and business intelligence.

Therefore, data is a significant asset to mining companies.

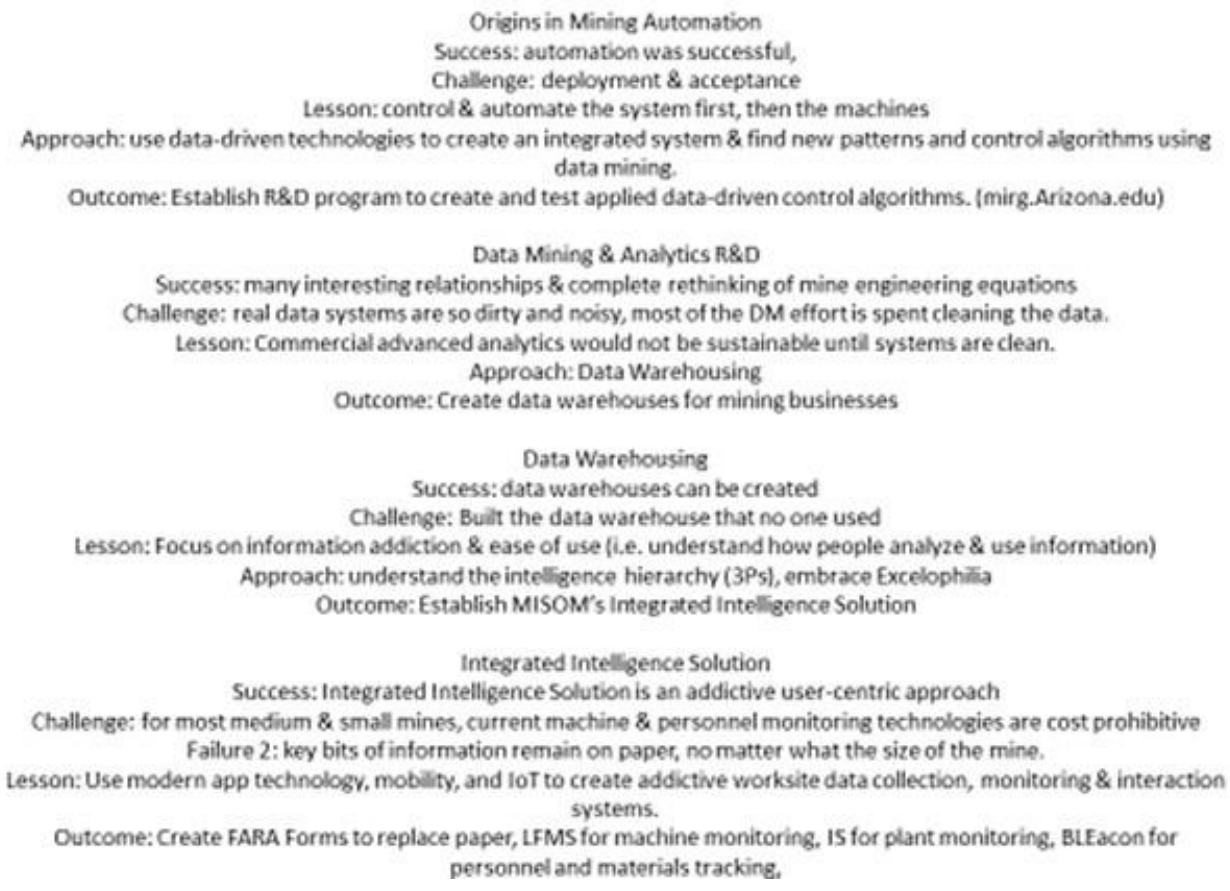

Figure 2-2: History of Dr. Dessureault's research and business (Dessureault, 2015)

The path of Dessureault's research is an excellent history and gauge of mining technology shown in Figure 2-2. Mine automation was the initial work of Dr. Dessureault. A series of successes and opportunities led to increased research in data mining and analytics. As the technology of data warehousing increased, another branch of research and consulting presented itself. Continued advances in technology lead to improved opportunities to disseminate and capture data by frontline supervisors and operators.

\subsection{Technology system deployment assessment: and Management of Information System (MIS) perspective}

Information Systems (IS) have matured rapidly over the past decades and the MIS industry has developed IS success models that assist in understanding the frameworks that lead to successful deployments (Nelson, et al., 2005). What's more, successful deployments are the 
outcome and driven by use of the systems or utilization of data (Bradley, et al., 2006). This section summarizes the current literature and techniques used for assessing IS success and data utilization.

Modeling successful deployments of technology and information systems began at the onset of information technology's use in business (Davis, 1989). Davis concluded there are two key determinates of user acceptance of technology: perceived usefulness and ease of use. DeLone and McLean built on the work of Davis by creating more detailed factors of what defines perceived usefulness and ease of use (DeLone \& McLean, 1992). DeLone \& McLean modeled additional determinants of technology acceptance which are summarized in Figure 2-3Error!

\section{Reference source not found.}

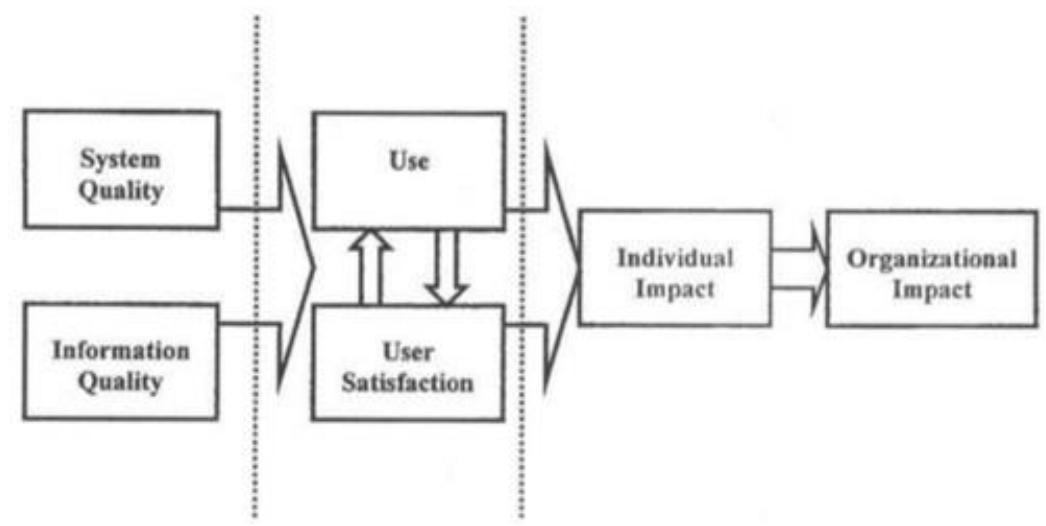

Figure 2-3: DeLone \& McLean Model factors

The D\&M IS success model has been used extensively to develop successful IS deployments (DeLone \& McLean, 2003). A summary of their definition of these variables is shown in Table

\section{2-2.}

Table 2-2: D\&M Variable Breakdown

Model Component Description

\begin{tabular}{ll}
\hline System Quality & IT hardware delivery systems \\
Informational Quality & Accuracy of information delivered through the system \\
Use & Frequency and purpose of system usage \\
User Satisfaction & Overall satisfaction of user related to the system and informational quality
\end{tabular}


Individual Impact Impact of system to an individual's work

Organizational Impact Impact of system to an organization's work

The work of DeLone \& McLean has been built upon and cited by numerous authors for over a decade (Bradley, et al., 2006). The technical aspect of technology, system and information quality have been explored extensively (Haug, et al., 2011), (Batini \& Scannapieca, 2006).

The cultural side of technology adoption has also been explored by subsequent authors. There is a key connection between the use of technology and the corporate culture of an organization (Venkatesh, et al., 2003). Venkatesh et al., explored the various scenarios of technology deployments. They came to a basic conclusion:

For technologies to improve productivity, they must be accepted and used by employees in organizations

Venkatesh et al., explored what factors drove the behavior of using a technology system. Their model is shown in Figure 2-4.

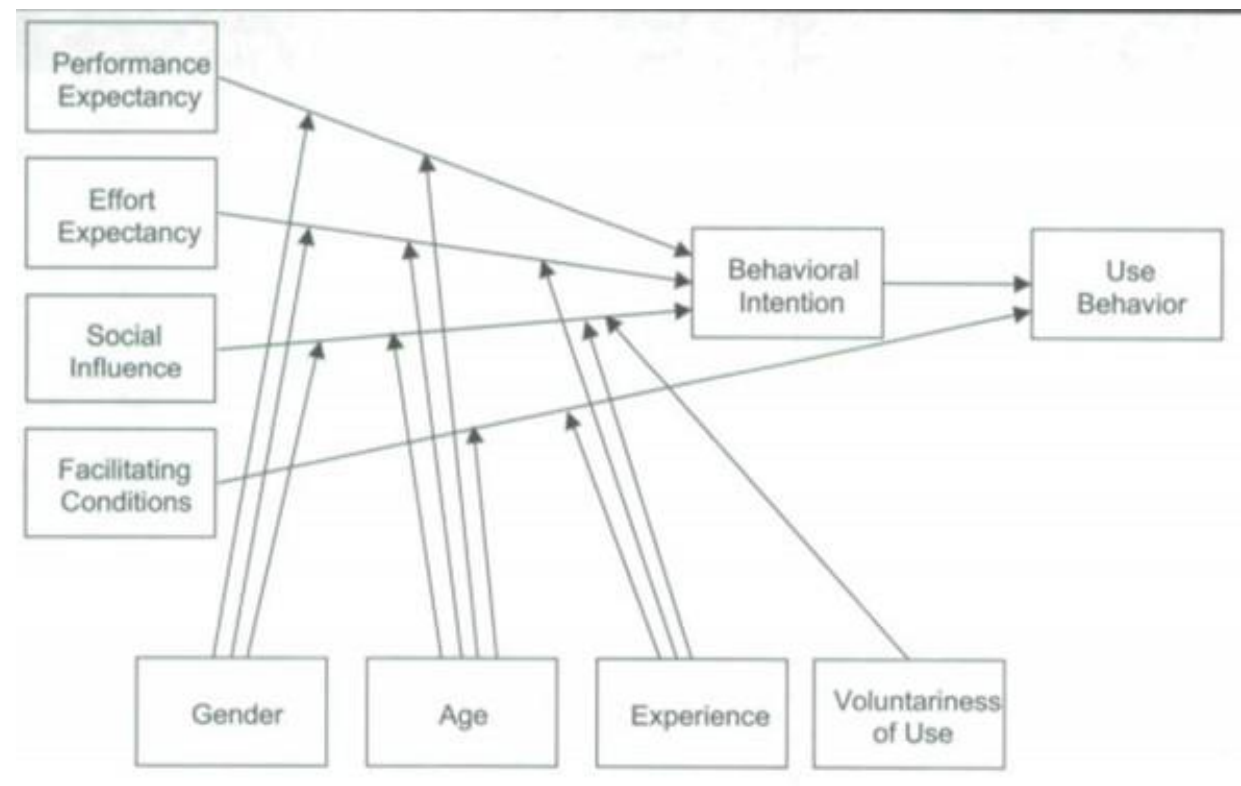

Figure 2-4: Performance expectancy model of factors driving usage behavior 
The model treats usage behavior as a dependent variable driven by many independent variables characterizing the culture of the organization and the individuals targeted to use the system. A description of each variable is shown in

\section{Table 2-3.}

Table 2-3: Description of performance expectancy model independent variables

\begin{tabular}{l} 
Model Variable \\
\hline \hline Performance Expectancy \\
Effort Expectancy \\
Social Influence \\
Facilitating Conditions \\
Gender \\
Age \\
Experience \\
Voluntariness of Use
\end{tabular}

Investment in IT is driven in large part by a corporate Information Technology department (Applegate, et al., 2007).

Along with defining the variables, there has been efforts to create scorecards of successful deployments (Jerry \& RKING, 2005), (Kaplan, et al., 1996).

As systems continue to mature and the business intelligence field develops, the models continue to advance (Ramamurthy, et al., 2008). Ramamurthy et al., explain the vital need to model:

The average first-year cost of a DW project is about \$1.26 million; the average project effort is about 4.46 person-years; and nearly half of all DW initiatives end up as failures.

Successful technology deployments are dependent upon the system and informational quality of the system being deployed. Usage is another key variable to the success of technology deployments. Technology usage is dependent upon the culture of the company and workforce. 


\subsection{Measuring and assessing value of information/data}

A recent study by LaValle et al., evidences that six out of ten organizations reported they have more data than can be used efficiently. Efficient use of data leads to untapped potential profit and efficiency gains (Williams \& Williams, 2010). Williams \& Williams explain that information is grouped into two value generating groups:

- Process improvement

- Business insight

Kaplan \& Norton provide a framework for determining the value of intangible assets like data and information. They suggest:

If managers could find a way to estimate the value of their intangible assets, they could measure and manage their company's competitive position much more easily and accurately.

Kaplan \& Norton present a scorecard methodology to assess how well IT and Human Resources (HR) resources are aligned with a corporate strategy. A set of key variables tracked in their model are as follows:

- Human Capital:

○ Skills

○ Talent

○ Knowledge

- IT

- Hardware - servers, networks

- Managerial expertise - standards, etc.

- Types of applications 
- Transaction - processing applications

- Analytical applications

- Quality of the code, ease of use, quality of documentation, and frequency of failure for each application

Through assessing these variables in a scorecard process, Kaplan \& Norton purport significant value creation:

Even if the measures are imprecise, the simple act of attempting to gauge the capabilities of employees, information systems, and organization capital communicates the importance of these drivers for value creation.

An example of a scorecard is shown inError! Reference source not found.. A series of ttributes is assessed through a strategic objective and measure. A target value is compared to an actual. 


\begin{tabular}{|c|c|c|c|c|}
\hline Attribute & Strategic Objective & Strategic Measure & Target & Actual \\
\hline \multirow[t]{2}{*}{ Culture } & \multirow{2}{*}{$\begin{array}{l}\text { Foster awareness and } \\
\text { internalization of the } \\
\text { mission, vision, and core } \\
\text { values needed to execute } \\
\text { the strategy }\end{array}$} & $\begin{array}{l}\text { Customer-focused (customer } \\
\text { survey; percentage who understand } \\
\text { the organization's mission) }\end{array}$ & $80 \%$ & $68 \%$ \\
\hline & & $\begin{array}{l}\text { Other core values (employee change } \\
\text { readiness survey) }\end{array}$ & $80 \%$ & $52 \%$ \\
\hline Leadership & $\begin{array}{l}\text { Develop leaders at all levels } \\
\text { who can mobilize the organi- } \\
\text { zation toward its strategy }\end{array}$ & $\begin{array}{l}\text { Leadership gap (percentage } \\
\text { of key attributes in competency } \\
\text { model rated above threshold) }\end{array}$ & $90 \%$ & $92 \%$ \\
\hline \multirow{2}{*}{ Alignment } & \multirow{2}{*}{$\begin{array}{l}\text { Align goals and incentives } \\
\text { with the strategy at all levels } \\
\text { of the organization }\end{array}$} & $\begin{array}{l}\text { Strategic awareness (percentage of } \\
\text { staff who can identify organization's } \\
\text { strategic priorities) }\end{array}$ & $80 \%$ & $75 \%$ \\
\hline & & $\begin{array}{l}\text { Strategic alignment (percentage of } \\
\text { staff whose objectives and incentives } \\
\text { link to Balanced Scorecard) }\end{array}$ & $100 \%$ & $60 \%$ \\
\hline Teamwork & $\begin{array}{l}\text { Ensure that knowledge and } \\
\text { staff assets that have strate- } \\
\text { gic potential are shared }\end{array}$ & $\begin{array}{l}\text { Sharing best practices (number } \\
\text { of knowledge management } \\
\text { system hits per employee) }\end{array}$ & 5.0 & 6.1 \\
\hline
\end{tabular}

Figure 2-5: Example scorecard used by Kaplan \& Norton in measuring intangible assets

Shin 2006 investigates the role of IT in the financial performance of diversified firms. Shin also examines the role of IT in creating value through improved coordination and finds empirical evidence to support that IT most assuredly adds value.

The sources of value of technology are in constant flux (LaValle, et al., 2013). LaValle et al., show that path of value is dependent upon available technology and the evolving culture of organization. They produced a graph that shows this evolution: 


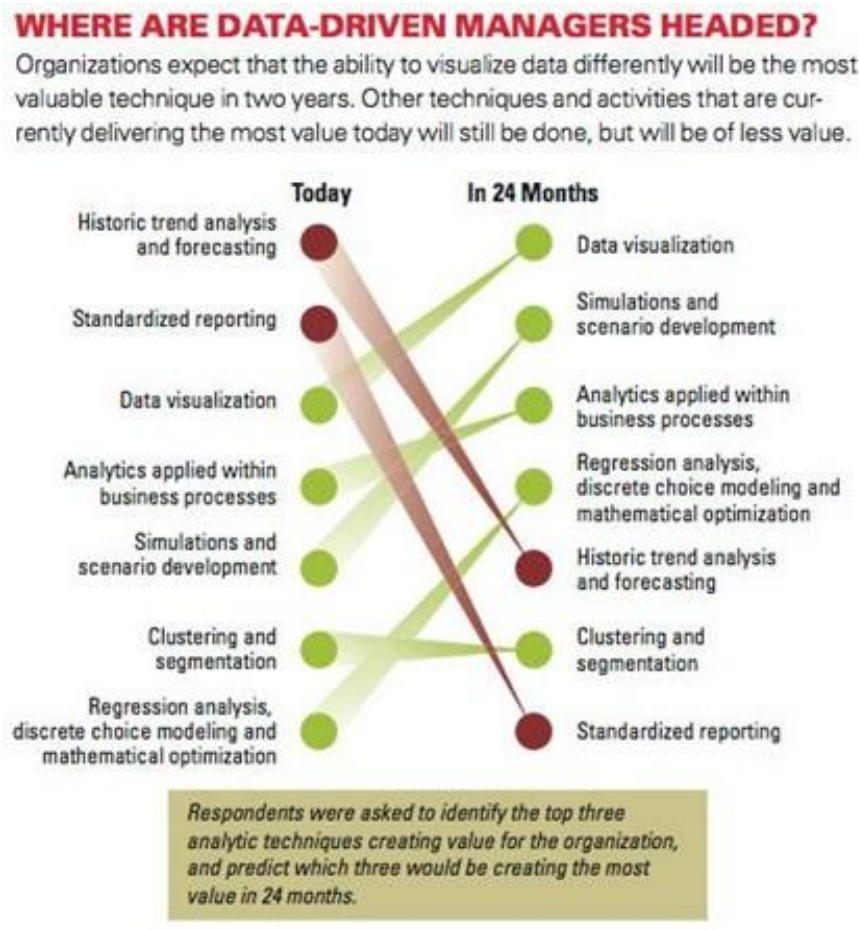

Figure 2-6: Lavelle et al., visualization of the constant flux of the pathway of value of data

Lavelle et al., suggests that organization leaders often demand analytics that quickly and easily exploit their growing data assets to "get smart, and get innovative, in ways they never could before".

The cost of poor data quality has been researched along with maintenance paths for ensuring adequate data maintenance being relevant and accurate (Haug, et al., 2011), (Batini \& Scannapieca, 2006), and (Sadiq, 2013). The theories provided by these authors provide the methods of correct data maintenance effort and costs inflicted by poor quality data. The authors suggest that in many companies such insights may lead to significant savings. 


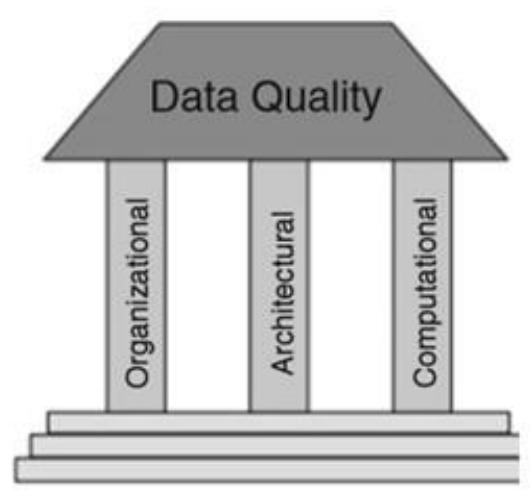

Figure 2-7: The three pillars of data quality presented by Sadiq

Figure 2-7 provides the three pillars of data quality presented by Sadiq, 2013. Sadiq organized data quality issues into three root causes:

Organizational - compliance to established processes and strategy objectives of an organization

Architectural - the technology landscape used to execute strategy objectives

Computational - efficiently of IT and the computational techniques to execute strategy objectives

Some specific computational variables listed by Sadiq are: "record linkage, lineage and provenance, data uncertainty, semantic integrity constraints, as well as information trust and credibility".

\subsection{Evaluation models}

There is value in using data. The next question raised is: Are there adequate models assessable to incorporate this value into the process of investment justification?

Dessureault investigated the role of real options in purchasing mining technology and provides a literature review of real options (Dessureault, 2002). From previous review using data for business insight and process improvement, real options are found to be highly intertwined with 
managerial flexibility. Real option theory was created for the purpose of mimicking managerial flexibility (Yeo \& Qui, 2003). Managers in many situations have the option, but not necessarily the requirement, to use data in their managerial strategy and philosophy (Brandao, et al., 2005). A review of the various types of real options analysis is given in Table 2-4.

Table 2-4: List of contributions to real options

\begin{tabular}{ll}
\hline Real Option Citations & Main Points \\
\hline (Brandao, et al., 2005) & Options analysis \\
\hline (Mathews, 2009), (Mathews, et & Datar-Mathews options pricing model \\
al., 2007) & \\
\hline (Yeo \& Qui, 2003) & Using real options to model managerial flexibility \\
\hline (Applegate, et al., 2007) & Corporate IT strategy, measurement, and evaluation \\
\hline (Chen, et al., 2009) & Real options analysis study of large IT investments with multiple \\
& sources of risk
\end{tabular}

\section{$2.5 \quad A B E T$}

Engineering departments are governed by a stringent set of requirements maintained by the Engineering Accreditation commission (ABET) (Anon., 2012). The general requirement for Mining Engineering curriculum is "proficient in additional engineering topics such as rock fragmentation, materials handling, mineral or coal processing, mine surveying". Given the proceeding research on data management: (Dessureault \& Scoble, 2003), (Benito \& Dessureault, 2008), (Dessurealt, et al., 2007), (Kahraman, 2015), among others; concerning the high tech nature of mining operations of fragmenting rock, handling the material, and processing the ore, technology is and should be a key component of the curriculum. These fields of operation management contain many systems and opportunities for management innovations 
(Dessureault, 2002), (Klippel, et al., 2008). Many mining engineering schools are responding to the changing times. South Dakota School of Mines is now an engineering and management school (Anon., 2015). Colorado School of Mines is offering many courses and specializations in management and technology (Anon., 2015). University of Arizona has a series of short courses and certificate programs related to mining engineering and technology (Anon., 2015).

\subsection{Literature review conclusions:}

The following are the main conclusions from the literature review:

- $\quad$ The mining industry is a high tech industry

- Existing models related to technology and innovation deal largely with high level productivity factors through macroeconomic models.

- The industry is in need of incorporating data utilization into its management culture.

- MIS industry has many models on successful technology deployment

- Information technology and information systems have different variables

- Corporate culture is a major factor in use of systems

- Additional models exist assessing the value of taking data into information

- Measurement of the use of intangible assets is dependent on specific variables

- Real options justification models are robust enough to model managerial flexibility relating to data utilization and the sources of uncertainty common in technology deployments

- The mining curriculum can consider data usage in courses and be compliant with ABET 


\section{Presenting the Building Blocks of the Model}

As discussed in Chapter 2, acquiring and using technology is more than simply purchasing technology. True technological adoption involves changing the business process and culture to maximize the benefits, as well as training personnel the requisite skills to use the technology for maximum advantage. Figure 3-1 is a Venn diagram reflecting the three pillars of technology adoption represented by the literature.

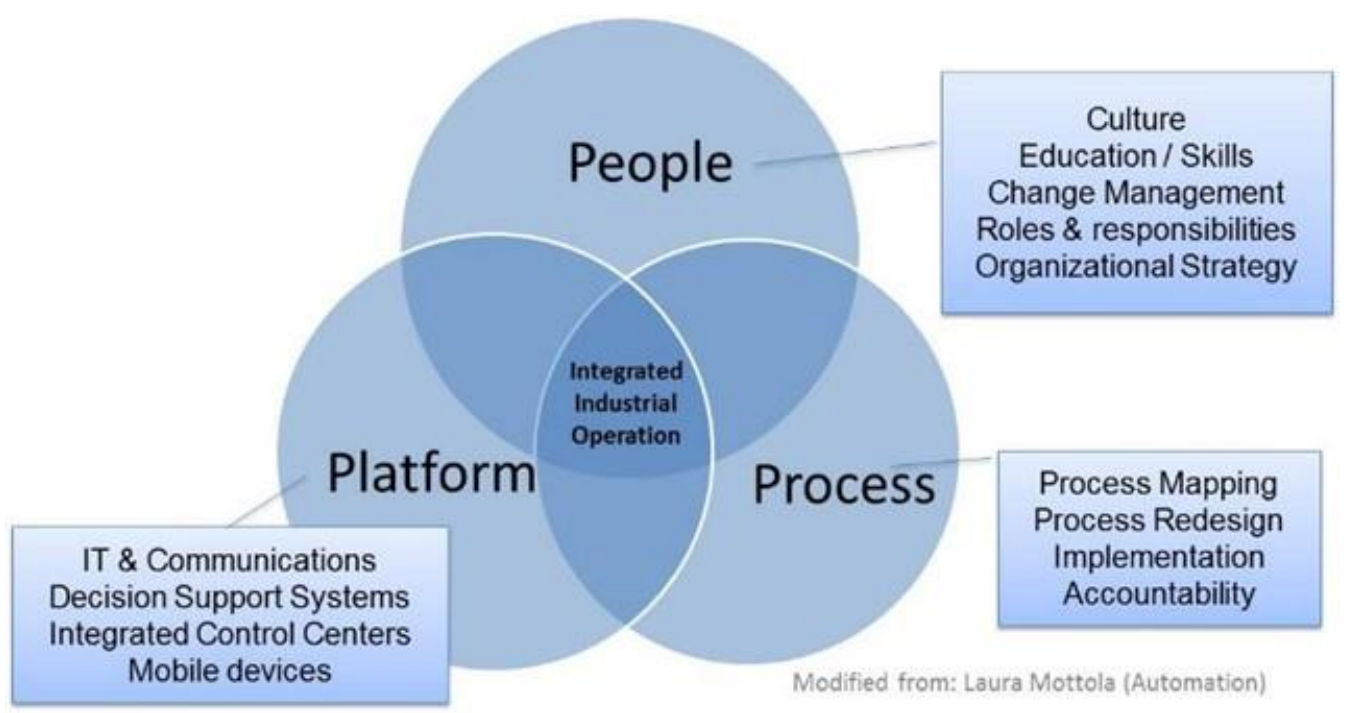

Figure 3-1. Three Pillars of Sustaining Data-Driven Technology (Mottola \& Payton, n.d.), (Dessureault, 2015)

Although all three pillars must be considered, the approach of data utilization requires a staged and sustainable data-driven process change. The process begins with data and is only completed at implementation. Figure 3-2 illustrates this process which builds upward on a foundation of integrated data, perpetual momentum gained through a demand stage (scorecards), and sustained progress to more advanced technical solutions (Dessureault, 2015). 


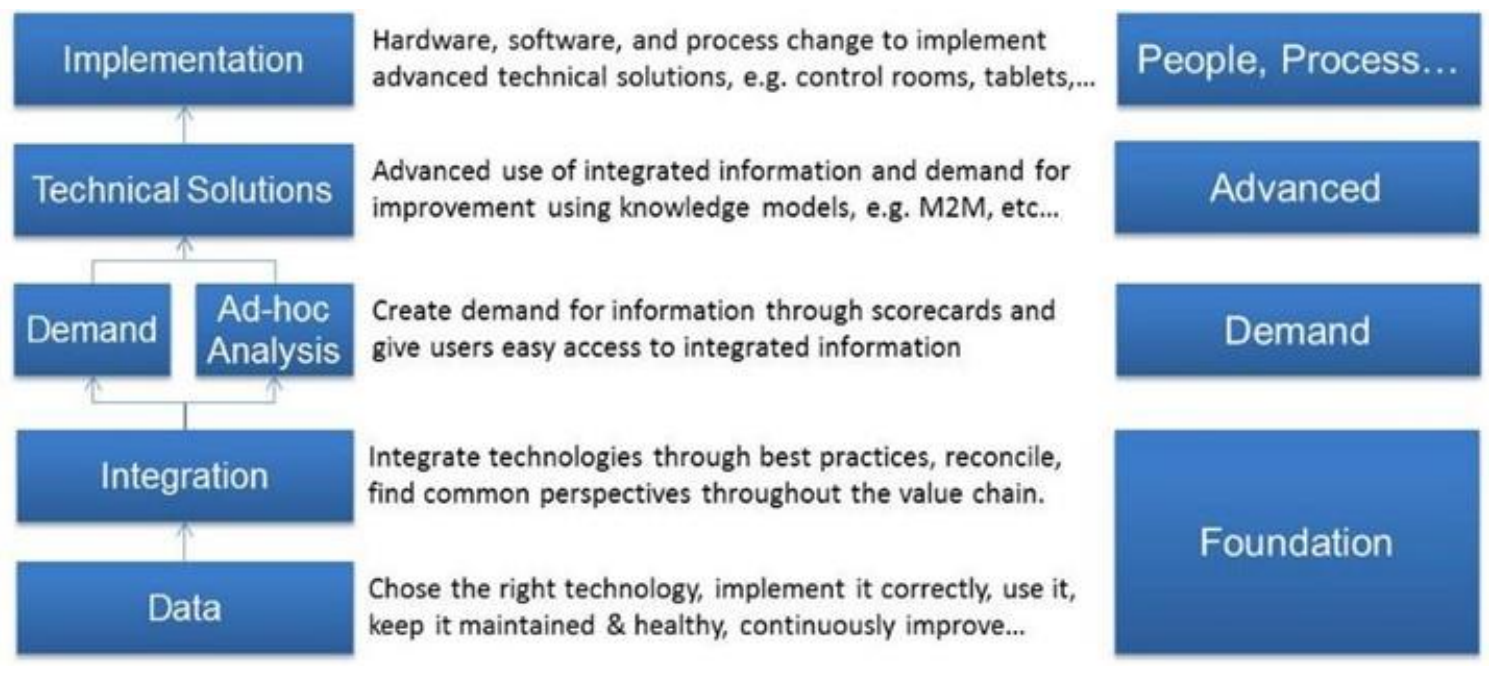

Figure 3-2. Data-Driven Process Change (Dessureault, 2015)

Chapter 2 also established the mining industry as a high tech industry. The technology and value models presented can be applied specifically to the mining industry. Prior to presenting a model and methodology, a discussion of the "data - action" business intelligence (BI) layers is needed. Specific mining examples are given for each respective BI layer.

\subsection{Data to Action Methodology - A mining perspective}

The data to action methodology consists of four layers:

1. Data - source data systems

2. Information layer - a series of data processing tools used to provide business context to data

3. Knowledge layer - presenting information to organizations

4. Action layer - defined processes that lead to action by an organization The methodology is enabled by a technology called Data Warehouse Business Intelligence (DWBI) systems. A DWBI is show in Figure 3-3 and each BI layer is labeled. 


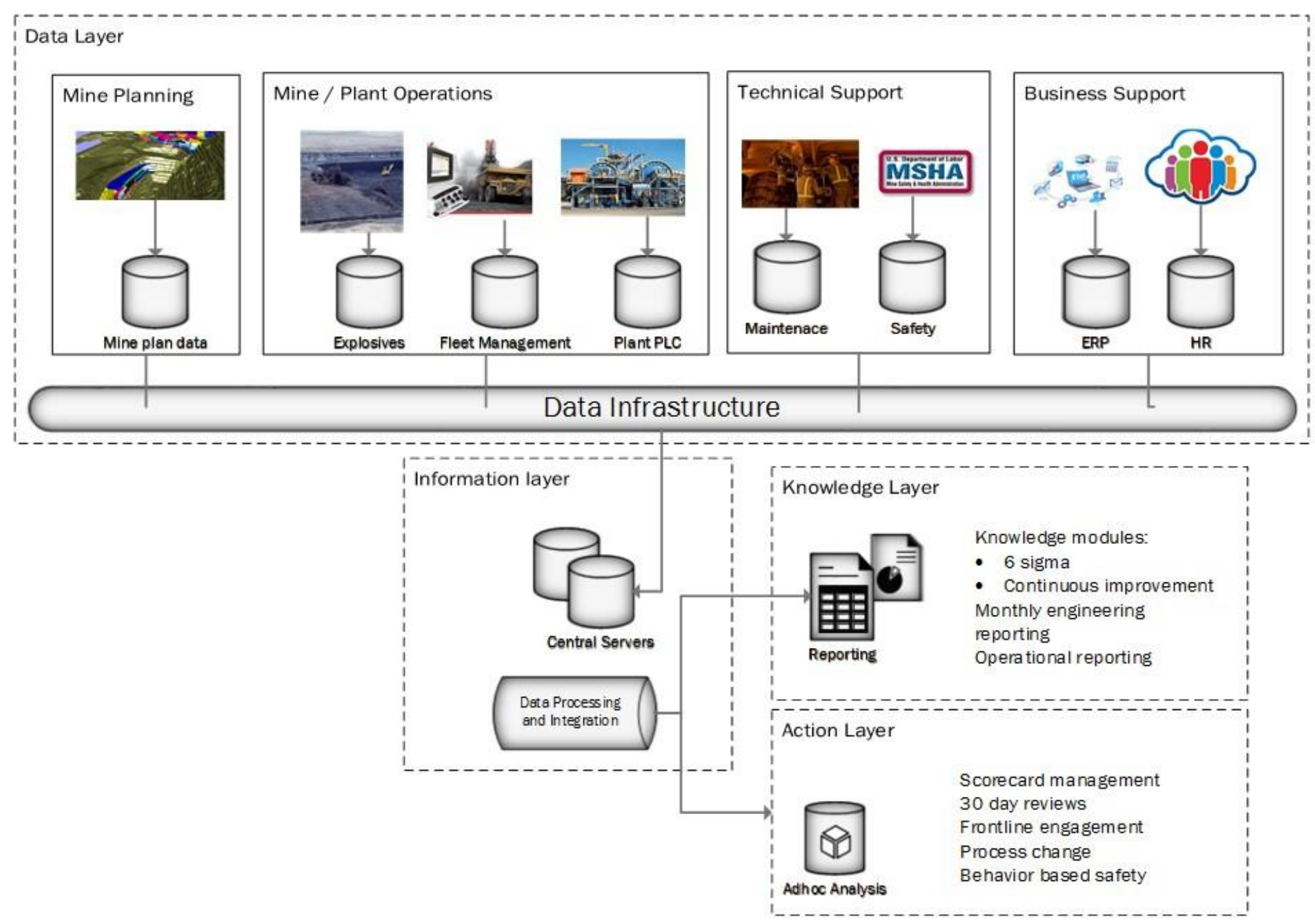

Figure 3-3: Data to Action technical architecture 
As displayed, dispersed data sources are shown consisting of the data foundation. The information layer is a separate and distinct system consisting of data processing by predetermined business rules. These are most successfully done on central servers so that consistent business rules can be applied to multiple source systems. Information is then assimilated through various knowledge modules and process change actions. A more thorough discussion on DWBI systems and the data to action methodology can be found in Rogers master's thesis (Rogers, 2012).

The main purpose of this section is to understand the unique challenges each layer presents to the mining industry. Each layer presents technical and cultural opportunities that can be addressed through a set of management best practices. Figure 3-4 diagrams the data to action methodology connected to each of the literature models presented in Chapter 2. As demonstrated below, data and information are system specific while the knowledge and action layers deal with value of systems. The model proposed by this dissertation considers these variables in its assessment processes of data utilization.

\begin{tabular}{|c|c|c|c|}
\hline Data & Information & Knowledge & Action \\
\hline \multicolumn{2}{|c|}{ System Deployments } & \multicolumn{2}{|c|}{ System Value } \\
\hline \multicolumn{2}{|c|}{$\begin{array}{l}\text { Perceived ease of use (Davis } \\
\text { 1989) } \\
\text { Role Definition (Lee \& Strong } \\
\text { 2003) } \\
\text { Information \& System Quality } \\
\text { (Nelson et. al., 2005) } \\
\text { Corporate culture (Bradley et } \\
\text { al., 2006) }\end{array}$} & \multicolumn{2}{|c|}{$\begin{array}{l}\text { Value from big data (LaVelle et } \\
\text { al., 2013) } \\
\text { Measuring value (Kaplan \& } \\
\text { Norton, 2004) } \\
\text { Value of BI (William \& } \\
\text { Williams, 2010) } \\
\text { IT and financial performance } \\
\text { (Shin, 2006) }\end{array}$} \\
\hline
\end{tabular}

Figure 3-4: Connecting literature to the data - action methodology

Each layer is briefly discussed along with the identified best practices or factors that will be used to build the data utilization assessment model. 


\subsubsection{Data}

The mining industry has made significant investments in technology and the paradigm of IT continues to advance within the industry (De Lemos, 2013). Information technology is quite unique for most mining companies (MacDonald, 2013). Modern mines must maintain a high level of network availability and robust IT infrastructure in some challenging locations and environments. The infrastructure supports a wide variety of systems.

Data is the fundamental building block of mining business intelligence and mine management systems (Dessureault, 2002). The role of technology in modern management practices has been thoroughly researched (see section 2.1). This section will provide some examples of data systems that exist at operating mines. Table 3-1 provides a list of systems at a single operating copper mine.

Table 3-1: Common systems used in the mining industry

\begin{tabular}{|c|c|}
\hline Source System & Description \\
\hline Jigsaw Mine Ops & $\begin{array}{l}\text { Fleet management system that uses an innovative on-board complete } \\
\text { database approach }\end{array}$ \\
\hline $\begin{array}{l}\text { Modular Mining } \\
\text { PowerView }\end{array}$ & $\begin{array}{l}\text { PowerView, the SQL-accessible database often has many custom fields and } \\
\text { tables not found in standard PowerView Must employ a custom database } \\
\text { language and approach. }\end{array}$ \\
\hline Terrain Shovels & $\begin{array}{l}\text { Known colloquially as CAES, has high-precision GPS of shovel dig-points. Used } \\
\text { to digitize daily digging profiles for grade control. }\end{array}$ \\
\hline Terrain Dozers & $\begin{array}{l}\text { Known colloquially as CAES, has high-precision GPS of dozer movements, and } \\
\text { cycles, mostly used to precisely build graded surfaces. Currently unused for } \\
\text { analysis. }\end{array}$ \\
\hline Ardvark & $\begin{array}{l}\text { High-precision GPS drill monitoring system that keeps track of drillability, and } \\
\text { could keep track of delays. Operator currently does not submit delays } \\
\text { through this system. Can be used to capture drill delays. Very similar to Drill } \\
\text { Terrain. }\end{array}$ \\
\hline $\begin{array}{l}\text { RCS - Surface } \\
\text { Manager }\end{array}$ & $\begin{array}{l}\text { Like Ardvark, high-precision GPS drill monitoring system that keeps track of } \\
\text { drillability, and could keep track of delays. Operator currently does not } \\
\text { submit delays through this system. }\end{array}$ \\
\hline AcQuire & $\begin{array}{l}\text { A well-defined drill-hole and blast-hole definition system. The assay results } \\
\text { from the blast hole samples are stored here. }\end{array}$ \\
\hline SWE & $\begin{array}{l}\text { A database populated and maintained by SouthWest Energy, detailing the } \\
\text { explosives consumption. Can be used to capture explosives use in shots. }\end{array}$ \\
\hline
\end{tabular}




$\begin{array}{ll}\text { Source System } & \text { Description } \\ \text { Bridgestone / } & \begin{array}{l}\text { A database that contains tire history. Level of integration with PowerView } \\ \text { Klinge }\end{array} \\ \text { unknown. } & \begin{array}{l}\text { System mounted on the shovel that currently takes pictures of the side of the } \\ \text { muck pile while digging. In the current system, the photos are transmitted to } \\ \text { an accessible folder where an engineer processes the photos on a daily basis. } \\ \text { Process requires both reengineering and potentially an upgrade in order to } \\ \text { achieve desired real-time M2M management. }\end{array} \\ \text { ASS } & \begin{array}{l}\text { A fatigue monitoring system somewhat tracked in the control room. There is } \\ \text { no direct access to the database. However, the data is re-typed into MS Excel } \\ \text { by dispatcher 3, including the corrective actions taken, if any. }\end{array} \\ \text { Pi } & \begin{array}{l}\text { Has many powerful tools and local plant personnel are becoming more } \\ \text { familiar with the system. Users can take advantage of DataLink, an license- } \\ \text { based MS Excel add-in for real-time link into process data. }\end{array} \\ \text { CAP } & \begin{array}{l}\text { Contains cost and maintenance records for the entire corporation. Always a } \\ \text { challenge to directly access a single table with all General Ledger transactions. }\end{array}\end{array}$

These systems support a variety of mine operations, plant processes, and many other business functions within the mine and parent company. For instance, the primary purpose of most fleet management systems is to provide a real time dispatch platform using GPS and onboard computers. A key component of this traditional system is an optimization algorithm used to manage the queue and hang time of the various fleets. These systems track a variety of variables: material movement (by location, machines, crew, etc.), equipment status, health, among others. Many of these systems have a level of automated reporting which interprets the data and delivers it as information through a series of dashboards and reports. These systems generate detailed data representing operational cycles of equipment activity. Granular cycle information provides key statistics on how productive and efficient operators were at using fleet assets. Managers then have the option to use these statistics for improved operation management.

Data management can be very challenging relevant to the following conditions:

- Data systems must be configured properly to be functional. 
- A high level of system availability must be maintained in some of the most rugged and extreme working environments.

- All systems have a unique vendor and supporting plan.

- Each are deployed on separator servers and in most cases completely different networks

- All systems have a unique database design.

All of these conditions play a role in the user acceptance. However, these barriers can be overcome and managed through following a set of best practices. These practices are summarized in five factors shown in Table 3-2.

Table 3-2: Proposed data layer best practices and modeling factors

\section{BI Layer Literature Variable Best Practice Factors}

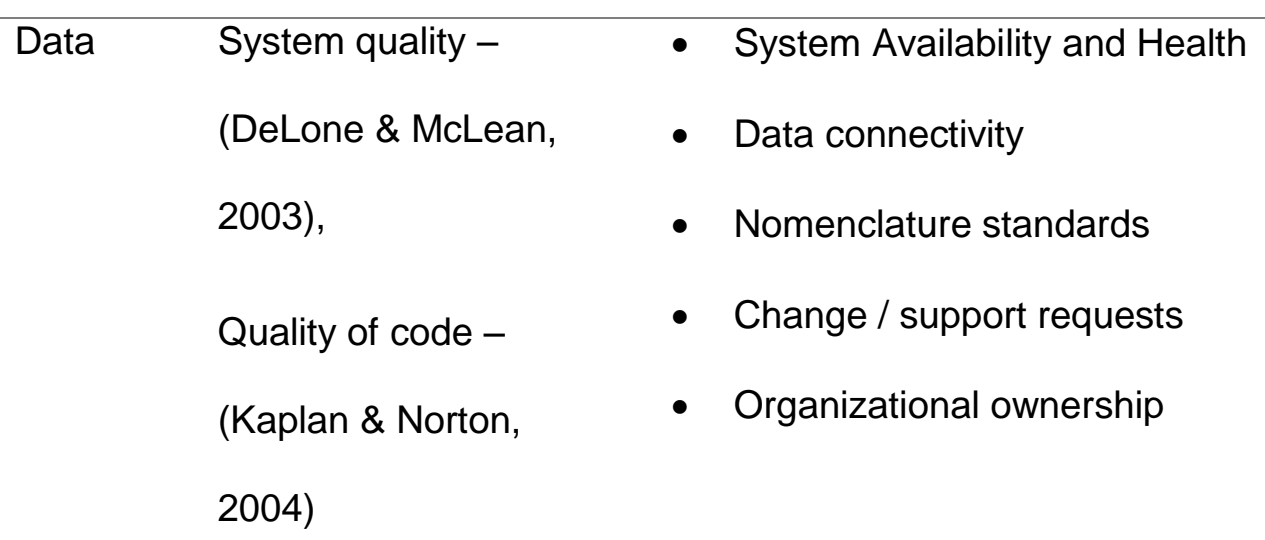

More details will be presented along with a process to measure each factor in Chapter 4 .

\subsubsection{Information}

Considering Table 3-1 and the research of Lavelle et al., mining organizations can have a difficult time transforming data into information due to the many systems within an organization. Information systems (IS) are used to assist business processes (i.e. operations, maintenance) 
to run more safely and efficiently which in turn adds value to shareholders (Applegate, et al., 2007). In a mining environment, there are many complex inputs that drive these processes, such as: geology, market conditions, weather, mine plans, workforce culture, etc. Figure 3-3 provides an architecture map of these inputs and the subsequent BI layers. Information technology (IT) are systems that generate data (or the data layer) and for the purpose of this study, information systems (IS) (information layers) are defined as a series of software and business rules which interpret data and deliver information to users.

Many source systems will transform their data into an information layer. For instance, a fleet management system may have an analytical platform that takes the source data, post processes it, and presents it in an analytical layer for reporting. However, when considering the many sources shown in Table 3-1, it can be overwhelming to gather data from multiple systems.

Information quality considers the base information or data that comes from source systems such as Fleet Management Systems, Drill Monitoring Systems, Dispatch, ERP's, etc. Additional information is added in the analytical environments through calculated members or measures that combine data. Information quality must consider both the source system and the additional logic added in the information layer.

A data warehouse is a very common IS and an example of one is shown in Figure 3-3. A data warehouse can provide organizations the ability to have an integrated analytical environment where data from all systems can be made accessible. Data is processed following a series of business rules, integrated upon common dimensions, and opened to users through a multitude of analytical channels. Not all information systems are created equal. Some can be very difficult to access, lack sufficient integration, or have faulty business rules leading to poor system health and information quality. In these situations, data is not successfully transformed into information resulting in low to zero data utilization in organizations. 
There are a set of best practices that when followed will ensure high level of acceptance and usage. Table 3-3 provides a set of factors that can be used to assess the quality of a mine site information system.

Table 3-3: Proposed information layer best practices and modeling factors

\begin{tabular}{lll}
\hline BI Layer & Literature Variable & Best Practice Factors \\
\hline Information & Information quality - (DeLone \& & - Excel connections \\
& McLean, 2003) & - Direct report linkage \\
& Analytical application - (Kaplan & - Ease of querying \\
\& Norton, 2004) & - Ratio of querying types \\
& - Level of system integration
\end{tabular}

More details on these factors are given in Chapter 4.

\subsubsection{Knowledge}

Considering Figure 3-2, the knowledge layer creates demand and addiction to data. William \& Williams classify the value of business intelligence initiatives into two main groups:

- Business insight

- Process improvement

The knowledge layer provides the business insight needed to gain value and the action layer is equivalent to process improvement. The knowledge layer considers how information is delivered to an organization through various knowledge modules. Dessureault, 2002 and more recently, Kahraman, 2015, thoroughly present many knowledge modules used within the mining industry. Some examples of key knowledge modules in the mining industry are:

- Bottleneck tracking 
- Activity based costing

- Monthly engineering reporting

- Operational reports

- Six sigma

Each knowledge module is connected to the information layer through a series of indicators. Key Performance Indicators (KPI's) and Leading Success Indicators (LSl's) are two types of metrics commonly used in the mining industry. Examples of a KPI are "tons produced" or "safety incidents". These are dependent upon a variety of variables such as the mine plan, weather, operational performance, and shift start up. LSI's are independent variables that are left solely to operational performance. An example of an LSI is "last to first load". This indicator measures the time between the last truck loaded of a shift and the first load of the next shift. It essentially measures shift change. Another LSI is "safety observations". The philosophy behind these knowledge indicators is that as LSI's are met, they assist in driving KPI's to meet high level goals.

The knowledge layer presents data developed in the information layer to end users (see Figure 3-3). Many best practices have been researched on the process of integrating people with information (Janseen \& de Poot, 2006). On the flipside, Eppler \& Mengis, 2004 explore the alternative when the knowledge layer is overloaded with information resulting in "cognitive overload". As shown in Chapter 2, information quality and functionality of reporting is critical to successful deployments. A set of knowledge layer best practices can be summarized from these in previously cited works. Table 3-4 shows the proposed factors that will be used to assess the health of the knowledge layer.

Table 3-4: Proposed knowledge layer best practices and modeling factors
BI Layer
Literature Variable
Best Practice Factors 


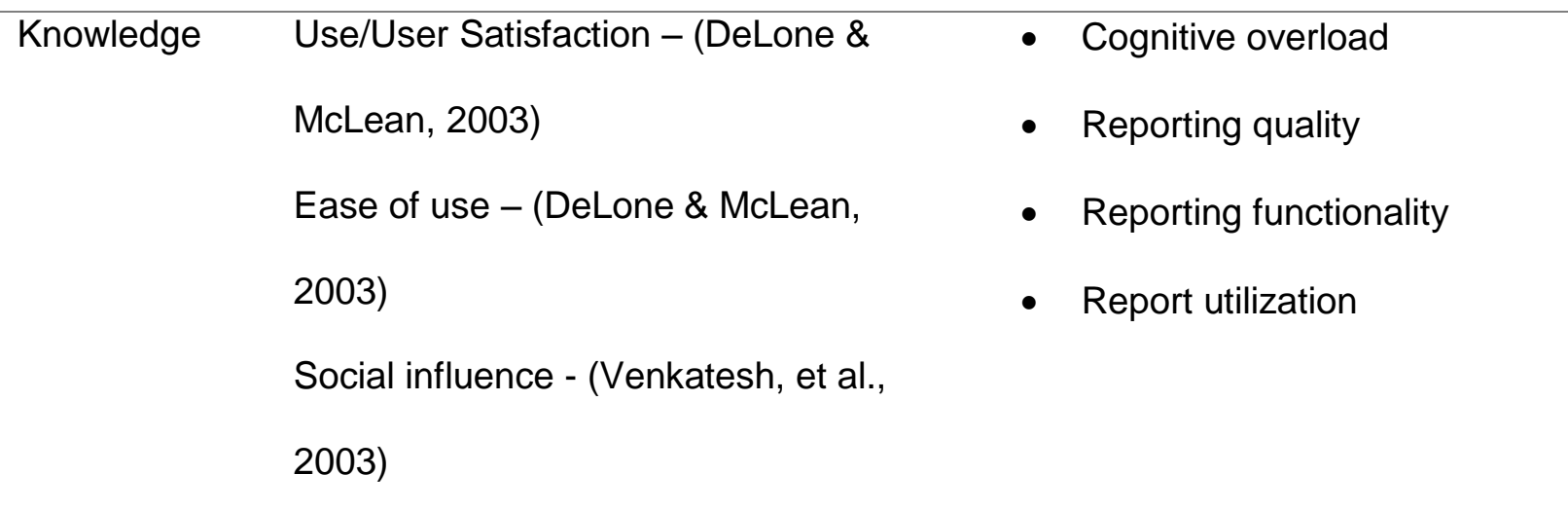

More details on these factors are given in Chapter 4.

\subsubsection{Action}

As seen in Figure 3-3, the action layer is dependent upon the information and knowledge layer. This layer represents the actions of an organization enabled by information. An example of a successful action plan developed by MISOM Technologies (Dessureault, 2015) is represented in Figure 3-5.

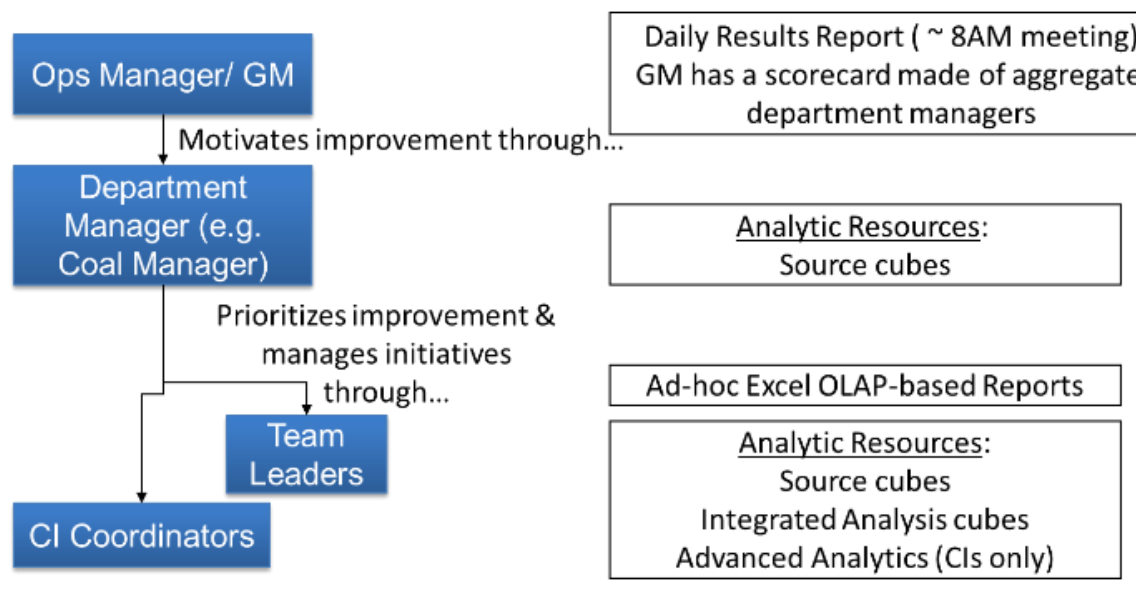

Figure 3-5: Scorecard Prioritization Process (Dessureault, 2015)

Figure 3-5 indicates that a daily scorecard process is attended by an ops manager and his subordinates; coal manager, overburden manager, $\mathrm{Cl}$ coordinator, and various team leaders. Through reviewing the knowledge tool "the scorecard", at the 8:00 am meeting, a series of 
actions are generated. Actions are prompted through questions regarding the performance of the previous shift. These actions can happen at various levels of the mining value chain.

Some additional examples of actions are:

- Frontline supervisors and crew engagement

- Yearly plan augmentation

- Operational scorecards

- Real time dashboards

- Continuous improvement initiatives

- Ad hoc analysis

Process improvements generally focus on leading indicators with limited use of KPI's. Initiatives such as these require aggregatable data across multiple dimensions. The data and information platforms must have high information quality, system health, and ease of use in order to support process improvement initiatives. Front line engagement requires that the local site is the main consumer of information. These factors are important and can be assessed. Table 3-5 provides the final list of best practice factors that will be used to assess the action layer.

Table 3-5: Proposed action layer best practices and modeling factors

\begin{tabular}{llc}
\hline BI Layer & Literature Variable & Best Practice Factors \\
\hline Action & Individual and Organization Impact - & $\bullet$ Leading indicators \\
& (DeLone \& McLean, 2003) & Improvement \\
& Facilitating conditions - (Venkatesh, et al., & initiatives \\
& 2003) & $\bullet$ Level of queries \\
& Effort expectancy - (Venkatesh, et al., 2003) & $\bullet$ Frontline Engagement \\
& & $\bullet$ Report turnover
\end{tabular}


More details on these factors are given in Chapter 4.

\subsection{Measuring utilization as a means of motivation}

Many of the models mentioned in the literature were meant to help understand technology deployments and the independent and dependent variables. The cited works are shown and summarized in Figure 3-4. D \& M consider "system use" as the critical success measure of an IS. IS usage is a complex variable which includes the nature of usage, extent of use, quality of use, and appropriateness of a system. Important questions that need to be asked will assist in developing the "nature of use". Is the system used to full functionality? What is the extent of use by key personnel? Most modern data warehouses contain tracking mechanisms that can measure non-use of basic and advanced system capabilities. Declining usage is an example of perceived benefits not being realized. User satisfaction is fairly self-explanatory. Are users satisfied with the system and what items are needed to improve the user experience?

Considering Kaplan \& Norton, 2004, there is great value in measuring asset use. The work by LaValle et al., establishes that organizations derive great value from information. The literature shown in Chapter 2 and the discussion of the data - action just presented provide key variables that can be used to assess system deployment success and usage.

Kaplan \& Norton, 1996 provide a balanced scorecard process that can lead to significant improvements in a desired behavior and culture. They show that measuring and presenting information in a balanced scorecard is a method most likely to motivate individuals to perform. The literature presented provides many of the variables and management tools but fails to provide a consistent method to measure data utilization in near real-time. Sections 3.1.1-3.1.4 present a set of factors that can be used to assess the data to action methodology. These factors will be integrated into a model used to measure data utilization within a mining company. 


\subsection{Deriving value}

LaValle, et al. and Applegate show that there are significant return on investment (ROI) for organizations that have high levels of data utilization. Data utilization and process change are linked, albeit indirectly, to organizational or operational improvements (LaValle, et al., 2013). Understanding the true value of data assets can therefore be challenging. Measuring data utilization consistently over time may provide the ability to more directly correlate operational improvements to data assets.

\subsection{Variables/Key Definitions:}

Many variables and factors have been discussed in this and previous chapters. Table 3-6 provides a summarized definition of these key factors. 


\begin{tabular}{|c|c|}
\hline Variable & Definition \\
\hline $\begin{array}{l}\text { Data Value Index } \\
\text { (DUVI) }\end{array}$ & $\begin{array}{l}\text { An index that is the outcome of and assessment used to describe } \\
\text { the health of systems in delivering information within an } \\
\text { organization and how and to what extent that information is used }\end{array}$ \\
\hline $\begin{array}{l}\text { Data Utilization } \\
\text { Gap }\end{array}$ & $\begin{array}{l}\text { A term used in the research project to describe the barriers } \\
\text { (technical, cultural, and process) limiting the ability of actionable } \\
\text { data getting in front of decision makes. This results in decision } \\
\text { bases solely on intuition and not analytics. }\end{array}$ \\
\hline Data & A set of statistics or values used to measure a predefined variable \\
\hline Information & Data organized based by a set of business rules \\
\hline Knowledge & Information applied to answer a business or process question \\
\hline Action & $\begin{array}{l}\text { Change associated with the knowledge derived from information } \\
\text { and data }\end{array}$ \\
\hline Business Insight & $\begin{array}{l}\text { Used to describe the benefits of information systems (data } \\
\text { warehousing, source systems, reporting) in understanding the } \\
\text { accurate outcomes of mining processes (ore produced, cost, etc.) }\end{array}$ \\
\hline $\begin{array}{l}\text { Process } \\
\text { Improvement }\end{array}$ & $\begin{array}{l}\text { Used to describe the benefits of data utilization in driving process } \\
\text { change (performance management, continuous improvement, etc.) } \\
\text { at mining operations. }\end{array}$ \\
\hline Platform & $\begin{array}{l}\text { Technology used within a business that is used to generate data } \\
\text { and deliver information }\end{array}$ \\
\hline $\begin{array}{l}\text { Information } \\
\text { Technology (IT) }\end{array}$ & $\begin{array}{l}\text { Systems that act primarily as a management system which store, } \\
\text { retrieve, and send data from equipment or processes within the } \\
\text { value chain of mining. Within a "data warehouse context" they can } \\
\text { be referred to as "source systems". }\end{array}$ \\
\hline
\end{tabular}




\begin{tabular}{|c|c|}
\hline $\begin{array}{l}\text { Information } \\
\text { Systems (IS) }\end{array}$ & $\begin{array}{l}\text { Systems defined as a series of computing software that interprets } \\
\text { data generated from IT or the business processes within mining and } \\
\text { delivers information to people. }\end{array}$ \\
\hline People & $\begin{array}{l}\text { Resources that assist in technology strategy such as Operational } \\
\text { Excellence groups, programmers, or management. This variable } \\
\text { can also be used interchangeably with culture and intellectual } \\
\text { capacity. }\end{array}$ \\
\hline Process & $\begin{array}{l}\text { Business / engineering best practices that are in place to use } \\
\text { information as a means of understanding and improving operational } \\
\text { outcomes. }\end{array}$ \\
\hline Ad-hoc analysis & $\begin{array}{l}\text { Knowledge discovery through using highly aggregated data which } \\
\text { matches the value chain of an organization. }\end{array}$ \\
\hline Drilldown & $\begin{array}{l}\text { Ability to see high level statistics by themselves while having some } \\
\text { kind of ability to click or quickly navigate to lower level statistics in } \\
\text { another view. This reduces the amount of variables in a single view } \\
\text { and any given time. }\end{array}$ \\
\hline AHP & $\begin{array}{l}\text { Analytical Hierarchy Process is a very structured methodology to } \\
\text { weigh many variables in a consistent process. }\end{array}$ \\
\hline Aggregatable & $\begin{array}{l}\text { A new term used to describe the ability of a user to aggregate a } \\
\text { measure variable across many dimensions and dimensional } \\
\text { attributes. }\end{array}$ \\
\hline Data Granularity & $\begin{array}{l}\text { Lower levels of data across dimensions leading to more detailed } \\
\text { information about an inquiry }\end{array}$ \\
\hline $\begin{array}{l}\text { Leading } \\
\text { indicator (LSI) }\end{array}$ & $\begin{array}{l}\text { An indicator representing a critical sub-process of a higher level } \\
\text { process }\end{array}$ \\
\hline
\end{tabular}




\begin{tabular}{ll}
\hline $\begin{array}{l}\text { Lagging } \\
\text { indicator (KPI) }\end{array}$ & $\begin{array}{l}\text { An indicator of a high level process which represents the outcome } \\
\text { of several lower level process. }\end{array}$ \\
\hline Hang time & A portion of a loading units operational cycle at which it is waiting \\
on a piece of equipment to load.
\end{tabular}




\section{Data Utilization and Value Index}

\subsection{Introducing the Model}

Data utilization is dependent upon a successfully deployed technological platform as well as a management culture interconnected with data. Systems that are used in a vertically integrated managerial strategy can have greater deployment success along with an increased return on investment. Consequently, data utilization is the crucial factor for sustained technology adoption. The supporting referenced literature lacks a balanced measurement approach considering the data to action methodology. Furthermore, the mining industry needs an assessment model owing to the amount of data assets common at all mine sites. Data, when treated as any other asset, needs a method to measure its effectiveness in the value chain. This can pose a challenge as data is an "intangible asset". Chapter 3 presented the building blocks for an assessment process. Each layer of the BI data to action methodology was discussed along with a set of best practices. Figure 4-1Error! Reference source not found. summarizes these factors.
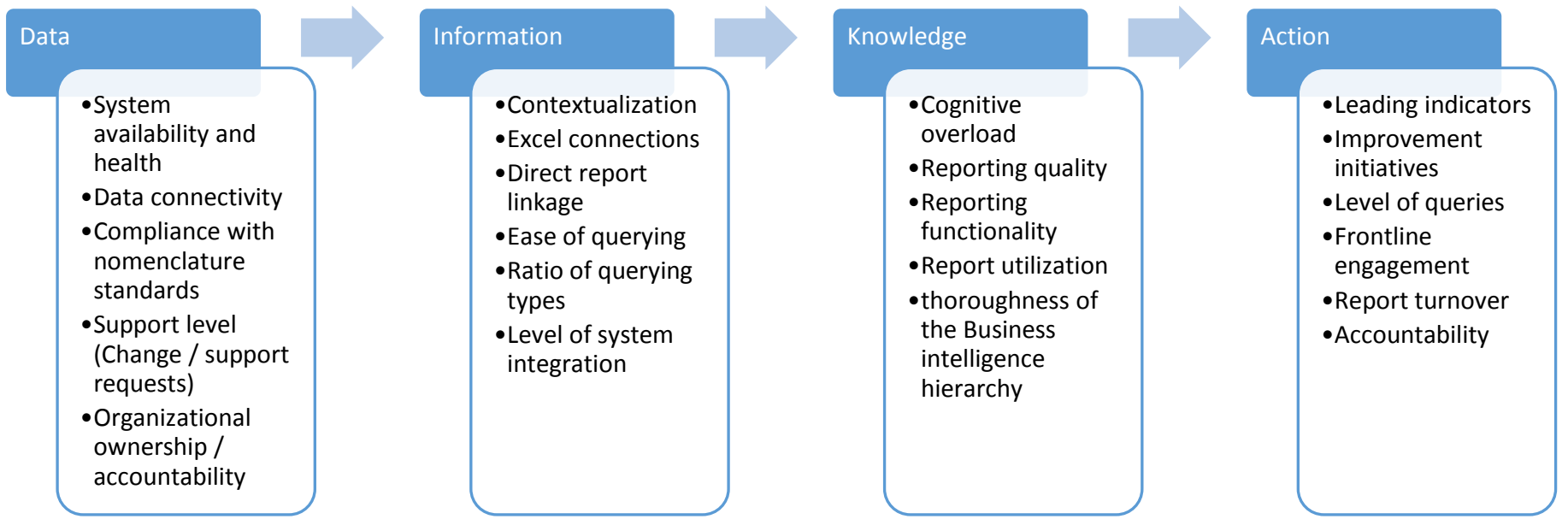

Figure 4-1: Data to action methodology with a set of best practice factors 
This section presents a model called the Data Utilization and Value Index (DUVI). It measures how successful the data to action process is functioning by quantifying the aforementioned factors.

To generate the DUVI, three main processes are utilized:

- Strategy definition and weighting

- Factor assessment and quantification

- Using the DUVI to manage data utilization

Figure 4-2 shows the processes and sub-processes involved in DUVI assessment. Each are presented in more detail in the upcoming sections. 


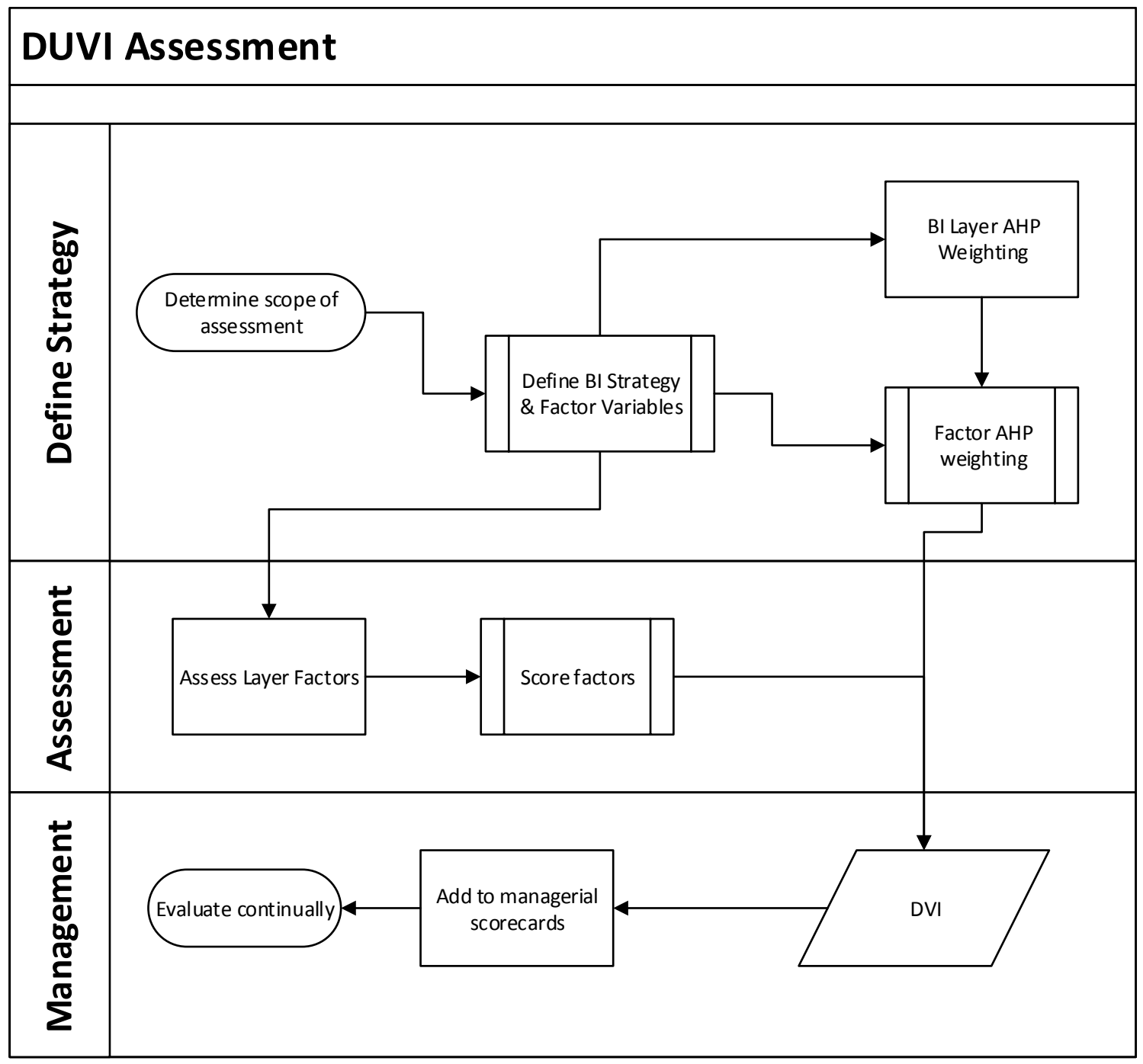

Figure 4-2: Data Value Index and assessment process map

\subsection{Strategy Definition and Weighting}

A clearly defined technology strategy is important for calculating the DUVI. This will provide a lucid scope of the assessment and a weighting of each BI layer and factor. The DUVI is a quantified index. A weighting of these variables accounts for the diverse technological maturity and strategies of mine sites. 


\subsubsection{Scope of assessment}

Figure 3-1 \& Figure 3-2 provide the building blocks of technology strategy. A technology strategy assessment consists of multiple interviews with site IT and mine management. Through these interviews the site strategy can be determined. Each pillar (people, process, \& platform) is considered. Technology investments, both existing and planned, are reviewed. The processes that use technology are identified and mapped out. The people pillar is important and considers the human capital of a mine site. Human capital considers the number of people, their training, and availability. An example of a process map defining the strategy is shown in Figure 4-3. This example is a swim lane process detailing how various data tools are consumed by multiple people. 


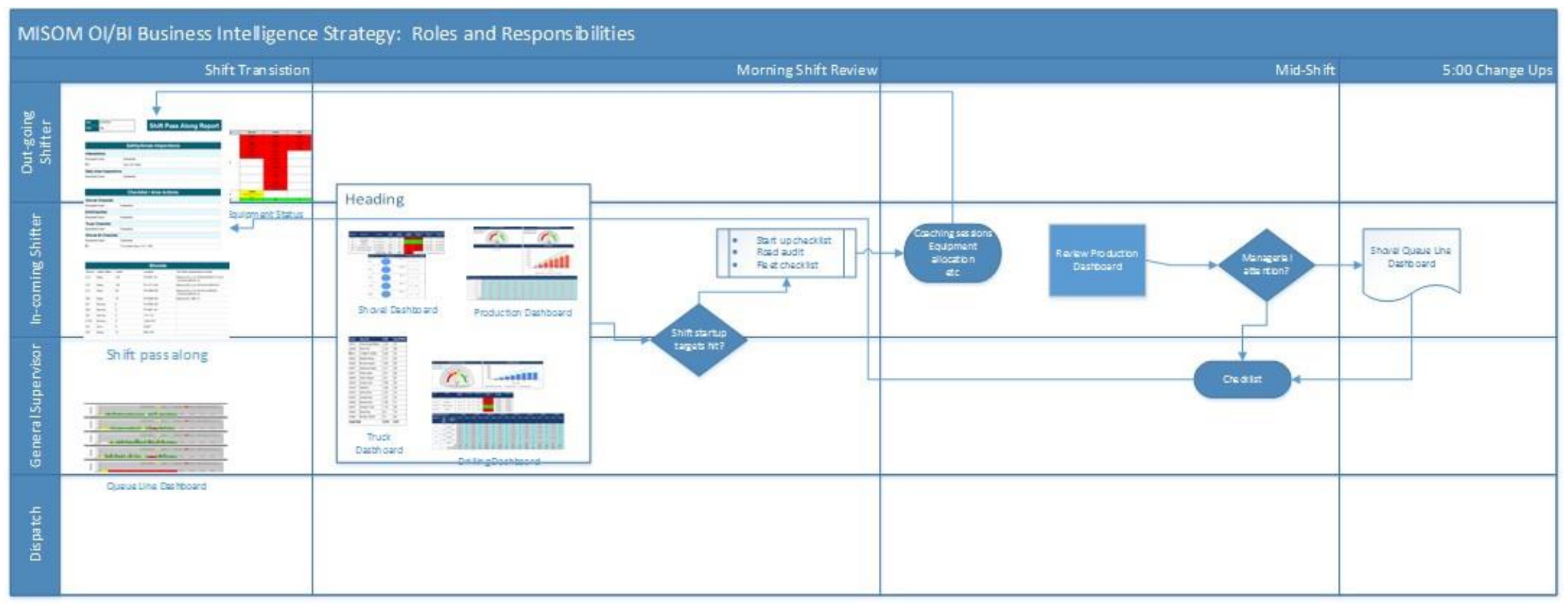

Figure 4-3: Defining strategy through business process mapping 
A clear strategy provides the scope of the assessment. These limits can be based upon a functional organization, mine site, or complex. Organizations may choose only to assess the top sources or the total amount of sources.

\subsubsection{Define BI strategy and factor variables}

Another key part of the technology and business intelligence is assessing the maturity of each layer of the data to action methodology. Every mine site will be at a different level of data and BI maturity. A site may have a large data foundation but completely lack a clear information layer. Alternatively, a site may have a robust information technical platform but lack a stable data foundation. The unique $\mathrm{BI}$ strategy of a mine needs to be considered when assessing data utilization. The DUVI accounts for this natural variance by weighting each BI layer and factor used in the assessment. This is done through a weighting of importance of each layer. As shown in Figure 4-1, each business intelligence layer has a set of factors. These factors can also be weighted based on the unique conditions of the mine. This flexibility is necessary because of the wide differences in technology and processes that exist at a site. In order to provide consistency, a formal weighting process is used called the Analytical Hierarchy Process $(\mathrm{AHP})$

\subsubsection{AHP weighting}

The Analytical Hierarchy Process (AHP) and the pairwise comparison framework were chosen to rank and weight the $\mathrm{BI}$ layers and factors of the DUVI. AHP can provide users a consistent method of ranking the layers and factors of the DUVI. The modeling flexibility accounts for the differences of maturity and strategy of a unique site.

The first step is to weigh each of the BI layers. The technology strategy will guide which layer needs more managerial focus and execution priority. A pairwise comparison allows a 
quantification of this managerial focus. Table 4-1 provides a comparison example for the BI layers.

Table 4-1: Pairwise comparisons among BI Layers

\begin{tabular}{l|cccc|}
\multicolumn{1}{c}{} & Data & Information & Knowledge & Action \\
\cline { 2 - 5 } Data & 1 & 1 & 2 & 1 \\
Information & 1 & 1 & 3 & 1 \\
Knowledge & $1 / 2$ & $1 / 3$ & 1 & $1 / 4$ \\
Action & 1 & 1 & 4 & 1 \\
\hline
\end{tabular}

Each layer is compared to the others. They are ranked by importance or emphasis of the study. The numeric values are based on a scoring index shown in Figure 4-4.

\begin{tabular}{ccccc}
\multicolumn{5}{c}{ Factor Weighting Score } \\
Factor (row) & More Important & Equal Less important & Factor (column) \\
1 & 8765432 & 1 & 2345678 & 2 \\
2 & 8765432 & 1 & 2345678 & 3 \\
3 & 8765432 & 1 & 2345678 & 1
\end{tabular}

Figure 4-4 Pairwise weighting score assumptions

In the example, data and information are scored with a "1" meaning they are equally important. While information compared to knowledge is given a " 3 " signifying that information is more important than the knowledge layer. A "1/4", comparing knowledge to action, indicates that the knowledge layer is far less important than the action layer.

Using matrix algebra these comparisons are summarized with a weighting factor and the AHP calculations; $\mathrm{Cl}, \mathrm{RI}$ and $\mathrm{C}$ ratio as shown in Table 4-2. The calculations are shown in the appendix. The data layer has a weight of .27 while the action layer is ranked highest with 0.32 . Some key AHP calculations are used to ensure consistency in ranking are being followed. The variable $\mathrm{RI}$ is a given variable from the AHP scale based upon the " $\mathrm{n}$ " of factors in the ranking. The $\mathrm{C}$ ratio is used to determine if there is consistency in the ranking matrix. A $\mathrm{C}$ ratio less than 
.1 is acceptable for most situations. If a $\mathrm{C}$ ratio is greater than .1 , the rankings need to be revisited as there are inconsistent rankings.

Table 4-2: Pairwise and AHP results

\begin{tabular}{rrrr} 
& & \multicolumn{2}{c}{$\begin{array}{c}\text { Consistency } \\
\text { measure }\end{array}$} \\
Data & 0.27 & 4.04 \\
Information & 0.30 & 4.06 \\
Knowledge & 0.10 & & 4.02 \\
Action & 0.32 & & 4.07 \\
& & $\mathrm{Cl}$ & 0.02 \\
& & $\mathrm{RI}$ & 0.90 \\
& & $\mathrm{C}$ & \\
& & Ratio & 0.02
\end{tabular}

Each factor within the BI layers will need to be compared with each other. When finished, the AHP comparison will look like Table 4-3. As demonstrated, all respective factor are compared to each other within each BI layer. Their weighting factors are calculated following the same process. Some $\mathrm{C}$ ratios are greater than the standard .1 compliance signifying that those layers need to be revisited. 
Table 4-3: Full ranking of all factors

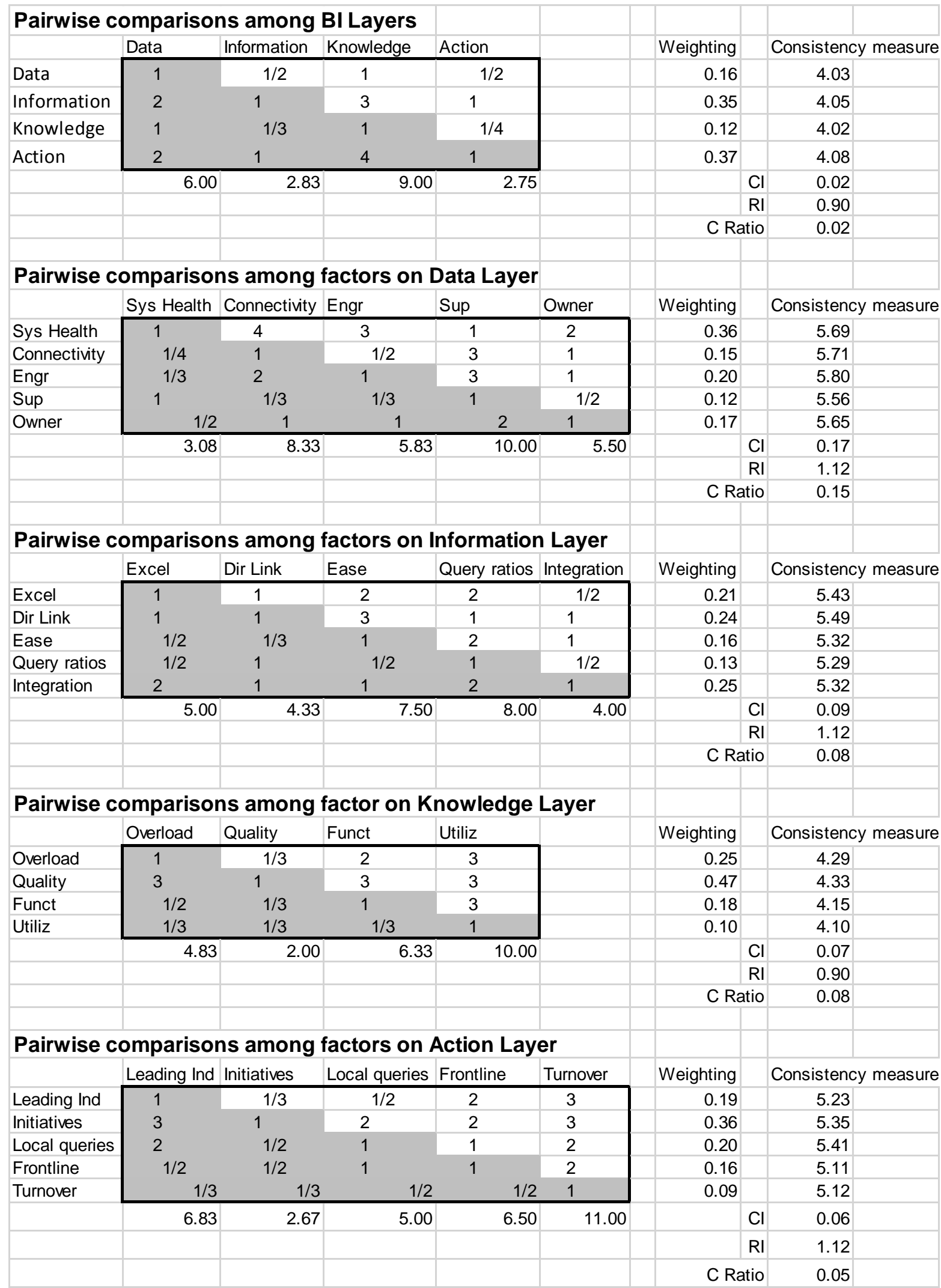


At this point each BI layer and factor have an AHP weighting. Table 4-4 provides a sample DUVI table showing how the AHP is used within the index. Each factor is shown with its calculated AHP weight. These weightings will be used in quantifying the DUVI.

Table 4-4: Sample DUVI with AHP weights and scores example.

\begin{tabular}{lll} 
Layer & Key Factors & AHP Weight \\
\hline \hline Data & System availability and health & 0.39 \\
& Data connectivity & 0.18 \\
& Nomenclature standards & 0.22 \\
& Change / support requests & 0.11 \\
& Organizational ownership & 0.10 \\
\hline Information & Excel connections & 0.19 \\
& Direct report linkage & 0.19 \\
& Ease of querying & 0.24 \\
& Ratio of querying types & 0.09 \\
& Level of system integration & 0.29 \\
\hline Knowledge & Cognitive overload & 0.33 \\
& Reporting quality & 0.46 \\
& Reporting functionality & 0.11 \\
& Report utilization & 0.11 \\
\hline Action & Leading indicators & 0.15 \\
& Improvement initiatives & 0.38 \\
Level of queries & 0.28 \\
Frontline engagement & 0.13 \\
Report turnover & 0.06 \\
\hline
\end{tabular}

Data Subtotal:

BI Layer AHP Weight

Information Subtotal:

0.33

Knowledge Subtotal:

0.46

0.11

Action Subtotal:

0.11 


\subsection{Assessing the DUVI factors}

Now that a clear strategy has been defined and each layer and factor weighted, the assessment can occur. Each factor is formalized with questions, surveys, and system data usage statistics reviewed during the site visits. Many factors are quantitative using meta-data from modern information systems to calculate usage. Each Bl layer's scoring approach is summarized in a table.

\subsubsection{Data}

Technological platforms are fundamental to data generation and the interpretation of information. Examples of these platforms in the mining industry were given in Chapter 3 . The DUVI considers how well the systems accurately generate data and also the functionality of the sources system. The following paragraphs introduce the variable used to assess the factors presented in Chapter 2. A focus is on the key best practices that drive system health and ease of use.

The DUVI treats the data layer as an IT system which stores, retrieves and sends packets of data from equipment or processes within the value chain of mining. As well, IT inherently consists of the network and power architecture that is built to support them. IT systems must be dependable and applicable for an organization to integrate them into their managerial processes. The Data DUVI group consists of five factors:
A. System availability and health
B. Data connectivity
C. Nomenclature standards: compliance with mine plan and Time Usage Model (TUM)
D. Change requests
E. Organizational ownership 
Each factor generates a score between 1 and 10. Table 4-5 provides a brief description of each factor, the purpose, and the variables used for the scoring mechanism. 
Table 4-5: Summary of data factors of DUVI

\begin{tabular}{|c|c|c|c|}
\hline Factor & Factor Description & Factor Purpose & Variables - Scoring Mechanisms \\
\hline $\begin{array}{l}\text { System } \\
\text { Availability and } \\
\text { Health }\end{array}$ & $\begin{array}{l}\text { A quantitative factor describing the } \\
\text { mechanical or network availability of } \\
\text { the systems and the overall health } \\
\text { of the data systems within the scope } \\
\text { of the assessment. }\end{array}$ & $\begin{array}{l}\text { Assess the health and accuracy of data } \\
\text { generated by transactional data systems } \\
\text { within scope. System health and } \\
\text { informational quality are fundamental to } \\
\text { the success and use of information } \\
\text { systems. }\end{array}$ & $\begin{array}{l}10-\text { Top three critical systems have } \\
95 \% \text { availability, } 90 \% \text { of table columns } \\
\text { populate, and } 95 \% \text { of reports work } \\
\text { accurately } \\
1-\text { Top three critical systems have } 75 \% \\
\text { availability, } 75 \% \text { of tables columns } \\
\text { populate, and } 75 \% \text { of reports are } \\
\text { accurate. }\end{array}$ \\
\hline $\begin{array}{l}\text { Data } \\
\text { connectivity }\end{array}$ & $\begin{array}{l}\text { A quantitative factor describing how } \\
\text { data is retrieved from system. }\end{array}$ & $\begin{array}{l}\text { Data connectivity is representative of } \\
\text { ease of use of the systems data. } \\
\text { Systems that don't auto populate on a } \\
\text { central server are difficult to use and } \\
\text { integrate into the managerial activities. }\end{array}$ & $\begin{array}{l}10 \text { - All systems (in scope) are } \\
\text { connected to data network and load to a } \\
\text { central server } \\
1 \text { - No systems are connected directly to } \\
\text { the data network or load to a central } \\
\text { server }\end{array}$ \\
\hline $\begin{array}{l}\text { Nomenclature } \\
\text { standards }\end{array}$ & $\begin{array}{l}\text { Factor describing nomenclature } \\
\text { standards regarding compliance of } \\
\text { system to mine plan and site's } \\
\text { common time usage model (TUM). }\end{array}$ & $\begin{array}{l}\text { System accuracy is fundamental to user } \\
\text { acceptance and informational quality. } \\
\text { Mine plan compliance as well as time } \\
\text { usage are fundamental to tracking } \\
\text { activity at a mine site. }\end{array}$ & $\begin{array}{l}10-\text { During assessment all systems (in } \\
\text { scope) and classifications comply with } \\
\text { mine plan and TUM nomenclature } \\
\text { standards } \\
1-\text { No system compliance }\end{array}$ \\
\hline $\begin{array}{l}\text { Change / } \\
\text { support } \\
\text { requests }\end{array}$ & $\begin{array}{l}\text { A quantitative factor describing the } \\
\text { response rate of change requests. }\end{array}$ & $\begin{array}{l}\text { All systems need maintenance. The } \\
\text { purpose of this factor is to measure the } \\
\text { timeliness of this maintenance. User } \\
\text { satisfaction is based on timeliness of } \\
\text { change requests. }\end{array}$ & $\begin{array}{l}10-<3 \text { day turn around help ticket turn } \\
\text { around on top } 3 \text { reports systems } \\
1->14 \text { day turnaround help ticket turn } \\
\text { around on top } 3 \text { reports systems }\end{array}$ \\
\hline $\begin{array}{l}\text { Organizational } \\
\text { ownership }\end{array}$ & $\begin{array}{l}\text { Factor describing the existence of a } \\
\text { local / site owner and an identifiable } \\
\text { vendor supporter }\end{array}$ & $\begin{array}{l}\text { All systems need to have an owner in } \\
\text { order to achieve optimal integration into } \\
\text { an organization and maintaining viability } \\
\text { over time. }\end{array}$ & $\begin{array}{l}10-\text { All systems (in scope) have an } \\
\text { identifiable owner and vendor supporter } \\
1-\text { No systems have an identifiable } \\
\text { owner }\end{array}$ \\
\hline
\end{tabular}


Mine sites have many systems and it is important to isolate the key ones. An organizational strategy will define the top three systems. Process maps are useful for this definition shown in Figure 4-5. They are important in identifying the key systems of a report or meeting.

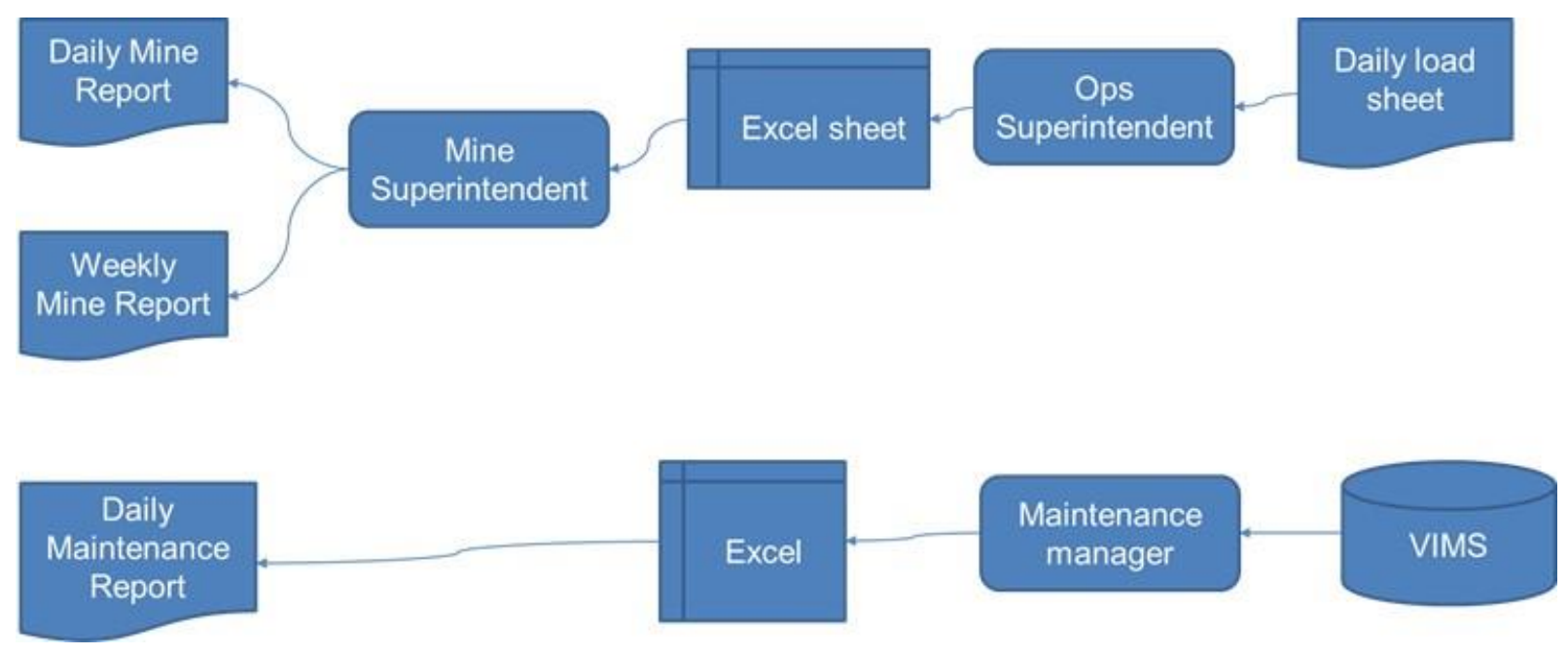

Figure 4-5: Key system isolation process mapping.

Once these systems are isolated, the variables that make up these factors may need to be adjusted accordingly. For instance, if three key systems were identified, the system health of each may need to be audited differently. The case studies provide more information on how these variables may change for each system type.

\subsubsection{Information}

The contextualization and integration of data provides users information that can be used for improved decisions and actionable intelligence to drive behavior. The Information Layer contains a set of factors as follows:
A. Excel connections
B. Direct report linkage
C. Ease of querying
D. Ratio of querying types
E. Level of system integration 
Each factor assesses the ease of use and accuracy at which information is delivered to users. Factors related to IS provide the best practices and variables helpful in understanding informational quality and ease of use. Table 4-6 provides a brief description of each factor, the purpose, and the variables used for the scoring mechanism. 
Table 4-6: Summary of IS factors

\begin{tabular}{|c|c|c|c|}
\hline Factor & Factor Description & Factor Purpose & Variables - Scoring Mechanisms \\
\hline Excel connections & $\begin{array}{l}\text { Factor describing the amount } \\
\text { of systems that allow excel } \\
\text { querying (i.e. easily } \\
\text { accessible through excel) }\end{array}$ & $\begin{array}{l}\text { Direct system excel connections represent ease } \\
\text { of getting data or information out and in an } \\
\text { analytical tool widely used. This differs from } \\
\text { exporting, where users must execute reports, } \\
\text { then export a static copy of data into a } \\
\text { spreadsheet }\end{array}$ & $\begin{array}{l}10-\text { All informational systems (within } \\
\text { scope) have direct Excel connection } \\
\text { available } \\
1 \text { - No informational systems have } \\
\text { direct Excel connection available }\end{array}$ \\
\hline $\begin{array}{l}\text { Direct report } \\
\text { linkage }\end{array}$ & $\begin{array}{l}\text { Factor describing the amount } \\
\text { of steps required to update } \\
\text { any type of report. }\end{array}$ & $\begin{array}{l}\text { When systems complicate obtaining information, } \\
\text { users must take a series of complex steps to } \\
\text { create and or update a report. This factor is } \\
\text { another measure of ease of use as well as } \\
\text { informational quality. }\end{array}$ & $\begin{array}{l}10 \text { - Do the top } 3 \text { daily and monthly } \\
\text { reports require } 1 \text { step report updates? } \\
1 \text { - Do the top } 3 \text { daily and monthly } \\
\text { reports require more than } 5 \text { steps to } \\
\text { update? }\end{array}$ \\
\hline Ease of querying & $\begin{array}{l}\text { Factor describing the steps } \\
\text { required for normal users to } \\
\text { execute a query to the } \\
\text { informational layer. }\end{array}$ & $\begin{array}{l}\text { Information systems are created to query } \\
\text { through updating a report or ad hoc knowledge } \\
\text { discovery. This factor assesses this difficulty and } \\
\text { also the level of training for key people such as } \\
\text { frontline supervisors. Systems that are easy to } \\
\text { query lead to use and user satisfaction. }\end{array}$ & $\begin{array}{l}10 \text { - Ratio of frontline supervisors and } \\
\text { site engineers of top } 3 \text { information } \\
\text { systems is greater than } 50 \% \text { of queries } \\
1 \text { - No frontline supervisors and } \\
\text { engineers query top } 3 \text { information } \\
\text { systems reporting tools }\end{array}$ \\
\hline $\begin{array}{l}\text { Level of system } \\
\text { integration }\end{array}$ & $\begin{array}{l}\text { Factor describing the level of } \\
\text { integration between various } \\
\text { systems on the site. }\end{array}$ & $\begin{array}{l}\text { System independence leads to data inaccuracy } \\
\text { especially related to employees, machines, and } \\
\text { time codes. Many organizations have colloquial } \\
\text { names of assets that vary by department. When } \\
\text { key dimensions are integrated, information }\end{array}$ & $\begin{array}{l}10-\text { The dimensions: employee, } \\
\text { machine, and time codes are consistent } \\
\text { between all systems in the scope } \\
1 \text { - No consistency between systems for } \\
\text { employee, machine, and time codes }\end{array}$ \\
\hline
\end{tabular}


quality increases significantly as well as user satisfaction. 
Most modern information systems contain significant "meta-data" that tracks the use and health of the system. This data is important to provide a real time and quantitative measurement of usage. All queries can be tracked back to the user and database queried. Using these metrics to drive usage is a key point of the information layer and DUVI. Specific examples are given in the cases studies.

\subsubsection{Knowledge}

The DUVI considers two major groups for which information is used: Knowledge - Business Insight and Action - Process Improvement. Each of these groups are dependent upon the available platform, people involved, and the processes discussed in Chapter 3 . Each must follow a set of best practices that align with a strategy which is reflected in the knowledge layer factors:

- Cognitive overload

- Reporting quality

- $\quad$ Reporting functionality

- Report utilization

Table 4-7 provides a brief description of each factor, the purpose, and the variables used for the scoring mechanism. 
Table 4-7: Summary of factors for the knowledge layer

\begin{tabular}{|c|c|c|c|}
\hline Factor & Factor Description & Factor Purpose & $\begin{array}{l}\text { Variables - Scoring } \\
\text { Mechanisms }\end{array}$ \\
\hline Cognitive overload & $\begin{array}{l}\text { Factor describing the cognitive } \\
\text { overload that a user will } \\
\text { experience while interacting with } \\
\text { a report or set of reports. }\end{array}$ & $\begin{array}{l}\text { This factor is used to describe the } \\
\text { overall effectiveness of business } \\
\text { insight reporting. Reports that result } \\
\text { in cognitive overload will have little } \\
\text { individual or organizational impact. } \\
\text { Making informed and timely } \\
\text { decisions are more difficult due to a } \\
\text { lack of clear focus. }\end{array}$ & $\begin{array}{l}10-2 \text { indictors per } 1 \text { graphic or } \\
\text { chart in top } 3 \text { reports } \\
1-10 \text { indicators to } 1 \text { graphic } \\
\text { ratio in top } 3 \text { reports have no drill } \\
\text { down capability }\end{array}$ \\
\hline Reporting quality & $\begin{array}{l}\text { Factor describing the quality of } \\
\text { the monthly and weekly reports }\end{array}$ & $\begin{array}{l}\text { This factor is used to understand the } \\
\text { quality of the reporting platforms. It } \\
\text { is a direct gauge of information } \\
\text { quality. }\end{array}$ & $\begin{array}{l}10-100 \% \text { of reports get a } \\
\text { survey of high quality } \\
1-50 \% \text { of reports get a survey } \\
\text { of low quality }\end{array}$ \\
\hline $\begin{array}{l}\text { Reporting } \\
\text { functionality }\end{array}$ & $\begin{array}{l}\text { Factor describing the functional } \\
\text { impact of a report on the } \\
\text { managerial process }\end{array}$ & $\begin{array}{l}\text { This factor is used to measure } \\
\text { whether a report is likely to enact } \\
\text { change. }\end{array}$ & $\begin{array}{l}10-\text { Top } 3 \text { reports are } \\
\text { discussed within a cross } \\
\text { functional team environment and } \\
\text { deliberative process } \\
1 \text { - Top } 3 \text { reports are not utilized } \\
\text { within a cross functional team } \\
\text { environment }\end{array}$ \\
\hline Report utilization & $\begin{array}{l}\text { Factor describing the estimated } \\
\text { utilization of a report by users. }\end{array}$ & $\begin{array}{l}\text { Compare system generated reports } \\
\text { to user generated report to quantify } \\
\text { a utilization factor. }\end{array}$ & $\begin{array}{l}10-1 \text { to } 1 \text { relationship between } \\
\text { system generated queries and } \\
\text { user queries } \\
1-10 \text { to } 1 \text { relationship between } \\
\text { system generated queries and } \\
\text { user queries. }\end{array}$ \\
\hline
\end{tabular}


The primary benefit of data to an organization or business unit is business insight. An example of business insight is the use of high level monthly reports shared in business meetings that streamline relevant information. Using business insight, the modern mine manager who is usually overwhelmed with reports of all kinds, can utilize "key performance indicators" or lagging indicators. These metrics are usually "look backs" on the past performance of an organization. Keying in on this organized insight, the management team can more easily create a solid action plan for the future.

\subsubsection{Action - Process Improvement}

Process improvement activities attempt to change behavior of frontline management and operators though prescribed activities or steps which create focus and pointed questions. Frontline managers which are correctly focused with timely questions drive subordinates to act and improve. The factors considered in the DUVI for process improvement are:
A. Leading indicators
B. Improvement initiatives
C. Level of queries
D. Frontline engagement
E. Report turnover 
Table 4-8 provides a brief description of each factor, the purpose, and the variables used for the scoring mechanism. 
Table 4-8: Summary of factors for process improvement

\begin{tabular}{|c|c|c|c|}
\hline Factor & Factor Description & Factor Purpose & Variables - Scoring Mechanisms \\
\hline Leading indicators & $\begin{array}{l}\text { Factor describing the } \\
\text { amount of available leading } \\
\text { indicators in the information } \\
\text { systems }\end{array}$ & $\begin{array}{l}\text { Leading indicators provide insight } \\
\text { into an organization's ability and } \\
\text { desire to drill down into their } \\
\text { available data. These improve } \\
\text { informational quality and lead to } \\
\text { organizational impacts. }\end{array}$ & $\begin{array}{l}10-5 \text { Leading indicators per KPI } \\
1 \text { - } 0 \text { Leading indicators }\end{array}$ \\
\hline $\begin{array}{l}\text { Improvement } \\
\text { initiatives }\end{array}$ & $\begin{array}{l}\text { Factor of initiatives based } \\
\text { on data generated from the } \\
\text { systems in the scope. }\end{array}$ & $\begin{array}{l}\text { Improvement initiatives represent an } \\
\text { organization's desire to change } \\
\text { through data driven activities. This } \\
\text { indicator is a direct measure of the } \\
\text { use and information in an } \\
\text { organization culture. }\end{array}$ & $\begin{array}{l}10-\text { The top three systems have } 5 \\
\text { defined improvement initiatives } \\
\text { dependent upon system data } \\
1 \text { - No data driven initiatives }\end{array}$ \\
\hline Level of queries & $\begin{array}{l}\text { Factor describing the } \\
\text { proliferation of leading } \\
\text { indicators within the } \\
\text { organization at different } \\
\text { levels. }\end{array}$ & $\begin{array}{l}\text { Measures the usage of data assets } \\
\text { at a local level. Queries are an } \\
\text { indicator of use and therefore user } \\
\text { satisfaction of informational quality. }\end{array}$ & $\begin{array}{l}10-90 \% \text { of queries are local to the } \\
\text { site } \\
1-25 \% \text { of queries local to the site }\end{array}$ \\
\hline $\begin{array}{l}\text { Frontline } \\
\text { Engagement }\end{array}$ & $\begin{array}{l}\text { Factor describing the } \\
\text { amount and quality of } \\
\text { engagement at the frontline } \\
\text { supervisors and operator } \\
\text { level. }\end{array}$ & $\begin{array}{l}\text { Frontline engagement is where } \\
\text { process change occurs. This factor } \\
\text { is used to measure the reporting } \\
\text { tools available to frontline } \\
\text { supervisors to enact change with } \\
\text { their operators. }\end{array}$ & $\begin{array}{l}10-50 \% \text { of reports are for frontline } \\
\text { supervisors and operators } \\
1-\text { No reports generated are for } \\
\text { frontline supervisors and operators }\end{array}$ \\
\hline Report turnover & $\begin{array}{l}\text { Factor to describe the } \\
\text { continual use and freshness } \\
\text { of systems reporting. }\end{array}$ & $\begin{array}{l}\text { The purpose of this factor is to } \\
\text { describe the user satisfaction and } \\
\text { continual use of systems. Reports } \\
\text { can get stale and change is helpful to } \\
\text { keep them fresh. Report turnover } \\
\text { can indicate a continual focus on } \\
\text { new bottlenecks. }\end{array}$ & $\begin{array}{l}10-80 \% \text { of indicators have goals } \\
\text { that change monthly } \\
1-0 \% \text { on indicators have goals } \\
\text { that change monthly }\end{array}$ \\
\hline
\end{tabular}


This group of factors is related to initiatives that drive this interaction between behavior and information.

\subsection{Visualizing and Managing Data Utilization}

At this point in the assessment a process for scoring each factor has been shown. Table 4-9 provides a sample assessment. As seen, every factor has an AHP weight and an assessment score. The Bl layers also have an AHP weight and score. Each layer is ranked with a single value by taking the sum product of the weight and the factor assessment score. The final score is taking another sum product of the BI scores and the layer weight. The calculations are shown in Appendix 8.3. The DUVI is an index between 1 and 10.

Table 4-9: Sample results of the DUVI assessment

\section{Data Utilization Index (DUVI)}

\begin{tabular}{lllcc} 
& Key Factors & AHP & Assessment \\
Layer & System Availability and Health & Sys Health & 0.23 & 10 \\
\hline \hline Data & Data connectivity & Connectivity & 0.10 & 10 \\
& Nomenclature standards & Engr & 0.34 & 8 \\
& Change / support requests & Sup & 0.21 & 6 \\
& Organizational ownership & Owner & 0.12 & 10 \\
\hline Information & Excel connections & Excel & 0.19 & 5 \\
& Direct report linkage & Dir Link & 0.12 & 6 \\
& Ease of querying & Ease & 0.29 & 3 \\
& Ratio of querying types & Query ratios & 0.16 & 3 \\
& Level of system integration & Integration & 0.24 & 8 \\
\hline Knowledge & Cognitive overload & Overload & 0.37 & 3 \\
& Reporting quality & Quality & 0.18 & 8 \\
& Reporting functionality & Funct & 0.24 & 6 \\
& Report utilization & Utiliz & 0.21 & 2 \\
\hline Action & Leading indicators & Leading Ind & 0.26 & 6 \\
& Improvement initiatives & Initiatives & 0.15 & 4 \\
& Level of queries & Local queries & 0.29 & 5
\end{tabular}


Frontline Engagement

Frontline

0.19

6

$\begin{array}{rcc} & & \text { AHP Weight } \\ \text { Data Subtotal: } & 8.5 & 0.16 \\ \text { Information Subtotal: } & 4.9 & 0.24 \\ \text { Knowledge Subtotal: } & 4.4 & 0.32 \\ \text { Action Subtotal: } & 5.4 & 0.28\end{array}$

DUVI:

5.5

Like most quantitative variables the DUVI can be tracked over time and managed accordingly.

Managerial scorecards were reviewed in Chapter 2 and can be an important tool to manage complicated initiatives and intangible assets. The DUVI can be a critical variable for site management and corporate officers. Visualization tools as seen in Figure 4-6 can also be very valuable in communicating information. Once the index is incorporated into the managerial strategy of an organization it will need to be assessed over time.

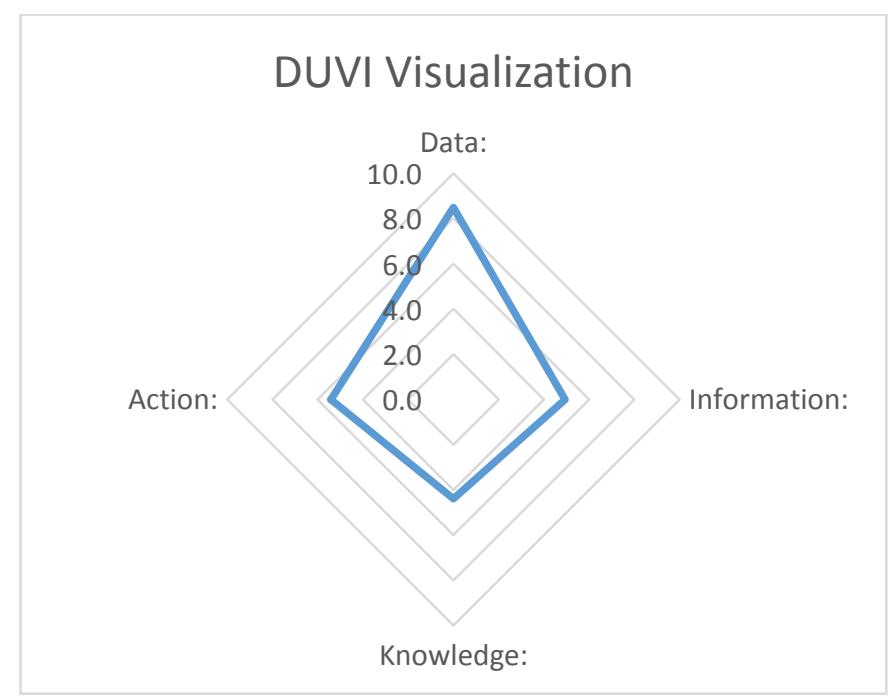

Figure 4-6 DUVI visualization tool: 


\section{DUVI Assessment Case Studies}

Four DUVI assessments will be presented in this chapter. The case studies demonstrate the applicability of the DUVI for mines of various sizes and data strategies. Specifically, each case study will:

- Show how to rank each BI layer and DUVI factors

- Assess the DUVI at various stages of technology adoption based on quantitative and qualitative variables

- Show that DUVI is applicable to all mines of different sizes and commodities

Prior to the assessment each mining company had invested in some level of technology and business intelligence support systems. As well, each desired to improve technology return on investment (ROI). Each assessment was done at different points of the technology adoption lifecycle. This resulted in each evaluation having a unique theme. Each case study focuses on only one $\mathrm{BI}$ layer to protect the anonymity of the mine sites.

The first case study will focus on the data layer. It takes place at a medium sized phosphate mine. The second case study focuses on the information layer at a medium sized coal mine. This assessment was initiated one year after a deployment of a data warehouse. The third case study will be of a large high tech coal mine with a focus on the knowledge layer. Finally the action layer is presented in the fourth case study using the results of an assessment of a large coal mine. Using this wide variety of case studies, the applicability of the DUVI for the mining industry will be established. 


\subsection{Case study 1: Data layer and information technology}

\subsubsection{Introduction - Scope of assessment}

The first case study is a DUVI assessment at a medium sized phosphate mine and will be referred to as Mine A. The focus of this study is the data layer. Mine A had previously made significant investments in technology without realizing an acceptable level of access to data and felt they lacked improvement initiatives with the technology. Management recognized they were not obtaining the desired returns from that technology within the operations and maintenance departments. A data foundation had been built over the years, but some key pieces were missing to fully utilize these systems. A technology and data utilization assessment was undertaken to review their current systems and develop a strategy to improve the utilization of these systems. The results of the DUVI follow. Specific details are given for the factors of the data layer and the full DUVI is given.

\subsubsection{Strategy definition and weighting}

\subsubsection{Identify scope of assessment}

Mine $A$ is a medium sized mine truck and shovel operation. A small drill fleet is used occasionally along with a large fleet of reclamation dozers. Ore is hauled to four stockpiles by two hoppers which feed a low and high grade process flow through the mill. The ore is then processed in a milling circuit to concentrate the ore into a liquid form. It is then piped 30 miles to a processing plant. Management requested that a business intelligence platform be created to allow consistent daily reporting and continuous improvement initiatives. The main technology systems are shown in Table 5-1. 
Table 5-1: Mine A DUVI assessment systems

\begin{tabular}{|c|c|c|}
\hline Source System & Description & Bl Options \\
\hline VIMS & $\begin{array}{l}\text { Equipment health and hours tracking } \\
\text { system on most Caterpillar equipment. } \\
\text { Additional event and cycle data can also be } \\
\text { derived from the system. }\end{array}$ & $\begin{array}{l}\text { Main source of production and } \\
\text { downtime reporting solution. } \\
\text { Additional data is used for } \\
\text { maintenance planning. }\end{array}$ \\
\hline VisionLink & $\begin{array}{l}\text { Equipment health and hours tracking } \\
\text { system on secondary Caterpillar equipment. } \\
\text { VisionLink is referred to occasionally as a } \\
\text { lite version of VIMS. }\end{array}$ & $\begin{array}{l}\text { Additional source of production } \\
\text { and downtime reporting solution. } \\
\text { Additional data is used for } \\
\text { maintenance planning. }\end{array}$ \\
\hline DeltaV & $\begin{array}{l}\text { Mill analog controller and data historian of } \\
\text { about } 15 \text { PLC data points }\end{array}$ & $\begin{array}{l}\text { Will be used for mill production } \\
\text { and downtime reporting solution }\end{array}$ \\
\hline $\begin{array}{l}\text { Sebia Slurry } \\
\text { Analyzer }\end{array}$ & An automated ore quality tracking system & Mill quality data solution \\
\hline Assay Lab Data & A manual ore quality tracking system & Mill quality data solution \\
\hline Safety Incidents & $\begin{array}{l}\text { Department and site incident tracking } \\
\text { spreadsheets that will be consolidated into } \\
\text { a single database. }\end{array}$ & $\begin{array}{l}\text { Used for Safety KPI and incident } \\
\text { reporting }\end{array}$ \\
\hline $\begin{array}{l}\text { (Corporate Safety } \\
\text { System) }{ }^{1}\end{array}$ & Corporate safety culture tracking system & Used for safety LSI on scorecards \\
\hline JD Edwards (KPI's) & ERP system reporting views & $\begin{array}{l}\text { Used to get WO, equipment list, } \\
\text { and high level costs }\end{array}$ \\
\hline Lawson & Human resource reporting application & $\begin{array}{l}\text { Used to get employee lists and } \\
\text { hours worked }\end{array}$ \\
\hline
\end{tabular}

\footnotetext{
${ }^{1}$ Name withheld to maintain site anonymity
} 


\subsubsection{Define BI strategy and AHP weighting factors}

From the initial interviews with management during the assessment it was determined that the primary focus would be on the information and action layers of the $\mathrm{BI}$ approach. The site wanted to improve the technology $\mathrm{ROI}$ and productivity through setting up some operational excellence and continuous improvement. Their goals are summarized as follows:

- Improve safety tracking, reporting of incidents, and safety culture.

- Greatly facilitate the "ease of access" and reliability of integrated data for onsite engineers and managers (i.e. use Excel to access and analyze all online integrated data).

- Improve production and downtime reporting (real time and historical) for all mobile and fixed assets by -

- Near-real time dashboards, scorecards, weekly / monthly engineering reports, etc.

- Automation of existing reports and eliminating data re-entry.

- Dramatically increasing the utilization of data in value-generating process change.

- Develop continuous improvement programs through shared granular data across all levels of supervision and management which will facilitate the highest-quality product being delivered at the lowest cost without a safety incident.

- Replace paper forms and automate their entry into databases for reporting.

This strategy and set of goals are reflected in Table 5-2.

Table 5-2: Pairwise comparisons among BI Layers for Mine A.

\begin{tabular}{|c|c|c|c|c|c|c|c|}
\hline \multicolumn{8}{|c|}{ Pairwise comparisons among BI Layers } \\
\hline & Data & Information & Knowledge & Action & Weighting & & $\begin{array}{l}\text { Consistency } \\
\text { measure }\end{array}$ \\
\hline Data & 1 & $1 / 2$ & 1 & $1 / 2$ & 0.16 & & 4.03 \\
\hline Information & 2 & 1 & 3 & 1 & 0.35 & & 4.05 \\
\hline Knowledge & 1 & $1 / 3$ & 1 & $1 / 4$ & 0.12 & & 4.02 \\
\hline \multirow[t]{4}{*}{ Action } & 2 & 1 & 4 & 1 & 0.37 & & 4.08 \\
\hline & 6.00 & 2.83 & 9.00 & 2.75 & & $\mathrm{Cl}$ & 0.02 \\
\hline & & & & & & $\mathrm{RI}$ & 0.90 \\
\hline & & & & & & $\begin{array}{r}\mathrm{C} \\
\text { Ratio }\end{array}$ & 0.02 \\
\hline
\end{tabular}


Table 5-2 manifests the final weighting factors for the information layer and the action layer are significantly higher than the other layers.

Now that the Bl layers have been weighed, the next step is to review the factors within each factor. In review, a specific strategy guides these weightings which have been determined through interviews and discussion with key management personnel during the assessment. The data layer factor weighting is shown in Table 5-3. As demonstrated below, System Health and Engineering compliance are the key factors that management desired to focus on.

Table 5-3: Pairwise comparison the key DUVI factors grouped by BI layers.

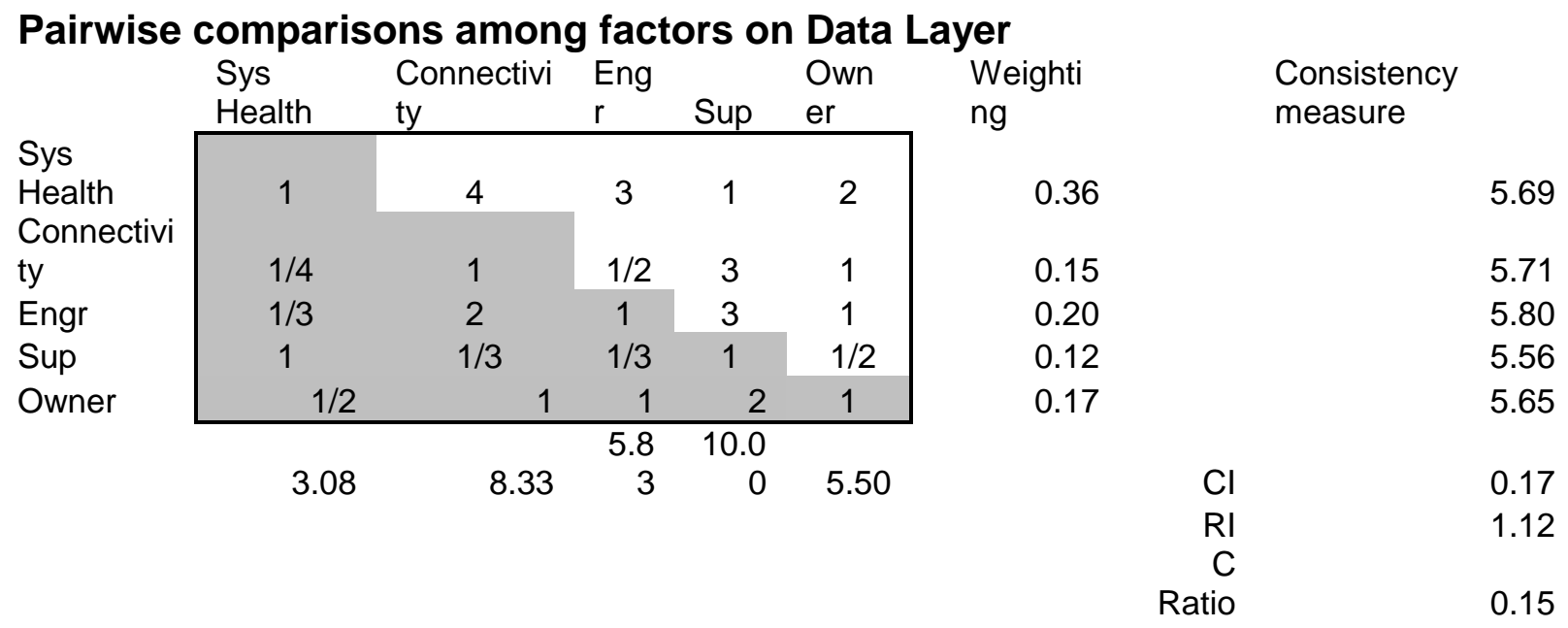

Management had serious concerns about the health of their primary systems. VisionLink had significant issues with functionality as an example. Their plant monitoring system was an antiquated version no longer supported by normal channels. Also concerning was the need to upgrade the operating system off of Windows XP. Due to these concerns management put heavy emphasis on system health.

\subsubsection{Assessing the DUVI factors}

A list of the key data sources was introduced in previous sections. This section will review each factor of the data layer and the score assigned. The scores received by each factor are shown 
below in Table 5-4. The top three systems are VIMS, VisionLink and DeltaV. Some brief scoring notes are given in the table followed by more specific information about each factor. 


\begin{tabular}{|c|c|}
\hline Key Factors & Variables - Scoring Mechanisms \\
\hline $\begin{array}{l}\text { System } \\
\text { Availability and } \\
\text { Health }\end{array}$ & $\begin{array}{l}10-\text { Top three critical systems have } 95 \% \text { availability, } \\
90 \% \text { of table columns populate, and } 95 \% \text { of reports work } \\
\text { accurately. } \\
1-\text { Top three critical systems have } 75 \% \text { availability, } 75 \% \\
\text { of table columns populate, and } 75 \% \text { of reports are } \\
\text { accurate. }\end{array}$ \\
\hline Data connectivity & $\begin{array}{l}10-\text { All systems (in scope) are connected to data } \\
\text { network and load to a central server. } \\
1 \text { - No systems are connected directly to the data } \\
\text { network or load to a central server. }\end{array}$ \\
\hline $\begin{array}{l}\text { Nomenclature } \\
\text { standards }\end{array}$ & $\begin{array}{l}10 \text { - During assessment all systems (in scope) and } \\
\text { classifications comply with mine plan and TUM } \\
\text { nomenclature standards } \\
1 \text { - No system compliance }\end{array}$ \\
\hline $\begin{array}{l}\text { Change / support } \\
\text { requests }\end{array}$ & $\begin{array}{l}10-<3 \text { day average help desk ticket response on top } 3 \\
\text { systems } \\
1->14 \text { day average help desk ticket response on top } 3 \\
\text { reports systems }\end{array}$ \\
\hline $\begin{array}{l}\text { Organizational } \\
\text { ownership }\end{array}$ & $\begin{array}{l}10-\text { All systems (in scope) have an identifiable owner } \\
\text { and vendor supporter. } \\
1-\text { No systems have an identifiable owner. }\end{array}$ \\
\hline
\end{tabular}

\section{Score: Scoring notes:}

$6 \quad$ Maintenance manager was not able to access VisionLink as-of-the date of assessment. This is very common problem with such systems. His estimate is that it is only available to use $30 \%$ of time. DeltaV is an older system that isn't populating data correctly all of the time (60\%). VIMS is used fairly regularly and has a $90 \%$ availability.

Site had invested in Hornet Radios for the key mobile equipment with VIMs and VisionLink. DeltaV is connected to an onsite server. It had regular connectivity problems.

The remaining sources are supported through corporate or live on shared servers and distributed accordingly.

3 VIMS and VisionLink do not have consistent equipment nomenclature or ability to assign down codes to fit the time usage model.

DeltaV didn't provide a method to track downtime of process equipment.

Site also had an extremely difficult time tracking ore through the milling processes.

Vender support for VisionLink and VIMS take an average greaterthan-10-day turnaround for support requests. The software version of DeltaV running in the mill is antiquated and requires additional channels of support through the distributer increasing turnaround time.

Each system had a defined "owner" on site. Maintenance manager was clear owner of VIMS and VisionLink. Site IT is owner of the DeltaV system along with process engineer. Other systems were supported through corporate and local IT. 
Many of these factors are subjective; however, there are some important objective measures in these factors. Table 5-5 provides a bit more specific scores by source system.

Table 5-5: Data layer scoring summary

\begin{tabular}{|c|c|c|c|c|c|}
\hline $\begin{array}{l}\text { Source } \\
\text { System }\end{array}$ & System health & Connectivity & $\begin{array}{l}\text { Engineering } \\
\text { Compliance }\end{array}$ & $\begin{array}{l}\text { Change } \\
\text { support }\end{array}$ & Ownership \\
\hline VIMS & 10 & 10 & 3 & 10 & 10 \\
\hline VisionLink & 4 & 10 & 3 & 6 & 10 \\
\hline DeltaV & 5 & 7 & 1 & 2 & 10 \\
\hline $\begin{array}{l}\text { Sebia Slurry } \\
\text { Analyzer }\end{array}$ & 8 & 10 & 1 & 6 & 10 \\
\hline $\begin{array}{l}\text { Assay Lab } \\
\text { Data }\end{array}$ & 8 & 3 & 1 & $n / a$ & 10 \\
\hline $\begin{array}{l}\text { Safety } \\
\text { Incidents }\end{array}$ & $\mathrm{n} / \mathrm{a}$ & 1 & $n / a$ & $\mathrm{n} / \mathrm{a}$ & 6 \\
\hline $\begin{array}{l}\text { (Corporate } \\
\text { Safety } \\
\text { System) }\end{array}$ & 10 & 10 & $\mathrm{n} / \mathrm{a}$ & 9 & 10 \\
\hline $\begin{array}{l}\text { JD Edwards } \\
\text { (KPI's) }\end{array}$ & 10 & 10 & 7 & 7 & 10 \\
\hline Lawson & 10 & 6 & $\mathrm{n} / \mathrm{a}$ & 8 & 10 \\
\hline
\end{tabular}

Some specific system measures were used. Each system can use a variety of ways to measure system health. For instance, the system health of DeltaV was measured by querying

\footnotetext{
${ }^{2}$ Name withheld to maintain site anonymity
} 
the database. There were days when the table would not populate due to hardware issues. A simple query of "days with a 'null' value" on a key single tag was conducted. Over a year's time we found that approximately $10 \%$ of the time data did not populate. Additionally, when interviewing the process engineer and IT, it was determined that the system had the opportunity to populate the data but the access was not available. This caused the score for Systems Availability to be very low for DeltaV on System Health. The remaining layers are summarized below in the full DUVI for the site shown in Table 5-6.

Table 5-6: DUVI factors for phosphate mine case study

\begin{tabular}{llllc} 
& & & AHP & Assessment \\
Layer & Key Factors & Abbreviation & Weight & Score \\
\hline \hline Data & System availability and health & Sys Health & 0.36 & 5 \\
& Data connectivity & Connectivity & 0.15 & 8 \\
& Nomenclature standards & Engr & 0.20 & 3 \\
& Change / support requests & Sup & 0.12 & 4 \\
& Organizational ownership & Owner & 0.17 & 8 \\
\hline Information & Excel connections & Excel & 0.21 & 2 \\
& Direct report linkage & Dir Link & 0.24 & 4 \\
& Ease of querying & Ease & 0.16 & 4 \\
& Ratio of querying types & Query ratios & 0.13 & 1 \\
& Level of system integration & Integration & 0.25 & 1 \\
\hline Knowledge & Cognitive overload & Overload & 0.25 & 8 \\
& Reporting quality & Quality & 0.47 & 5 \\
& Reporting functionality & Funct & 0.18 & 4 \\
& Report utilization & Utiliz & 0.10 & 2 \\
\hline \hline Action & Leading indicators & Leading Ind & 0.19 & 3 \\
& Improvement initiatives & Initiatives & 0.36 & 4 \\
& Level of queries & Local queries & 0.20 & 4 \\
& Frontline engagement & Frontline & 0.16 & 3 \\
& Report turnover & Turnover & 0.09 & 2 \\
\hline \hline
\end{tabular}

As mentioned previously the main focus of this case study was the data layer. The scoring for the other BI layers were done during the assessment but are not presented in this dissertation. 
After each factor and layer are weighted using AHD and scored by assessing the factors and variables, the DUVI can be summarized and reviewed.

\subsubsection{Visualizing and managing data utilization}

Each BI layer has been AHP weighted based on the strategy expressed by management. As well, each factor was reviewed and a score was given based on the results of the assessment. During the assessment surveys were conducted (both verbal and data driven) to assess the key variables. A final score was given and the sum product was determined to obtain a subtotal DUVI for each layer. The final DUVI shown in Table 5-7 was calculated by taking the sum product of the layer subtotals and AHP weighting factor.

Table 5-7: Mine A DUVI score

\begin{tabular}{rll}
\hline & Factor weighted score & AHP Weighting \\
\hline Data Subtotal: & 4.7 & 0.16 \\
\hline Information Subtotal: & 2.4 & 0.35 \\
\hline Knowledge Subtotal: & 5.3 & 0.12 \\
\hline Action Subtotal: & 3.5 & 0.37 \\
\hline & & \\
\hline DUVI & 3.5 &
\end{tabular}

\subsubsection{Conclusions and discussion}

Each of the core automated data systems were highly underutilized for reporting and asset management. Many of the Excel sheets and access data bases currently used for asset management can be replaced by linking to a data warehouse. Other manual data sets, such as safety data, was scattered between a various Excel sheets and corporate web entry systems.

Mine A had no formal Continuous Improvement (Cl) department or position. The on-site IT resource was a skilled SQL developer and could provide valuable assistance in maintaining and managing the long term DW. The workforce seemed skilled in Excel and open-minded to the better utilization of their systems with the correct infrastructure in place. The lack of integration 
of key systems, "ease of access" to data, and non-compliance to TUM nomenclature standards seems to be the main breakdown in process improvement. A key risk for the site is a lack of analytical support and $\mathrm{Cl}$ department to maintain processes.

The DUVI will provide a key management tool for the site to measure going forward to ensure compliance to the overall business intelligence strategy. It provides visibility to the areas that need managerial attention.

\subsection{Case study 2: Information layer and information systems}

\subsubsection{Introduction - Scope of assessment}

The second case study is of a medium sized coal mine which will be referred to as Mine $\mathrm{B}$. The site had made significant investments in technology platforms. An assessment was given on the role of these investments in delivering actionable information to the organization. The study will present the applicability of the DUVI in mines that have technology systems along with a data warehouse to determine the utilization of the information layer.

Prior to the assessment the site had invested in a fleet management system, advanced drill monitoring systems, and other critical data systems. A data warehouse had been developed and in place for over two years. The management wanted to continue to derive value from these systems through setting up engagement initiatives for frontline supervisors and equipment operators. The assessment was undertaken and a DUVI generated. The results follow.

\subsubsection{Strategy definition and weighting}

\subsubsection{Identify scope of Assessment}

The sources included in the data warehouse (DW) are shown in Table 5-8. Also included is the potential value of the information by the source. Many of the data layer issues were addressed 
during the deployment of the DW. However, the level of data granularity needed for these engagement initiatives required some support for certain systems that are discussed.

Table 5-8: Mine B assessment systems scope

\begin{tabular}{|l|l|l|}
\hline Source System & \multicolumn{2}{l}{ Description } \\
\hline Modular Dispatch & $\begin{array}{l}\text { Fleet management system used to track } \\
\text { and manage truck and shovel fleets. Site } \\
\text { has } 5 \text { loading units and } 20 \text { trucks tracked } \\
\text { with the system. }\end{array}$ & $\begin{array}{l}\text { Detailed production } \\
\text { information of truck and } \\
\text { shovel fleets. Real time } \\
\text { data providing information } \\
\text { on queue time, cycle times, } \\
\text { status, productivity, and } \\
\text { many other statistics. }\end{array}$ \\
\hline Terrain & $\begin{array}{l}\text { Drill monitoring system tracking GPS } \\
\text { location, drill depth, rock hardness, and } \\
\text { various drill statistics. The system was } \\
\text { installed on 4 of their drills. }\end{array}$ & $\begin{array}{l}\text { Detailed productivity of } \\
\text { drilling fleet and key usage } \\
\text { statistics. Real time } \\
\text { dashboards were used to } \\
\text { provide critical information } \\
\text { to manage drillers. }\end{array}$ \\
\hline MineCare & $\begin{array}{l}\text { Health alarm systems that show abusive } \\
\text { operator behavior on key pieces of } \\
\text { equipment. Used properly these systems } \\
\text { can be an indicator of activities that will lead } \\
\text { to equipment damages or injuries. }\end{array}$ & $\begin{array}{l}\text { Equipment abuse statistics } \\
\text { by operator and crew. Very } \\
\text { useful to focus training on } \\
\text { key operators and activities. }\end{array}$ \\
\hline $\begin{array}{l}\text { SAP with an Oracle } \\
\text { database back-end }\end{array}$ & $\begin{array}{l}\text { Excel tracking system of information about } \\
\text { safety incidents and safety interaction. } \\
\text { orders, and may other accounting activities. }\end{array}$ & $\begin{array}{l}\text { Detailed information on } \\
\text { incidents to use for trending } \\
\text { and comparison by crew } \\
\text { and shift. }\end{array}$ \\
\hline Safety & $\begin{array}{l}\text { on controllable costs by } \\
\text { department and } \\
\text { consumables }\end{array}$ \\
\hline
\end{tabular}

\subsubsection{Define Bl strategy and AHP weighting factors}

As mentioned earlier site wanted to extend the value of data through frontline engagement.

Therefore the primary focus would be on the information of the $\mathrm{BI}$ approach. The information 
layer needs to be robust and of high quality in order to engage frontline operators. This strategy is reflected in Table 5-9 showing a high weighting for the information and action layer.

Table 5-9: Pairwise comparisons among Bl layers for medium sized coal mine.

\begin{tabular}{|c|c|c|c|c|c|c|c|}
\hline \multicolumn{8}{|c|}{ Pairwise comparisons among BI Layers } \\
\hline & Data & Information & Knowledge & Action & Weighting & & $\begin{array}{l}\text { Consistency } \\
\text { measure }\end{array}$ \\
\hline Data & 1 & $1 / 2$ & $1 / 3$ & $1 / 2$ & 0.13 & & 4.08 \\
\hline Information & 2 & 1 & 3 & 1 & 0.34 & & 4.41 \\
\hline Knowledge & 3 & $1 / 3$ & 1 & $1 / 3$ & 0.19 & & 4.32 \\
\hline \multirow[t]{4}{*}{ Action } & 2 & 1 & 3 & 1 & 0.34 & & 4.41 \\
\hline & 8.00 & 2.83 & 7.33 & 2.83 & & $\mathrm{Cl}$ & 0.10 \\
\hline & & & & & & $\mathrm{Rl}$ & 0.90 \\
\hline & & & & & & $\begin{array}{r}\mathrm{C} \\
\text { Ratio }\end{array}$ & 0.11 \\
\hline
\end{tabular}

\subsubsection{Ranking of each factor}

Now that the $\mathrm{BI}$ layers have been weighed the next step is to review the BI layer factors. The best practice factors for the information layer provide key direction and focus. This ranking takes into account the technology platform that the DW was built on as well as the objectives of the initiatives they were proposing. The information layer factor weightings are shown in Table $5-10$.

Table 5-10: Pairwise comparison of the key DUVI factors grouped by BI layers.

\section{Pairwise comparisons among factors on information layer}

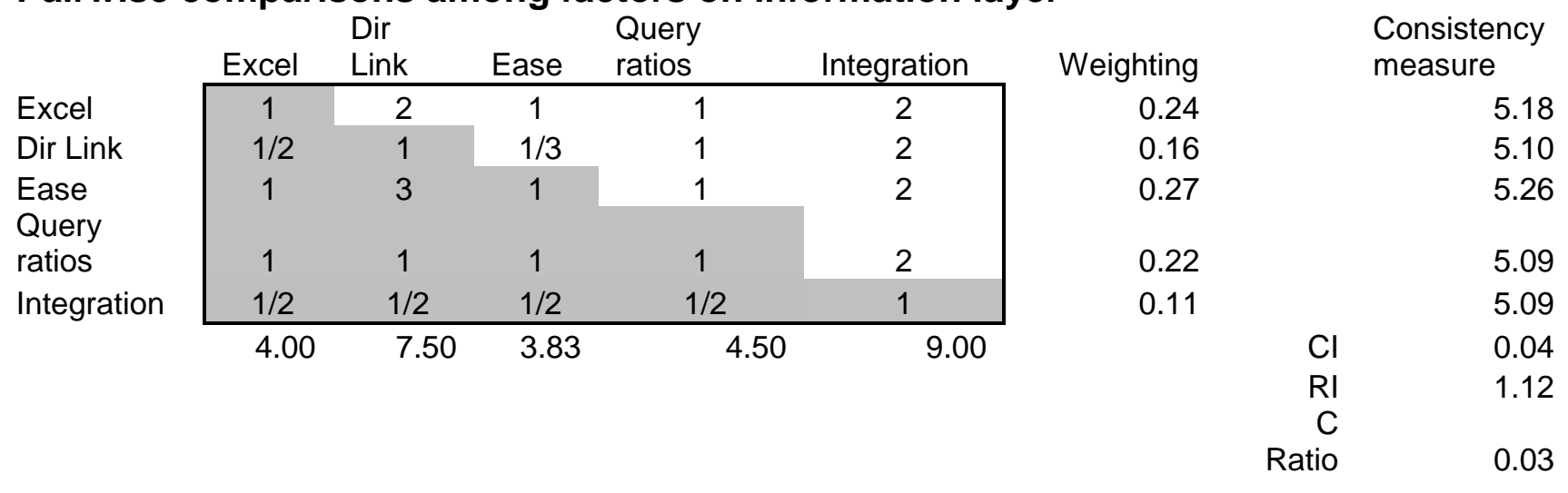


Priorities were established with the factors of ease of use, Excel, and query ratios ranking the highest. These factors reflect the necessity of frontline supervisors and engineers having quick and easy access to information. These can in turn be used to drive performance and compliance to the mine plan. The querying ratio will be important to monitor if these key people are using the system according to the strategy.

\subsubsection{Assessing the DUVI factors}

Now that the information layer and factors have a strategy-driven weighting, the assessment scoring can be discussed. These factors contain more quantitative variables used for scoring based upon usage statistics. Each score is shown in Table 5-11. Some brief scoring notes are given in the table followed by more specific information about each factor. 


\begin{tabular}{|c|c|}
\hline Key Factors & Variables - Scoring Mechanisms \\
\hline $\begin{array}{l}\text { Excel } \\
\text { connections }\end{array}$ & $\begin{array}{l}\text { 10 - All informational systems (within scope) have } \\
\text { direct Excel connection available. } \\
1 \text { - No informational systems have direct Excel } \\
\text { connection available. }\end{array}$ \\
\hline $\begin{array}{l}\text { Direct report } \\
\text { linkage }\end{array}$ & $\begin{array}{l}10 \text { - Do the top } 3 \text { daily and monthly reports require } 1 \\
\text { step report updates? } \\
1 \text {-Do the top } 3 \text { daily and monthly reports require } \\
\text { more than } 5 \text { steps to update? }\end{array}$ \\
\hline Ease of querying & $\begin{array}{l}10-\text { Ratio of frontline supervisors and site engineers } \\
\text { of top } 3 \text { information systems is greater than } 50 \% \text { of } \\
\text { queries. }\end{array}$ \\
\hline & $\begin{array}{l}1-\text { No frontline supervisors and engineers query top } 3 \\
\text { information systems reporting tools. }\end{array}$ \\
\hline $\begin{array}{l}\text { Ratio of querying } \\
\text { types }\end{array}$ & $\begin{array}{l}10 \text { - Ratio } 2 \text { to } 1 \text { of report queries to ad hoc queries } \\
1 \text { - Ratio } 10 \text { to } 1 \text { of report queries to ad hoc queries }\end{array}$ \\
\hline $\begin{array}{l}\text { Level of system } \\
\text { integration }\end{array}$ & $\begin{array}{l}10 \text {-The dimensions: employee, machine, and time } \\
\text { codes are consistent between all systems in the scope } \\
1 \text { - No consistency between systems for employee, } \\
\text { machine, and time codes }\end{array}$ \\
\hline
\end{tabular}

\section{Score: Scoring notes:}

10 Each data source was part of the company's data warehouse.

This system was built using the Microsoft stack of $\mathrm{BI}$ tools with the end result being OLAP cubes. OLAP cubes link very well to Excel for analysis enabling each data source a connection to excel.

With the development of their data warehouse the site deployed a series of managerial scorecards. These scorecards were web based and used for daily reporting of safety, cost, and production. During the assessment it was determined that the engineering team was generating reports outside of the data warehouse. This required many steps to update.

Querying the usage statistics of the data warehouse it was determined that the system had very little usage by frontline supervisors and site engineers. There were a few "super users" out of the site $\mathrm{Cl}$ department.

After investigating the usage statistics of the data warehouse, it was determined that the majority of queries on the system were generated from scorecard queries.

During the data warehousing initiative these dimensions were investigated and made consistent through dimensional modeling of the sources. 
The Excel connection factor is fairly straight forward and the score is a result of all sources having a connection to Excel. The next factor is the direct report linkage. As mentioned in the assessment table, the site had been using a web based scorecard reporting system for their daily production reporting. An example is shown in Figure 5-1. There are many indicators listed and the actuals, goals, and points are shown. Additionally, some trending calculations are included showing the past 30 day compliance. These were accessed by navigating to a web page and populated from the DW. Mine A had a strong $\mathrm{Cl}$ department that developed eight scorecards similar to the drill and blast report shown below.

\begin{tabular}{|c|c|c|c|c|c|c|}
\hline \multirow{2}{*}{$\begin{array}{l}\text { Date } \\
\text { Shift }\end{array}$} & \multirow{2}{*}{$\begin{array}{l}\text { Monday, April } 072014 \\
\text { All }\end{array}$} & \multirow{2}{*}{ HOME } & & & & \\
\hline & & & & & & \\
\hline \multicolumn{2}{|r|}{ Key Performance Indicator } & Actuals & Goals & $\begin{array}{c}\text { Points } \\
\text { Possible }\end{array}$ & \begin{tabular}{|c|} 
Points \\
Achieved
\end{tabular} & \begin{tabular}{|l|} 
Last 30 \\
Doys \%
\end{tabular} \\
\hline \multirow{3}{*}{ 曰 } & Safety incidents (frst aid or any incidert) & 0.0 & 0.0 & 20 & 20 & $96.8 \%$ \\
\hline & Prinary Drled Meters & $1,640.2$ & $2,370.0$ & 85 & 35 & \\
\hline & & & Total & 105 & 55 & \\
\hline \multicolumn{2}{|r|}{ Leading Indicators } & Actuals & Goals & $\begin{array}{l}\text { Points } \\
\text { Possible }\end{array}$ & \begin{tabular}{|l|} 
Points \\
Achieved
\end{tabular} & $\begin{array}{l}\text { Lest } 30 \\
\text { Doys \% }\end{array}$ \\
\hline \multirow{3}{*}{ 由 } & Safefy interactions & 10.0 & 10.0 & 20 & 20 & $19.4 \%$ \\
\hline & Drilled MetersReady Hour & 30.6 & 28.1 & 50 & 20 & \\
\hline & Drill Production (Meters) - between 6 an to 8 an & 37.4 & 202.0 & 10 & 0 & $0.0 \%$ \\
\hline \multirow{3}{*}{ 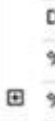 } & Dral Production (Meters) - between 6pm to $8 \mathrm{pm}$ & 38.1 & 202.0 & 10 & 0 & $0.0 \%$ \\
\hline & $\%$ of Redrilled (ineters) & $18.6 \%$ & $4.0 \%$ & 10 & 0 & $3.2 \%$ \\
\hline & \% drilling hours of drill avalable hours & $34.3 \%$ & $70.0 \%$ & 75 & 30 & \\
\hline 由 & \% Unknown and Delay Tine & $65.1 \%$ & $10.0 \%$ & 75 & 30 & \\
\hline \multirow[t]{5}{*}{$\mathrm{\Theta}$} & Driling Hours & 37.3 & 1320 & 50 & 30 & \\
\hline & Drill Operating Deloys Duration (hours) & 8.8 & 200 & 10 & 10 & $96.8 \%$ \\
\hline & Dril Pad Prep Delays & 0.0 & 0.0 & 10 & 10 & $29.0 \%$ \\
\hline & Fara Checklist-Yes (\%) & $40.0 \%$ & $90.0 \%$ & 10 & 0 & $0.0 \%$ \\
\hline & & & Total & 330 & 150 & \\
\hline
\end{tabular}

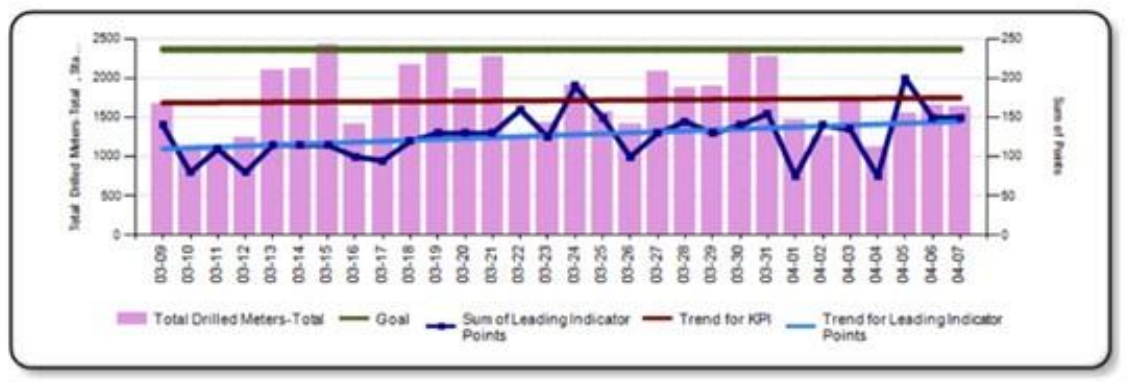

Total Dnlled Meters-Total 
During the assessment it was found that the engineering department had not fully grasped the power of the reporting ability of the data warehouse. Many engineering reports were found which were maintained by the site engineers and a few clerks through a highly manual handentry process. As part of the assessment, these reports were scrutinized with a series of process maps. The summary of these process maps is shown in Figure 5-2. The first step was to initiate a "remote desktop connection" into the fleet management server. Through a series of queries they generated a data export in a CSV file. The data was then transposed and entered into a very large engineering tracking spreadsheet. Equipment hours and material information had to be entered into different tabs of the spreadsheet. This process alone required about 4-5 steps. At that point the reports were reviewed. In each instance this process required many iterations. The same process was followed for mine plan data and safety data. This process required at least 10 steps to update and populate these reports. These monthly reports lowered the score for the direct report linkage factor.

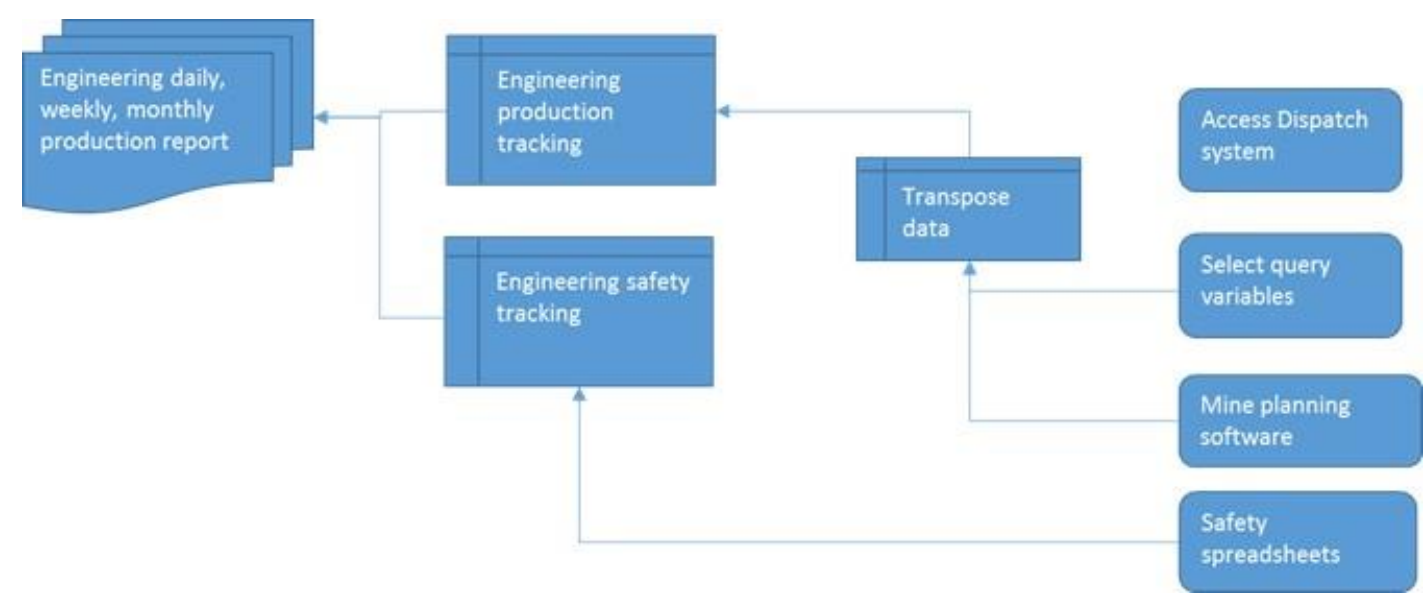

Figure 5-2: Steps to update engineering reports

The next two factors are related to the querying of the information system. Modern data warehouses track metadata of users. Statistics on who is querying the data, how often, and the type of queries can be determined. Each are very helpful in tracking how the systems are being used. Table 5-12 provides a sample set of data from the Microsoft OLAP system of the site. 
Table 5-12: Sample data set of OLAP use metadata

\begin{tabular}{|c|c|c|c|c|c|}
\hline $\begin{array}{l}\text { MSOLAP_Datab } \\
\text { ase }\end{array}$ & MSOLAP_ObjectPath & $\begin{array}{l}\text { MSOLAP_U } \\
\text { ser }\end{array}$ & $\begin{array}{l}\text { Datas } \\
\text { et }\end{array}$ & StartTime & $\begin{array}{l}\text { Durati } \\
\text { on }\end{array}$ \\
\hline Corp DW & $\begin{array}{l}\text { Corp.DW.DailyResults. Fact } \\
\text { DBO2 } 1\end{array}$ & $\begin{array}{l}\text { Corp\UserS } \\
\text { ys }\end{array}$ & $X X$ & $\begin{array}{r}7 / 17 / 135: 48 \\
\text { PM }\end{array}$ & 0 \\
\hline Corp DW & $\begin{array}{l}\text { Corp.DW.DailyResults. Fact } \\
\text { DBO2 } 1\end{array}$ & $\begin{array}{l}\text { Corp\UserS } \\
\text { ys }\end{array}$ & $X X$ & $\begin{array}{r}\text { 7/17/13 5:50 } \\
\text { PM }\end{array}$ & 0 \\
\hline Corp DW & $\begin{array}{l}\text { Corp.DW.DailyResults. Fact } \\
\text { DBO2 } 1\end{array}$ & Corp\User1 & $X X$ & $\begin{array}{r}7 / 1 / 137: 39 \\
\text { PM } \\
\end{array}$ & 565 \\
\hline Corp DW & $\begin{array}{l}\text { Corp.DW.DailyResults.Fact } \\
\text { DBO2 } 1\end{array}$ & $\begin{array}{l}\text { Corp\UserS } \\
\text { ys }\end{array}$ & $X X$ & $\begin{array}{r}7 / 15 / 1311: 39 \\
\text { PM }\end{array}$ & 0 \\
\hline Corp DW & $\begin{array}{l}\text { Corp.DW.DailyResults. Fact } \\
\text { DBO2 } 1\end{array}$ & $\begin{array}{l}\text { Corp\UserS } \\
\text { ys }\end{array}$ & $X X$ & $\begin{array}{r}8 / 2 / 134: 45 \\
\text { PM }\end{array}$ & 1 \\
\hline Corp DW & $\begin{array}{l}\text { Corp.DW.DailyResults.Fact } \\
\text { DBO2 } 1\end{array}$ & Corp\User1 & $X X$ & $\begin{array}{r}\text { 8/2/13 5:07 } \\
\text { PM }\end{array}$ & 1 \\
\hline Corp DW & $\begin{array}{l}\text { Corp.DW.Terrain.Fact } \\
\text { Snapshot }\end{array}$ & Corp\User1 & $X X$ & $\begin{array}{r}7 / 9 / 138: 01 \\
\text { AM }\end{array}$ & 1 \\
\hline Corp DW & $\begin{array}{l}\text { Corp.DW.Terrain.Fact } \\
\text { Snapshot }\end{array}$ & Corp\User1 & $X X$ & $\begin{array}{r}6 / 28 / 135: 08 \\
\text { PM }\end{array}$ & 0 \\
\hline Corp DW & $\begin{array}{l}\text { Corp.DW.Terrain.Fact } \\
\text { Snapshot }\end{array}$ & Corp\User2 & $X X$ & $\begin{array}{r}6 / 28 / 136: 53 \\
\text { PM } \\
\end{array}$ & 0 \\
\hline Corp DW & $\begin{array}{l}\text { Corp.DW.Terrain.Fact } \\
\text { Snapshot }\end{array}$ & Corp\User2 & $X X$ & $\begin{array}{r}7 / 11 / 13 \text { 1:45 } \\
\text { AM }\end{array}$ & 0 \\
\hline Corp DW & $\begin{array}{l}\text { Corp.DW.Terrain.Fact } \\
\text { Snapshot }\end{array}$ & Corp\User4 & $X X$ & $\begin{array}{r}7 / 28 / 135: 38 \\
\text { AM }\end{array}$ & 0 \\
\hline Corp DW & $\begin{array}{l}\text { Corp.DW.Dispatch.Fact Status } \\
\text { Events }\end{array}$ & Corp\User1 & $x X$ & $\begin{array}{r}8 / 1 / 135: 52 \\
\text { PM }\end{array}$ & 0 \\
\hline Corp DW & $\begin{array}{l}\text { Corp.DW.Dispatch.Fact Status } \\
\text { Events }\end{array}$ & Corp\User1 & $X X$ & $\begin{array}{r}8 / 7 / 132: 43 \\
\text { AM }\end{array}$ & 1 \\
\hline Corp DW & $\begin{array}{l}\text { Corp.DW.Dispatch.Fact Status } \\
\text { Events }\end{array}$ & Corp\User5 & $X X$ & $\begin{array}{r}6 / 28 / 134: 08 \\
\text { PM }\end{array}$ & 0 \\
\hline Corp DW & $\begin{array}{l}\text { Corp.DW.Dispatch.Fact Status } \\
\text { Events }\end{array}$ & Corp \User5 & $X X$ & $\begin{array}{r}\text { 6/28/13 5:07 } \\
\text { PM }\end{array}$ & 0 \\
\hline Corp DW & $\begin{array}{l}\text { Corp.DW.Dispatch.Fact Status } \\
\text { Events }\end{array}$ & Corp \User5 & $X X$ & $\begin{array}{r}7 / 10 / 132: 29 \\
\text { AM }\end{array}$ & 0 \\
\hline Corp DW & $\begin{array}{l}\text { Corp.DW.Dispatch.Fact Status } \\
\text { Events }\end{array}$ & Corp\User8 & $X X$ & $\begin{array}{r}7 / 11 / 131: 25 \\
\text { AM }\end{array}$ & 0 \\
\hline Corp DW & Corp.DW.Safety.Fact Incidents & Corp\User1 & $X X$ & $\begin{array}{r}7 / 11 / 1311: 21 \\
\text { AM }\end{array}$ & 27 \\
\hline Corp DW & Corp.DW.Safety.Fact Incidents & $\begin{array}{l}\text { Corp\User1 } \\
5\end{array}$ & $X X$ & $\begin{array}{r}7 / 30 / 134: 34 \\
\text { AM }\end{array}$ & 31 \\
\hline Corp DW & Corp.DW.Safety.Fact Incidents & $\begin{array}{l}\text { Corp\User1 } \\
6\end{array}$ & $X X$ & $\begin{array}{r}8 / 2 / 133: 51 \\
\text { PM } \\
\end{array}$ & 1 \\
\hline Corp DW & Corp.DW.Safety.Fact Incidents & Corp\User2 & $X X$ & $\begin{array}{r}\text { 8/2/13 10:56 } \\
\text { PM }\end{array}$ & 132 \\
\hline
\end{tabular}


Different systems will have slightly different tracking systems, but for this case study the Microsoft OLAP tracking system provides the columns shown. Each column is important to determine what is being used, by how, and the extent of the query.

The user "CorplUserSyS" is a system user employed to generate the web reports managed by the site. The other user names are for specific people at the site. Simple queries of the users can be used to populate the variables for the key factors "Ease of querying" and "Ratio of querying types". The main variable for each factor is related to the count of queries as shown Table 5-13. This is just a small snapshot of usage statistics. Users 15, 16, and 5 were site engineers and frontline supervisors which accounted for only $17 \%$ of the queries. The systemgenerated queries accounted for $39 \%$ of the queries.

Table 5-13: Count of queries by user

\begin{tabular}{lr} 
Row Labels & Count of Queries (00's) \\
\hline CorplUser1 & 10 \\
CorplUser15 & 1 \\
CorplUser16 & 1 \\
CorplUser2 & 4 \\
CorplUser4 & 1 \\
CorplUser5 & 4 \\
CorplUser8 & 1 \\
CorplUserSyS & 14 \\
\hline Grand Total & $\mathbf{3 6}$
\end{tabular}

These percentages resulted in a low scoring for the ease of use and querying type factors and the statistics auto populate and can be reviewed frequently. They are very important factors and variables to track over time. The site's data warehousing initiative provided deep integration between the key dimensions mentioned in the DUVI. This resulted in a high score for this factor.

The remaining layers are summarized in the full DUVI for the site shown in Table 5-14 below. 
Table 5-14: DUVI factors for Mine B

\begin{tabular}{lllcc} 
Layer & Key Factors & AHP & \multicolumn{2}{c}{ Assessment } \\
\hline \hline Data & System Availability and Health & Sys Health & 0.19 & 9 \\
& Data connectivity & Connectivity & 0.12 & 10 \\
& Nomenclature standards & Engr & 0.35 & 6 \\
& Change / support requests & Sup & 0.19 & 6 \\
& Organizational ownership & Owner & 0.16 & 10 \\
\hline Information & Excel connections & Excel & 0.24 & 10 \\
& Direct report linkage & Dir Link & 0.16 & 7 \\
& Ease of querying & Ease & 0.27 & 5 \\
& Ratio of querying types & Query ratios & 0.22 & 5 \\
& Level of system integration & Integration & 0.11 & 10 \\
\hline Knowledge & Cognitive overload & Overload & 0.18 & 6 \\
& Reporting quality & Quality & 0.29 & 6 \\
& Reporting functionality & Funct & 0.25 & 10 \\
& Report utilization & Utiliz & 0.29 & 8 \\
\hline \hline Action & Leading indicators & Leading Ind & 0.13 & 9 \\
& Improvement initiatives & Initiatives & 0.24 & 10 \\
& Level of queries & Local queries & 0.27 & 5 \\
& Frontline engagement & Frontline & 0.22 & 5 \\
& Report turnover & Turnover & 0.14 & 10 \\
\hline \hline
\end{tabular}

\subsubsection{Visualizing and managing data utilization}

The information layer factors have now been assessed and the final DUVI can now be reviewed. The sum product of the layer assessment score and AHP weight is executed resulting in Mine B's DUVI. This is shown in Table 5-15.

Table 5-15: Final DUVI score for Mine B

\begin{tabular}{rll}
\hline & Factor weighted score & AHP Weighting \\
\hline Data Subtotal: & 7.7 & 0.13 \\
\hline Information Subtotal: & 7.1 & 0.34 \\
\hline Knowledge Subtotal: & 7.6 & 0.19 \\
\hline Action Subtotal: & 7.4 & 0.34 \\
\hline
\end{tabular}




\section{DUVI 7.4}

. Management was pleased with this assessment, but recognized that there was room to improve through frontline engagement.

\subsubsection{Conclusions and discussion}

The DUVI of 7.4 is a relatively high number for a mine site. A key purpose for the assessment was to drive data utilization at the supervisor and operator level. Some key outcomes were the development of an operator scorecard and a scoreboard reporting platform. This is represented in Figure 5-3. Each tile depicts a report and checklist representing actions supervisors take to engage their crews.

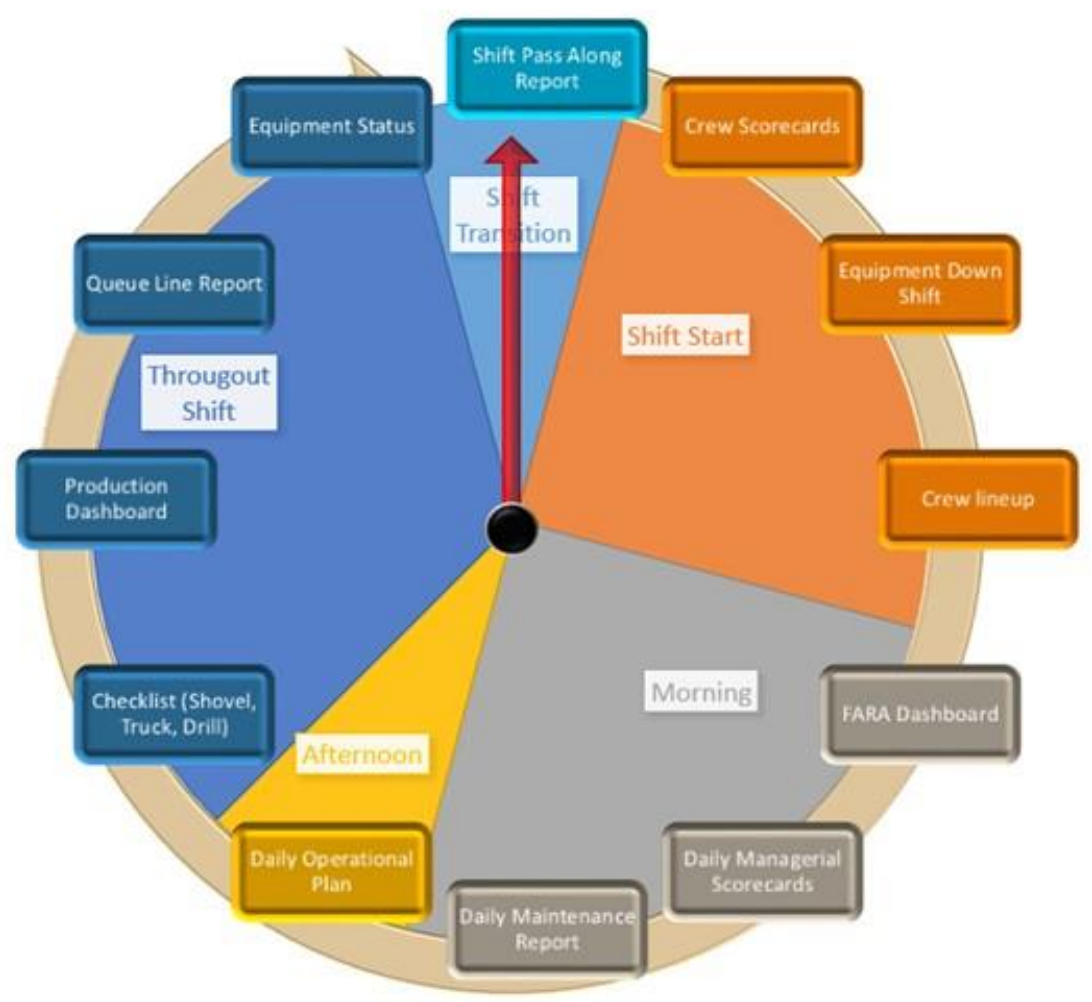

Figure 5-3: Frontline supervisor and operator engagement platform (Dessureault, 2015) 
The outcome of this platform would be a defined process improvement initiative giving frontline supervisors the tools needed to provide focused managerial activities. The DUVI assessment process will continue to help measures the effectiveness of this initiative ensuring that data to action methodology is generating value.

\subsection{Case study 3: Knowledge layer and business insight}

\subsubsection{Introduction - Scope of assessment}

The third case study is from a large copper mine labeled Mine C. Mine C has a multitude of source systems that generate and store large amounts of data. These systems are mature and maintained by the company's Information System (IS) Department. Other core systems, such as PowerView and $\mathrm{Pi}$ are on separate servers yet remain accessible and are controlled by the local IS. The IS department had delivered highly effective user-services by providing access through view-based macros, data imports in Excel through ODBC connections, and Visual Basic Macros. Additionally, training classes in Microsoft SQL Server Management Studio had been provided to the key knowledge workers. Considering all of this, the assessment focused on how data consumers used data for engineering and production management. The study presents the applicability of the DUVI in mines that have technology systems without an integrated and easily accessible information layer. Local management requested the assessment to determine the appropriate steps needed to drive data utilization at the site and provide a more integrated easy to use platform. The focus and theme of the case study will be the knowledge layer. The results of the assessment follow. 


\subsubsection{Strategy definition and weighting}

\subsubsection{Identify scope of assessment}

As shown in Table 5-16 there are many systems in the scope of this assessment. Mine $\mathrm{C}$ is clearly a high tech site with over twenty source systems. In sites such as this, it is very important to understand and clearly define the scope of the assessment.

Table 5-16: Mine C assessment source systems

\begin{tabular}{|c|c|c|}
\hline Source System & Description & Value of information \\
\hline Jigsaw Mine Ops & $\begin{array}{l}\text { Delays and cycle records for auxiliary } \\
\text { equipment. Not immediately accessible. } \\
\text { Currently unused for analysis. }\end{array}$ & $\begin{array}{l}\text { Fleet production statistics useful } \\
\text { for real time and historical } \\
\text { analysis and reporting }\end{array}$ \\
\hline $\begin{array}{l}\text { Modular Mining } \\
\text { PowerView }\end{array}$ & $\begin{array}{l}\text { Site's PowerView has many custom fields } \\
\text { and tables not found in standard PowerView } \\
\text { data model. }\end{array}$ & $\begin{array}{l}\text { Fleet production statistics useful } \\
\text { for real time and historical } \\
\text { analysis and reporting }\end{array}$ \\
\hline Terrain Shovels & $\begin{array}{l}\text { Known colloquially as CAES; has high- } \\
\text { precision GPS of shovel dig-points. Used to } \\
\text { digitize daily digging profiles. }\end{array}$ & Key shovel digging statistics \\
\hline Terrain Dozers & $\begin{array}{l}\text { Known colloquially as CAES; has high- } \\
\text { precision GPS of dozer movements and } \\
\text { cycles. Currently unused for analysis. }\end{array}$ & Key dozer production statistics \\
\hline Ardvark & $\begin{array}{l}\text { High-precision GPS drill monitoring system. } \\
\text { Operator currently does not submit delays } \\
\text { through this system. Can be used to } \\
\text { capture drill delays. }\end{array}$ & $\begin{array}{l}\text { Statistics on drillability and } \\
\text { tracking of delays. }\end{array}$ \\
\hline
\end{tabular}




\begin{tabular}{|c|c|c|}
\hline Source System & Description & Value of information \\
\hline $\begin{array}{l}\text { RCS - Surface } \\
\text { Manager }\end{array}$ & $\begin{array}{l}\text { Like Ardvark, a high-precision GPS drill } \\
\text { monitoring system that keeps track of } \\
\text { drillability and possible tracking of delays. } \\
\text { Operator currently does not submit delays } \\
\text { through this system. }\end{array}$ & $\begin{array}{l}\text { Statistics on drillability and } \\
\text { tracking of delays. }\end{array}$ \\
\hline AcQuire & $\begin{array}{l}\text { A well-defined drill-hole and blast-hole } \\
\text { definition system. The assay results from } \\
\text { the blast-hole samples are stored here. }\end{array}$ & $\begin{array}{l}\text { Mine plan on drill and blast layout } \\
\text { and naming convention of } \\
\text { benches and holes. }\end{array}$ \\
\hline SWE & $\begin{array}{l}\text { A database populated and maintained by } \\
\text { SouthWest Energy detailing the explosives } \\
\text { consumption. Can be used to capture } \\
\text { explosives use in shots. }\end{array}$ & $\begin{array}{l}\text { Key statistics on drilling } \\
\text { information }\end{array}$ \\
\hline $\begin{array}{l}\text { Bridgestone / } \\
\text { Klinge }\end{array}$ & A database that contains tire history & $\begin{array}{l}\text { Tire consumption and usage } \\
\text { statistics }\end{array}$ \\
\hline Split Shovels & $\begin{array}{l}\text { System mounted on the shovel that } \\
\text { currently takes pictures of the sides of the } \\
\text { muck pile while digging. }\end{array}$ & $\begin{array}{l}\text { Fragmentation information of the } \\
\text { dig face }\end{array}$ \\
\hline DSS & $\begin{array}{l}\text { A fatigue monitoring system somewhat } \\
\text { tracked in the control room. There is no } \\
\text { direct access to the database. However, } \\
\text { the data is re-typed into MS Excel by } \\
\text { dispatcher } 3 \text {, including the corrective } \\
\text { actions taken, if any. }\end{array}$ & Key statistics on operator fatigue \\
\hline
\end{tabular}




\begin{tabular}{|l|l|l|}
\hline Source System & Description & \multicolumn{2}{|c|}{ Value of information } \\
\hline $\mathrm{Pi}$ & $\begin{array}{l}\text { System has many powerful tools and local } \\
\text { plant personnel are becoming more familiar } \\
\text { with the system. Users can take advantage } \\
\text { of DataLink, a license-based MS Excel add- } \\
\text { in for real-time link into process data. }\end{array}$ & $\begin{array}{l}\text { Key signal based data for } \\
\text { trending and tracking of } \\
\text { thousands of tags. }\end{array}$ \\
& $\begin{array}{l}\text { Contains cost and maintenance records for } \\
\text { SAP }\end{array}$ & Controllable cost and key work \\
& the entire corporation. & order statistics \\
\hline
\end{tabular}

\subsubsection{Define BI strategy and AHP weighting factors}

From the initial interviews with management during the assessment, it was determined that the primary focus would be on the knowledge layer. While the other layers were important in their strategy, their initial short term focus was to control the information flow and reporting to key managers. It will be established that there were many issues in Mine C's delivery of business metrics to management. This strategy is reflected in Table 5-17.

Table 5-17: Pairwise comparisons among BI Layers for Mine C

\begin{tabular}{|c|c|c|c|c|c|c|c|}
\hline \multicolumn{8}{|c|}{ Pairwise comparisons among BI Layers } \\
\hline & Data & Information & Knowledge & Action & Weighting & & $\begin{array}{l}\text { Consistency } \\
\text { measure }\end{array}$ \\
\hline Data & 1 & 1 & $1 / 3$ & $1 / 2$ & 0.16 & & 4.08 \\
\hline Information & 1 & 1 & 1 & 1 & 0.24 & & 4.09 \\
\hline Knowledge & 3 & 1 & 1 & 1 & 0.32 & & 4.17 \\
\hline \multirow[t]{4}{*}{ Action } & 2 & 1 & 1 & 1 & 0.28 & & 4.13 \\
\hline & 7.00 & 4.00 & 3.33 & 3.50 & & $\mathrm{Cl}$ & 0.04 \\
\hline & & & & & & $\mathrm{RI}$ & 0.90 \\
\hline & & & & & & $\begin{array}{r}\mathrm{C} \\
\text { Ratio }\end{array}$ & 0.04 \\
\hline
\end{tabular}

The specific weightings of the knowledge factors follows in Table 5-18. As outlined below

Overload and Functionality are the key factors that management desired to focus on. 
Table 5-18: Pairwise comparison of the key DUVI factors grouped by BI layers.

\section{Pairwise comparisons among factors on knowledge layer}

\begin{tabular}{|c|c|c|c|c|}
\hline & $\begin{array}{l}\text { Overloa } \\
\text { d }\end{array}$ & $\begin{array}{l}\text { Qualit } \\
\mathrm{y}\end{array}$ & Funct & Utiliz \\
\hline $\begin{array}{l}\text { Overloa } \\
\text { d }\end{array}$ & 1 & 3 & 2 & 1 \\
\hline Quality & $1 / 3$ & 1 & 1 & 1 \\
\hline Funct & $1 / 2$ & 1 & 1 & 2 \\
\hline Utiliz & 1 & 1 & $1 / 2$ & 1 \\
\hline & 2.83 & 6.00 & 4.50 & 5.00 \\
\hline
\end{tabular}

Weightin

g

0.37

0.18

0.24

0.21
Consistency measure

Management had serious difficulties with the overload of reports received on a given day.

Compounding the problem, the functionality of many reports were called into question due to the lack of communication and interaction between department heads. The results of the assessment scoring follows.

\subsubsection{Assessing the knowledge layer factors DUVI}

The two day assessment of Mine $\mathrm{C}$ is summarized below in Table 5-16. Some brief scoring notes are given in the table followed by more specific information about each factor. 


\begin{tabular}{|c|c|}
\hline Key Factors & Variables - Scoring Mechanisms \\
\hline $\begin{array}{l}\text { Cognitive } \\
\text { overload }\end{array}$ & $\begin{array}{l}10-2 \text { indictors per } 1 \text { graphic or chart in } t \\
\text { reports are visual, quickly ascertained, ar } \\
\text { by management to ask focused questions } \\
1-10 \text { indicators to } 1 \text { graphic ratio in top } \\
\text { have no drill down capability. }\end{array}$ \\
\hline Reporting quality & $\begin{array}{l}10-100 \% \text { of reports get a survey of high } \\
1-50 \% \text { of reports get a survey of low qu }\end{array}$ \\
\hline $\begin{array}{l}\text { Reporting } \\
\text { functionality }\end{array}$ & $\begin{array}{l}10 \text { - Top } 3 \text { reports are discussed in a cro } \\
\text { functional team environment and delibere } \\
\text { process. } \\
1 \text { - Top } 3 \text { reports are not discussed in a cr } \\
\text { functional team environment. }\end{array}$ \\
\hline Report utilization & $\begin{array}{l}10-1 \text { to } 1 \text { relationship between system } \\
\text { generated queries and user queries. } \\
1-10 \text { to } 1 \text { relationship between system } \\
\text { generated queries and user queries. }\end{array}$ \\
\hline
\end{tabular}

Score: Scoring notes:

Mine C's reports were a mixture of PDF's, Excel files, and Microsoft Word files. Reports varied by size and format but each were textual with a high indicator to graphic ratio.

During the assessment, users remarked on the high quality auto-generated reports. However, some of the reports were identified "lower quality" due to the high level of manual entry to generate the report.

6 The site has various operational intelligence tools in use: i.e., PDF reports, screens in the control room, KPI dashboards, etc. However, there is a lack of identified purpose and clear business process to use these tools.

2 This factor was very difficult to measure at the time of the assessment. Many reports were auto-generated from the site's corporate data warehouse. There were many custom Excel sheets using dispersed SQL server database views. 
The site has many disparate data flows of various levels and processes flowing toward the managers. However, there is no consolidation of these reports or systematic way to represent the most critical performance measures that require managerial attention. Considering the amount of systems the site has (see Table 5-16), it is not uncommon for users to be in a state of cognitive overload. When assessing the reports, it was found that the current review process contains nearly all lagging indicators (i.e. tons, grade). Lagging indicators are metrics for which no direct attributable action can be immediately identified. For example, viewing a trend of recovery or tonnage for the mine does not help the managers identify processes that might be underperforming. To impact lagging indicators, leading indicators (shift change time, cycle efficiency, etc...) can be tracked and viewed by managers with the ability to make decisions that have impact.

The list of Mine $C$ reports assessed are:

- Daily Production Report (PDF, 6 page tabular) -

- MNE Size Distribution Report Morning (PDF, 32 pages, tabular and trends)

- Accuweigh Scorecard (PDF, 7 pages, tabular \& trends)

- MNE Haul Truck KPI (PDF, 1 page, tabular)

- OPS Shovel Payload Distribution (PDF, shovel operator scorecard, 20 pages, tabular \& histograms)

- Drill Operator Shift Performance (PDF, drill operator scorecard, tabular, trends, diagrams, 23 pages)

- Quality Hole Report (PDF, 3 pages, tabular and pie charts)

- Auto-Drill Utilization (PDF, 3 pages, tabular \& trends)

- Production Summary (PDF, daily, 4 pages, tabular

. Figure 5-4 provides a screen shot of a few sample reports from the site. They are all extremely large with a very low ratio of graphics to indicators. This resulted in a low scoring of cognitive overload. 

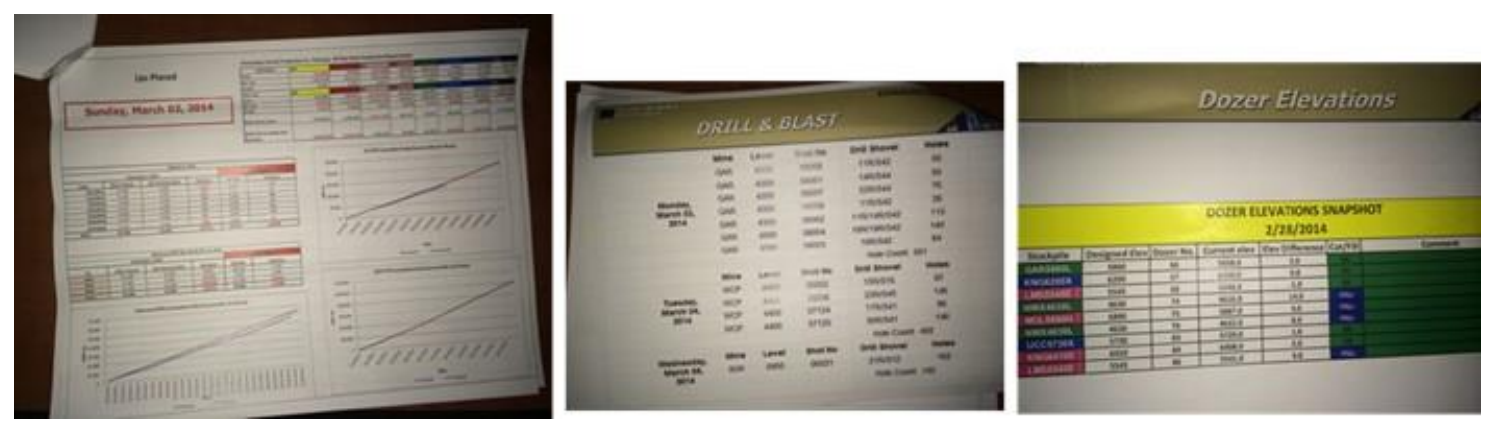

Figure 5-4: Examples of common reports at Mine C.

\subsubsection{Visualizing and managing data utilization}

During the assessment each BI layer was considered but similar to Mine A and B, in Mine C only one layer was given details. Each layer was weighted based on the current conditions and data strategy expressed by management. The scoring followed the standard factors although some variables changed due to system requirements. Each factor was reviewed and a score was given based upon the state of their systems and processes. A final score was given and the sum product was taken to obtain a subtotal DUVI for each layer. The final DUVI is taken by taking the sum product of the layer subtotal and AHP weighting factor as shown in Table 5-20.

Table 5-20: Final DUVI score for Mine C

\begin{tabular}{rll}
\hline & Factor weighted score & AHP Weighting \\
\hline Data Subtotal: & 8.5 & 0.13 \\
\hline Information Subtotal: & 4.9 & 0.34 \\
\hline Knowledge Subtotal: & 4.4 & 0.19 \\
\hline Action Subtotal: & 5.4 & 0.34 \\
\hline & & \\
\hline DUVI & 5.5 &
\end{tabular}

\subsubsection{Conclusions and discussion}

Demand for information was very high among top and middle management at this site. Mine planners, technicians, and operations personnel were desirous to have increased easy access to historical data. Consequently, it was observed that managers were flooded with reports. 
Engineers were also tasked with creating a multitude of reports on a daily basis. The reports were made of primarily high level lagging indicators and business metrics. Many commented on the lack of functionality leading to: decisions generated from the reports, questions generated from the reports, and who the most important consumers of the reports should be. As stated previously, many reports were excessively long leading to cognitive overload. The DUVI was used to isolate key violations of data driven best practices. The outcome of the DUVI was a proposal for improving the DUVI. The first step was to control the information flow, functionality, accuracy, and there by the utilization of information. A consolidation and flow mapping of reporting was proposed to assist in focusing management on the key issues that need to be solved and managed. A flow mapping of reports is a decision matrix of which report feeds into the next analytical level, be it a more detailed report or an interactive analytical toolkit. Figure $5-5$ is an examples of this process.
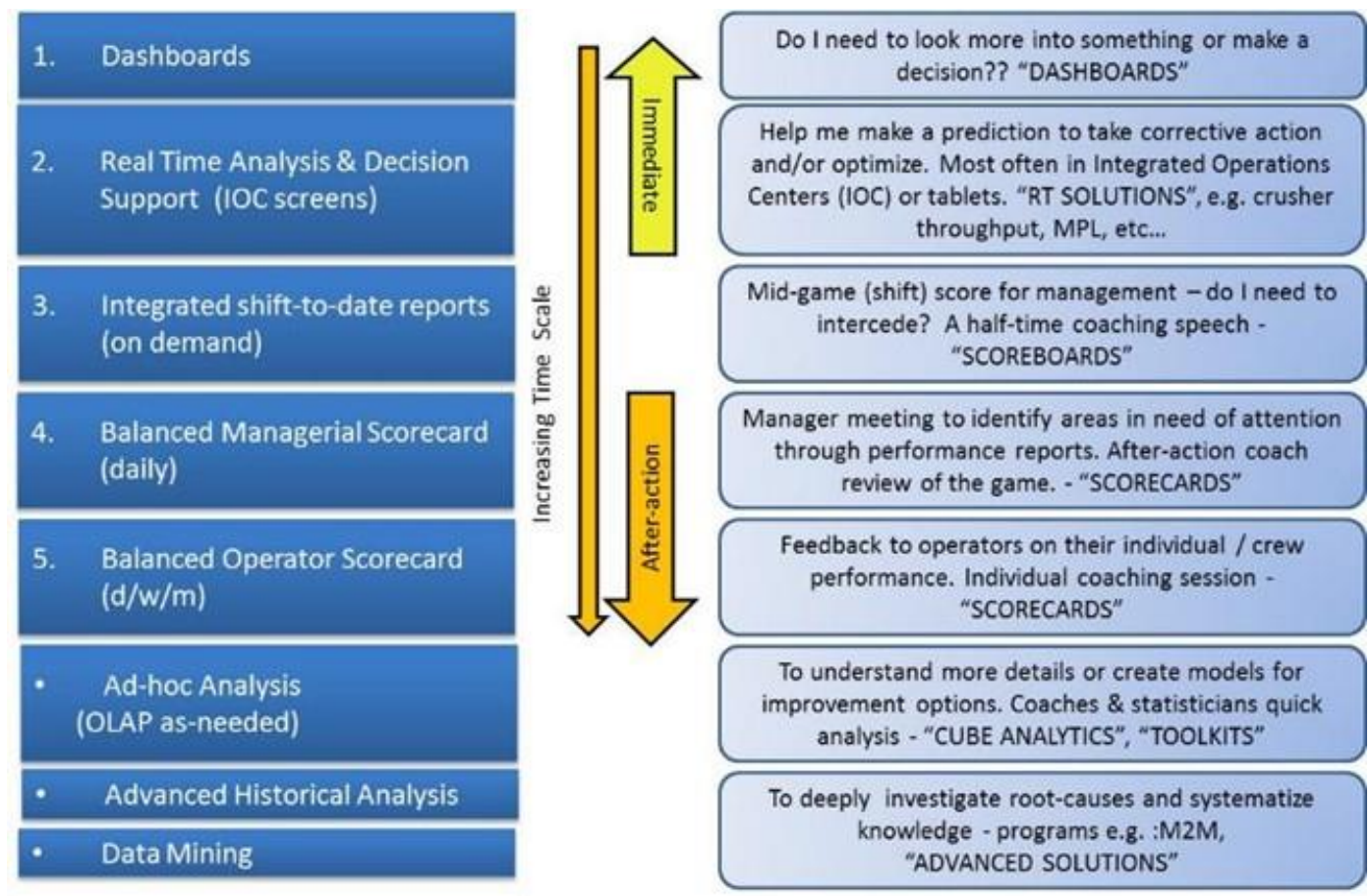

Figure 5-5: Business intelligence tool process maps (Dessureault, 2015) 
There was a need to identify, communicate, and track metrics that influence the lagging indicators contained in the many reports. Setting up a process as shown in Figure 5-5 is incomplete without a training plan. It was proposed to implement the $\mathrm{Bl}$ process with a training plan as highlighted in Table 5-21.

\section{Table 5-21: BI training plan for large copper mine}

\begin{tabular}{|c|c|c|}
\hline Training Label & Description & Impact \\
\hline $\begin{array}{l}\text { Basic OLAP Data } \\
\text { Access \& Pivot } \\
\text { Table } \\
\text { Manipulation }\end{array}$ & $\begin{array}{l}\text { Intended for: frontline supervisors, operator trainers, } \\
\text { command center operators* } \\
\text { This training program covers how to access and manipulate } \\
\text { pivot tables in Excel, using source OLAP cubes as the data } \\
\text { connection. }\end{array}$ & $\begin{array}{l}\text { - Less manual } \\
\text { recreation of } \\
\text { databases } \\
\text { - } \quad \text { Frontline supervisor } \\
\text { creativity in problem } \\
\text { solving. } \\
\text { - High data utilization }\end{array}$ \\
\hline $\begin{array}{l}\text { Advanced Pivot } \\
\text { Table }\end{array}$ & $\begin{array}{l}\text { Intended for: knowledge workers: i.e. engineers, continuous } \\
\text { improvement personnel } \\
\text { Covers advanced Excel topics in data manipulation and data } \\
\text { mining models. }\end{array}$ & $\begin{array}{l}\text { - Avoiding the use of } \\
\text { Macros to automate } \\
\text { data extraction } \\
\text { - } \quad \text { High-impact analytics } \\
\text { - } \quad \text { High data utilization }\end{array}$ \\
\hline $\begin{array}{l}\text { Scorecard } \\
\text { interpretation }\end{array}$ & $\begin{array}{l}\text { Intended for: IS, operations managers, supervisors } \\
\text { Trains personnel for scorecard meetings and trend } \\
\text { interpretation. }\end{array}$ & $\begin{array}{l}\text { - } \quad \text { reates demand for } \\
\text { analytics } \\
\text { - } \quad \text { High data utilization }\end{array}$ \\
\hline
\end{tabular}

The process and training plan was the first step proposed for the site. This plan could assist the mine in adhering to the business intelligence best practices leading to increased data utilization. Implementing the $\mathrm{BI}$ process and training above will provide a key plan to drive additional information and action at the site. The DUVI can be used to assess any changes over time.

\subsection{Case study 4: Action layer and process improvement}

\subsubsection{Introduction - Scope of assessment}

The final case study is of a large coal mine designated Mine D. The site has made significant investments in technology and has developed a robust information layer. The theme of this study is to assess the role of investments within a data warehouse in promoting action by a mine site. The study will present the applicability of the DUVI in mines that have technology 
systems along with a data warehouse to determine the utilization of the information layer. Previous to the assessment the site had invested in a fleet management system, high precision dragline systems, advanced drill monitoring systems, and other critical data systems. A data warehouse had been developed and in place for over eight years at the time of the study. Mine management wanted to continue deriving increased value from these systems and desired setting up several data engagement initiatives for frontline supervisors and equipment operators to utilize. The data utilization assessment was undertaken and a DUVI generated. The results follow.

\subsubsection{Strategy definition and weighting}

\subsubsection{Identify scope of assessment}

As mentioned in the preceding paragraph, Mine $\mathrm{D}$ is a large coal operation with many technology systems. Table 5-22 lists all of the sources included in the assessment. The data warehousing initiative completed and maintained by the company ensured that many systems were of good health with high levels of usage. The main purpose of the assessment was to drive increased data utilization with front line supervisors. The real-time systems were of top priority.

Table 5-22: Mine D mine assessment systems scope

\begin{tabular}{|l|l|l|}
\hline Source System & Description & Bl Options \\
\hline Accuweigh & $\begin{array}{l}\text { Improved dragline productivity through greater } \\
\text { visualization of utilization, availability, and real- } \\
\text { time equipment health monitoring. }\end{array}$ & Detailed dragline cycle data and \\
& equipment health statistics \\
\hline DMR Access & Custom data entry system for production and & High level business metrics \\
Database & down time tracking. & \\
\hline
\end{tabular}




\begin{tabular}{|c|c|c|}
\hline Source System & Description & BI Options \\
\hline E-mesa & $\begin{array}{l}\text { Work order tracking system used by } \\
\text { maintenance department that improves } \\
\text { maintenance planning and execution. }\end{array}$ & $\begin{array}{l}\text { Work order completion statistics } \\
\text { with particular focus on planned and } \\
\text { un-planned completions } \\
\text { percentages. }\end{array}$ \\
\hline Klinge & $\begin{array}{l}\text { Tire management software used to improve tire } \\
\text { life through tracking tread life, abuse, and } \\
\text { required maintenance. }\end{array}$ & $\begin{array}{l}\text { Tire health and usage statistics by } \\
\text { crew and operator }\end{array}$ \\
\hline Kronos & $\begin{array}{l}\text { Workforce management software used for shift } \\
\text { scheduling, attendance, and other HR and } \\
\text { Payroll purposes. Through integrated cubes } \\
\text { with Dispatch, users can track operator status } \\
\text { and a crew's long term utilization of operators. }\end{array}$ & $\begin{array}{l}\text { Employee utilization rates are very } \\
\text { helpful for crew based workforce } \\
\text { planning. }\end{array}$ \\
\hline $\begin{array}{l}\text { Matrikon and } \\
\text { MineCare }\end{array}$ & $\begin{array}{l}\text { Health alarm systems that show abusive } \\
\text { operator behavior on key pieces of equipment. } \\
\text { Used properly these systems can be an } \\
\text { indicator of activities that will lead to } \\
\text { equipment damage or injuries. }\end{array}$ & $\begin{array}{l}\text { Equipment health by operator, shift, } \\
\text { crew, etc. }\end{array}$ \\
\hline Custom Data Entry & $\begin{array}{l}\text { Custom data entry system (usually Excel) used } \\
\text { by contractor to collect information and load } \\
\text { into DW. }\end{array}$ & Business metrics \\
\hline
\end{tabular}




\begin{tabular}{|c|c|c|}
\hline Source System & Description & Bl Options \\
\hline Modular Mining & $\begin{array}{l}\text { Real time fleet management system used to } \\
\text { analyze production, improve equipment } \\
\text { performance, and ensure compliance to mine } \\
\text { plans. Fleet algorithms find the optimum truck } \\
\text { and loading scenarios to maximize production. }\end{array}$ & $\begin{array}{l}\text { Detailed status, cycle, and } \\
\text { equipment usage statistics. Critical } \\
\text { for real-time and aggregatable data. }\end{array}$ \\
\hline Pegasys & $\begin{array}{l}\text { Real-time dragline production and structural } \\
\text { monitoring to improve operational decisions of } \\
\text { operators and supervisors to maximize safe } \\
\text { dragline operations. }\end{array}$ & $\begin{array}{l}\text { Detailed dragline cycle data and } \\
\text { equipment health statistics }\end{array}$ \\
\hline Rockwell & $\begin{array}{l}\text { Real-time visibility of plant performance } \\
\text { allowing for improved decisions on plant } \\
\text { utilization and availability. }\end{array}$ & $\begin{array}{l}\text { Usage statistics on conveyors and } \\
\text { coal processing plans }\end{array}$ \\
\hline Safety - data entry & $\begin{array}{l}\text { System to track limited information on safety } \\
\text { incidents }\end{array}$ & Business metrics on incidents \\
\hline Sitewise Guardian & $\begin{array}{l}\text { Understand and reduce at-risk behavior } \\
\text { through a system that allows users to process } \\
\text { safe work observations. }\end{array}$ & $\begin{array}{l}\text { Detailed leading indicators on safety } \\
\text { culture and prevention processes }\end{array}$ \\
\hline Terrain & $\begin{array}{l}\text { Improve drill and dozer productivity and } \\
\text { accuracy through GPS monitoring of position, } \\
\text { equipment activity supervision, and improved } \\
\text { blasting efficiency. }\end{array}$ & $\begin{array}{l}\text { Detailed drill data and equipment } \\
\text { health statistics. Real-time and } \\
\text { highly aggregatable }\end{array}$ \\
\hline Tritronics & $\begin{array}{l}\text { Dragline production and downtime monitoring } \\
\text { system }\end{array}$ & $\begin{array}{l}\text { Detailed dragline cycle data and } \\
\text { equipment health statistics }\end{array}$ \\
\hline
\end{tabular}


The scope of the assessment is large, but manageable due to the maturity of the site in data utilization. As will be established however, even mature mines have opportunity's to drive data utilization.

\subsubsection{Define Bl strategy and AHP weighting factors}

Similar to the other case studies, interviews were used to assist the mine management in defining and fine-tuning their strategy. It was determined that the primary focus would be the action layer; particularly getting actionable information to the frontline supervisors and operators during the shift. This resulting strategy is indicated in the pairwise matrix in Table 5-23.

Table 5-23: Pairwise comparisons among BI Layers for Mine D.

\begin{tabular}{|c|c|c|c|c|c|c|c|}
\hline \multicolumn{8}{|c|}{ Pairwise comparisons among BI Layers } \\
\hline & Data & Information & Knowledge & Action & Weighting & & $\begin{array}{l}\text { Consistency } \\
\text { measure }\end{array}$ \\
\hline Data & 1 & $1 / 2$ & $1 / 3$ & $1 / 2$ & 0.13 & & 4.11 \\
\hline Information & 2 & 1 & 2 & $1 / 2$ & 0.27 & & 4.31 \\
\hline Knowledge & 3 & $1 / 2$ & 1 & $1 / 2$ & 0.22 & & 4.20 \\
\hline \multirow[t]{4}{*}{ Action } & 2 & 2 & 2 & 1 & 0.38 & & 4.25 \\
\hline & 8.00 & 4.00 & 5.33 & 2.50 & & $\mathrm{Cl}$ & 0.07 \\
\hline & & & & & & $\mathrm{RI}$ & 0.90 \\
\hline & & & & & & $\begin{array}{r}\mathrm{C} \\
\text { Ratio }\end{array}$ & 0.08 \\
\hline
\end{tabular}

As reflected above, the final weighting factors for the information layer and the action layer are significantly higher than the other layers.

\subsubsection{Ranking of action layer factors}

Now that the $\mathrm{BI}$ layers have been weighed, the next step is to review the BI layer factors. Once again, a specific strategy guides these weightings. This specific strategy was determined through interviews and discussion with key management personnel during the assessment. Table 5-24 summarized this strategy with a weighting for each factor. As shown, leading indicators, initiatives, and local queries all have a high weighting. 
Table 5-24: Mine D pairwise comparison for action layer.

\begin{tabular}{|c|c|c|c|c|c|}
\hline & $\begin{array}{l}\text { Leading } \\
\text { Ind }\end{array}$ & $\begin{array}{l}\text { Initiativ } \\
\text { es }\end{array}$ & $\begin{array}{l}\text { Local } \\
\text { queries }\end{array}$ & $\begin{array}{l}\text { Frontli } \\
\text { ne }\end{array}$ & $\begin{array}{l}\text { Turno } \\
\text { ver }\end{array}$ \\
\hline $\begin{array}{l}\text { Leading } \\
\text { Ind }\end{array}$ & 1 & 1 & 1 & 2 & 3 \\
\hline Initiatives & 1 & 1 & 2 & 1 & 2 \\
\hline $\begin{array}{l}\text { Local } \\
\text { queries }\end{array}$ & 1 & $1 / 2$ & 1 & 1 & 3 \\
\hline Frontline & $1 / 2$ & 1 & 1 & 1 & 1 \\
\hline \multirow[t]{2}{*}{ Turnover } & $1 / 3$ & $1 / 2$ & $1 / 3$ & 1 & 1 \\
\hline & 3.83 & 4.00 & 5.33 & 6.00 & 10.00 \\
\hline
\end{tabular}

Weighti ng

0.27

0.25

0.21

0.17

0.11

Consistency

measure

5.19

5.25

5.25

5.19

5.16

$\mathrm{Cl}$

0.05

$\mathrm{RI}$

1.12

Ratio

Leading Indicators scored the highest. Management recognized that actionable indicators drive behavior at the front line. Their philosophy was to drive usage and queries of data at the mine site for frontline supervisors. The assessment focused on the current state of these goals as well as what actionable changes were required to drive this successful behavior.

\subsubsection{Assessing the DUVI factors DUVI}

A list of the key data sources was introduced in previous sections. This section will review each factor of the data layer and assign a score. The scores received by each factor are shown below in Table 5-25. Some brief scoring notes are given in the table followed by more specific information about each factor. 


\begin{tabular}{|c|c|c|c|}
\hline Key Factors & Variables - Scoring Mechanisms & Score: & Scoring notes: \\
\hline $\begin{array}{l}\text { Leading } \\
\text { indicators }\end{array}$ & $\begin{array}{l}10-5 \text { leading indicators per KPI } \\
1-0 \text { leading indicators }\end{array}$ & 8 & $\begin{array}{l}\text { Site has had a long term scorecard process with clearly defined } \\
\text { lagging indicators and leading indicators. These scorecards are } \\
\text { separated by manager and vary by each manager. For the most } \\
\text { part each managerial scorecard had the required } 5 \text { leading } \\
\text { indicators / KPI. }\end{array}$ \\
\hline $\begin{array}{l}\text { Improvement } \\
\text { initiatives }\end{array}$ & $\begin{array}{l}10 \text { - The top three systems have } 5 \text { defined } \\
\text { improvement initiatives dependent upon system data } \\
1 \text { - No data driven initiatives }\end{array}$ & 10 & $\begin{array}{l}\text { Site management had a significant tracking system of continuous } \\
\text { improvement initiatives. Each initiative was connected to a } \\
\text { source of data or a system. Their data and information systems } \\
\text { were used in a defined and structured way for each initiative. }\end{array}$ \\
\hline Level of queries & $\begin{array}{l}10-90 \% \text { of queries are local to the site } \\
1-25 \% \text { of queries local to the site }\end{array}$ & 7 & $\begin{array}{l}\text { Site has recognized usage by key local super-users and corporate } \\
\text { users. There was a desire to improve usage at the site level by } \\
\text { extending usage to front line supervisors and additional site } \\
\text { engineering. Through examining the usage statistics it was clear } \\
\text { the need was at that level. }\end{array}$ \\
\hline $\begin{array}{l}\text { Frontline } \\
\text { Engagement }\end{array}$ & $\begin{array}{l}10-50 \% \text { of reports are for frontline supervisors and } \\
\text { operators } \\
1-\text { No reports generated are for frontline supervisors } \\
\text { and operators }\end{array}$ & 7 & $\begin{array}{l}\text { The site's scorecard process was at a managerial and area level. } \\
\text { Supervisors were indirectly represented with these scorecards. } \\
\text { At the time of the assessment, there were no identified operator } \\
\text { scorecards. Site had requested for real time dashboard to be } \\
\text { used by supervisors. }\end{array}$ \\
\hline Report turnover & $\begin{array}{l}10-80 \% \text { of indicators have goals that change } \\
\text { monthly }\end{array}$ & 8 & $\begin{array}{l}\text { The goals of the scorecard were frequently updated and changed } \\
\text { based on a variety of parameters such as operational restraints } \\
\text { and mine plans. }\end{array}$ \\
\hline
\end{tabular}

$1-0 \%$ on indicators have goals that change monthly 
Mine D had a strong continuous improvement department. The people capacity mixed with a robust technology platform lead to many improvement processes. The site had a very well managed scorecard process. Table 5-26 provides a snapshot of the scorecards. The site had eleven manager scorecards consisting of Key Performance Indicators (KPl's) and Leading Indicators. The ratio was calculated and used in the assessment.

Table 5-26: Mine D scorecard statistics for comparing KPl's to leading indicators

\begin{tabular}{|r|r|r|r|}
\hline $\begin{array}{r}\text { Scorecard } \\
\text { Name }\end{array}$ & KPI's & \multicolumn{1}{l|}{ Leading } & \multicolumn{1}{l|}{$\begin{array}{l}\text { Leading to } \\
\text { KPI Ratio }\end{array}$} \\
\hline Coal & 5 & 17 & 3.4 \\
\hline Drill \& Blast & 6 & 10 & 1.7 \\
\hline Dragline & 4 & 20 & 5.0 \\
\hline Coal Manager & 5 & 16 & 3.2 \\
\hline Electrical & 8 & 10 & 1.3 \\
\hline Maintenance 1 & 7 & 19 & 2.7 \\
\hline OB Mantenance 2 & 7 & 19 & 2.7 \\
\hline Ops Manager & 10 & 28 & 2.8 \\
\hline Plant Manager & 6 & 21 & 3.5 \\
\hline Utility & 4 & 8 & 2.0 \\
\hline & 4 & 6 & 1.5 \\
\hline & & & \\
\hline & \multicolumn{2}{|c|}{ Average Ratio } & \\
\hline & & & \\
\hline
\end{tabular}

As mentioned earlier, Mine D had a large $\mathrm{Cl}$ workforce. This workforce was considered the super-users of data. Figure 5-6 and Figure 5-7 provide two histograms of the DW usage statistics. Many data warehouses provided detailed usage statistics. Figure 5-6 shows the duration of queries against the data warehouse by OLAP cube. Figure 5-7 provides the amount of queries by user. As seen there are both site and corporate users of data. Table 5-27 summaries these statistics. As shown the local site accounts for $73 \%$ of the queries on the data warehouse. 


\section{Usage statistics}

0100002000030000400005000060000700008000090000

PRC DW.PRC Data Warehouse 1.Fact Hist Status Events

PRC DW.PRC Data Warehouse.Fact Load Cycle 1 PRC DW.PRC Data Warehouse 2.Fact Checklist Questions PRC DW.PRC Data Warehouse 3.Fact DBO2 1 PRC DW.DailyResults.Status Events 3 PRC DW.PRC Data Warehouse 1.Status Events PRC DW.DailyResults.Fact Load Cycle 1 PRC DW.PRC Data Warehouse 8.Fact Interim Greensheets RealTime_PRC.Dumps.Fact Hist Dumps RealTime_PRC.PRC DW RT 2.Fact Status Events PRC DW.PRC Data Warehouse 26.Fact Hist Fuelings PRC DW.PRC Data Warehouse 31.Fact Fuelsaver Email PRC DW.DailyResults. Fact Liebherr Payload PRC DW.PRC Data Warehouse 22.Fact Tire History PRC DW.PRC Data Warehouse 27.Fact Liebherr Payload PRC DW.PRC Data Warehouse 10.Fact Mine Care Simple PRC DW.DailyResults. Fact Drilling

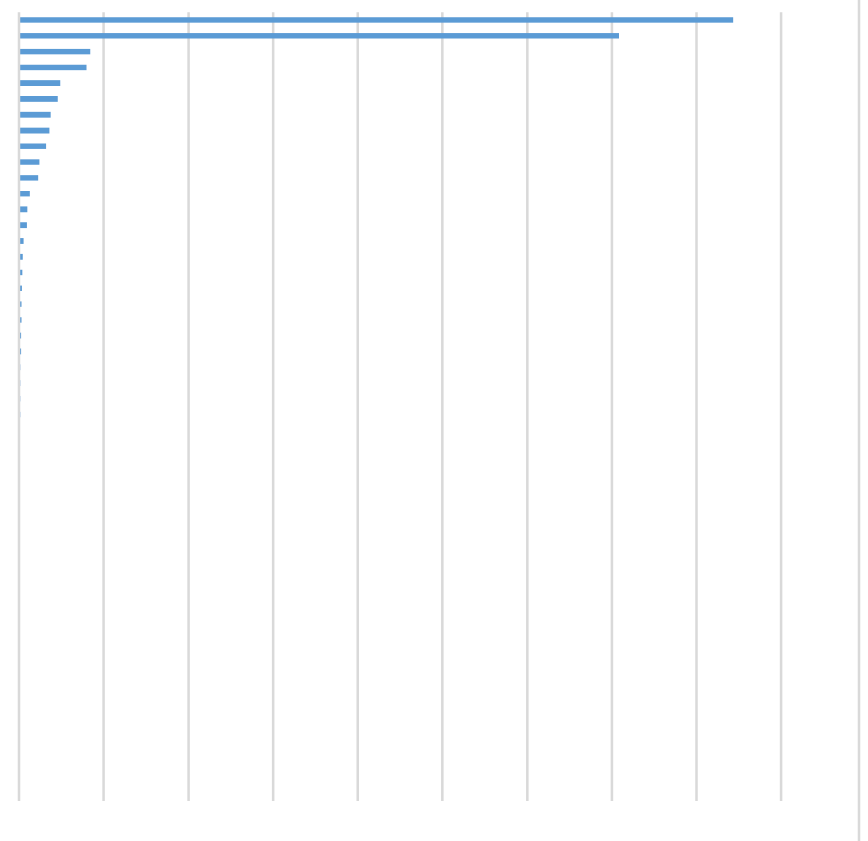

Figure 5-6: Mine D histogram of query duration of key knowledge modules

18000

Figure 5-7: Histogram of queries by user 
Table 5-27: Key usage statistics

\begin{tabular}{|l|l|l|}
\hline Row Labels & Count of Queries & $\%$ of Queries \\
\hline Corp & 22821 & $27 \%$ \\
\hline Site & 61056 & $73 \%$ \\
\hline Grand Total & $\mathbf{8 3 8 7 7}$ & \\
\hline
\end{tabular}

The remaining layers are summarized below in the full DUVI for the site shown in Table 5-28.

Table 5-28: DUVI factors for Mine D

\begin{tabular}{lllcc} 
& Key Factors & AHP & Assessment \\
Layer & System Availability and Health & Sys Health & 0.27 & 10 \\
\hline \hline \multirow{2}{*}{ Data } & Data connectivity & Connectivity & 0.12 & 10 \\
& Nomenclature standards & Engr & 0.17 & 9 \\
& Change / support requests & Sup & 0.27 & 6 \\
& Organizational ownership & Owner & 0.16 & 10 \\
\hline Information & Excel connections & Excel & 0.24 & 10 \\
& Direct report linkage & Dir Link & 0.16 & 8 \\
& Ease of querying & Ease & 0.27 & 8 \\
& Ratio of querying types & Query ratios & 0.12 & 6 \\
& Level of system integration & Integration & 0.21 & 10 \\
\hline Knowledge & Cognitive overload & Overload & 0.25 & 7 \\
& Reporting quality & Quality & 0.24 & 10 \\
& Reporting functionality & Funct & 0.21 & 10 \\
& Report utilization & Utiliz & 0.30 & 8 \\
\hline \hline Action & Leading indicators & Leading Ind & 0.27 & 8 \\
& Improvement initiatives & Initiatives & 0.25 & 10 \\
& Level of queries & Local queries & 0.21 & 7 \\
& Frontline Engagement & Frontline & 0.17 & 7 \\
& Report turnover & Turnover & 0.11 & 8 \\
\hline \hline
\end{tabular}




\subsubsection{Visualizing and managing data utilization}

During the assessment, surveys were conducted (both verbal and data driven) to assess the key variables and the site BI strategy. Similar to the previous cases studies the strategy lead to a weighting of importance and focus for each layer. Each layer was weighted based on the current conditions and data strategy expressed by management. The scoring followed the standard factors although some variables changed due to system requirements. A final score was given and the sum product was taken to obtain a subtotal DUVI for each layer. The final DUVI is taken by taking the sum product of the layer subtotal and AHP weighting factor as shown in Table 5-29.

Table 5-29: Final DUVI score for mine D

\begin{tabular}{rll}
\hline & Factor weighted score & AHP Weighting \\
\hline Data Subtotal: & 8.7 & 0.13 \\
\hline Information Subtotal: & 8.7 & 0.27 \\
\hline Knowledge Subtotal: & 8.6 & 0.22 \\
\hline Action Subtotal: & 8.1 & 0.38 \\
\hline & & \\
\hline DUVI & 8.5 &
\end{tabular}

\subsubsection{Conclusions and discussion}

Mine D has exceptional access to continuous improvement human resources derived from a permanent core of $\mathrm{Cl}$ professionals and consultants. Significant investment has been made in both creating the demand (scorecards) and establishing an IT infrastructure that allows for analysis (DW and cubes), particularly among the local sites.

The mine-site and regional $\mathrm{Cl}$ teams have the opportunity to systematically initiate structured analytical campaigns to analyze underperformance, design solutions, and then monitor (through temporary ad-hoc solution scorecards) the impact of the efforts. These would improve their action score. 
The DUVI can be set up to more closely monitor the execution and return derived from these campaigns by tracking data utilization (who queries and how often queries are executed). These measures (i.e. a scorecard for $\mathrm{BI}$ ) can be created such as: the number of new DW users, query complexity, length, and completing a measure request. These can act as the foundation of a Cl/ Operations support scorecard. Cl departments can create LSI measures such as the number of DW training delivered to Mine D personnel. IT department can set goals related to BI delivery systems and health of source data. A monthly in-depth scorecard-based performance review can help identify the outcomes and $\mathrm{ROI}$ of the improvement projects. The trended improvements from implemented projects can also be reviewed in this monthly meeting. 


\section{Discussion and Conclusions}

\subsection{Summary of research}

A major contribution of this dissertation is the Data Utilization \& Value Index (DUVI). At its simplest definition, the DUVI is an index summarizing an assessment process which focuses on the health and the ease at which systems deliver information and to what extent that information is used. The DUVI uses the data to action $\mathrm{BI}$ methods as a basis for grouping key factors. Each BI layer has a set of measurable factors representing best practices of system and data management resulting in an organization deriving value from data assets. The index has been compiled taking into account existing literature as well as experience in deploying data driven systems in the mining industry. It maintains MIS industry standards in modeling information system deployments. The DUVI provides a consistent approach in accounting for a variety of mine sizes and cultures by using AHP weighting. The DUVI combines quantitative measures (number of OLAP queries, \# of users, etc.) and qualitative (surveys, etc.) measures. These produce a baseline index that can be measured and managed over time. DUVI will be a model parameter determining the likelihood of achieving full benefits of the investments made in technology. This framework can be used as a planning mechanism to do scenario planning as well as feed new initiatives. A series of cases studies was presented to provide more detailed information on each factor and provide examples as to how the DUVI should be used. These were done in a variety of mining companies. Each had a wide variety of scores in the DUVI as shown in Figure 6-1. 


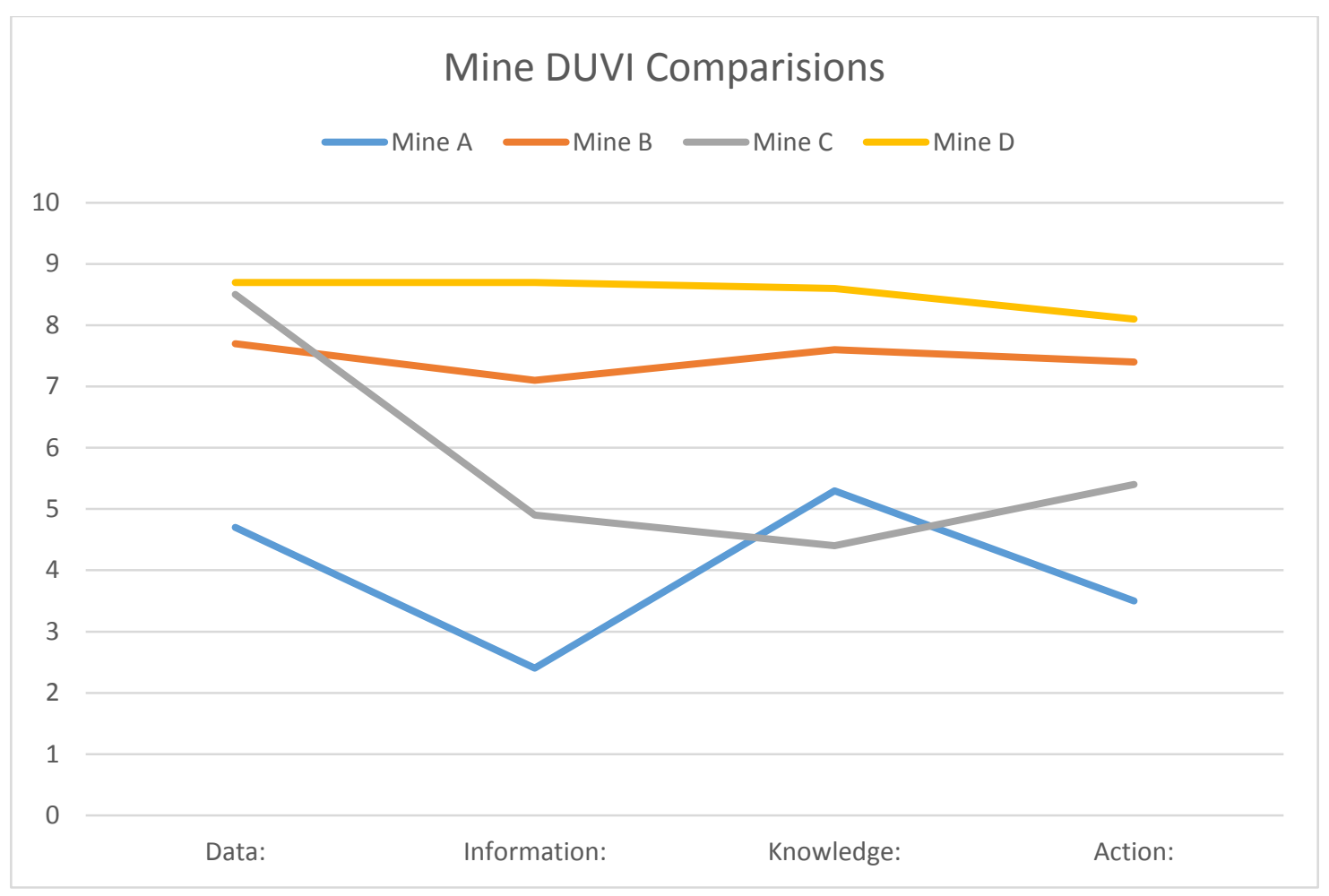

Figure 6-1: Comparisons of the DUVI of the case studies

As shown Mine A has consistently lower scores on all factors with exception of the knowledge layer. Mine C, interestingly, had close to the highest ranking in data but low scores with the other layers. Mine B and Mine D had consistent scores on each factor. A company desiring to improve their data utilization culture can make informed decisions on where to focus their managerial attention and focus.

The dissertation provides the following elements:

- Thorough review of MIS standards for technology deployment best practices (chapter 2)

- Review of methods to derive value from intangible data assets (chapter 2)

- Review of data models within the mining industry (chapter 2)

- Connecting the BI layers to best practice factors (chapter 3)

- Measurement philosophy and best practices for measuring BI system utilization (chapter 3) 
- Quantifying strategy through the AHP weighting (Chapter 4)

- Assessment process of measuring data utilization (chapter 4)

- Applicability of DUVI at four mining companies of various sizes and technology adoption (Chapter 5)

\subsection{Research contributions}

The MIS industry has human technology deployment models focusing on defining which variables are "independent" or "dependent". Many technology best practices have come from these models. However, many of these standards have been created in the retail / consumer industries whose data approach and methodology are quite different than systems used in mining or manufacturing. There is also many models on deriving value from data. A quantitative method for measuring data utilization and value is missing in the mining industry proven to have large data assets. Each mine presented in the case studies had over twenty data sets. The mining industry will benefit by having an assessment process to assist in managing utilization of these data assets. The contributions of the DUVI are:

\section{MIS contributions:}

- Expand the limited research on measurement of "data utilization" of data warehouses

- Industry standard DUVI of source systems

\section{Mining industry contributions:}

- Cross-functional insights into the "data utilization gap" for:

- Equipment manufactures

- Mining companies

- Academia

- Key definitions related to data utilization 
- Managers can manage technology deployments following a set of quantifiable best practices

- Reduction of culture risk by focusing on keeping DUVI at an acceptable level.

- Standard for updating curriculum to the Modern Mining management

- Method to model and manage investment strategies for advanced data driven systems.

- DUVI can be used to weigh benefits of initiatives.

- Improved opportunities for operational outcomes - potential for step change

- Key measurement tool for ROI discussion in technology

\subsection{Conclusions}

Conclusion of dissertation:

- Data utilization can be measured by assessing key best practices of technology adoption.

- Data assets have value similar to physical assets where consistent utilization of Information Systems can drive a step by step change in mining safety, operations, planning, financial modeling, and engineering.

- Case studies show that the DUVI model is applicable for all types of mine sizes.

- Industry would greatly benefit if investments were made in academia to enhance and promote data utilization in mining engineering curriculum.

\subsection{Methodology review and recommendations for future research:}

The modern mining industry has been, and will continue to be, shaped by technology. As shown in the literature and case studies technology is not just new and innovative equipment. Technology also consists of the data infrastructure that monitors and measures the use of that equipment. The industry can continue to innovate management and optimization theories that 
are applicable for all mining types. The DUVI will ensure these theories are applicable and sustainable within an organization. Additional research is needed in this area.

The amount of systems within an organization can be a major barrier to the success of the index. Limiting the scope to a manageable amount of systems will be critical. As shown in the source tables there are a large variety of data sources at any given mine site. The variables to measure ease of use and system availability will vary slightly by source systems. When choosing a variable it is important to consider the purpose and objective of the factor of the $\mathrm{BI}$ layer. Differences between information systems and source systems may lead to difficulty.

Future work in this area is unlimited. Being able to calculate technology $\mathrm{ROI}$ and relate it back to the DUVI would be beneficial conceptually as shown in Figure 6-2.

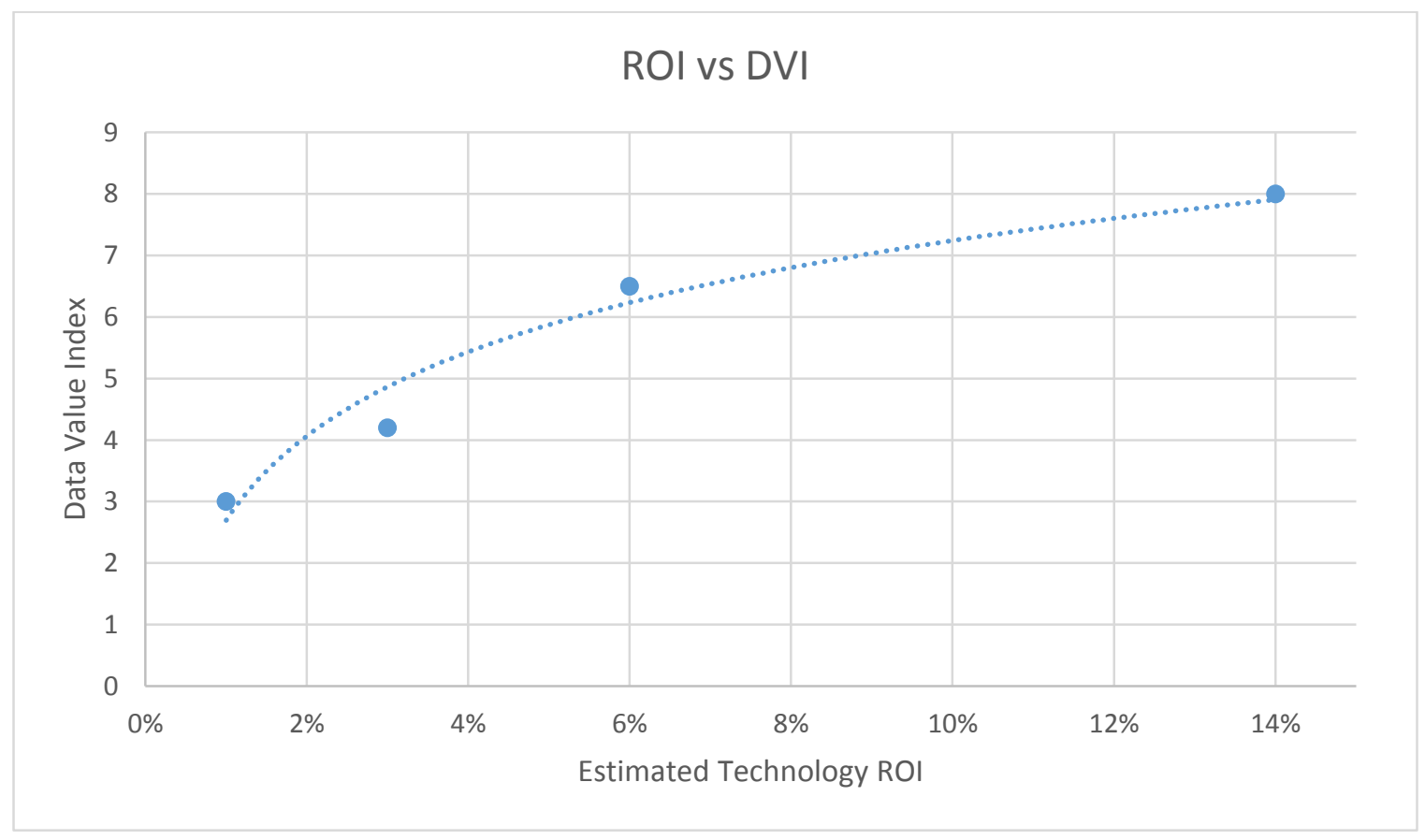

Figure 6-2: Conceptual model of ROI vs. DUVI

This relationship can provide industry with a robust justification model for large DWBI expense. Data utilization is very reflective of managerial flexibility which can be modeled by advanced financial real options analysis. 
Define and investigate methods to isolate direct and indirect benefits of data utilization:

- Safety and cost of incidents

- Productivity improvements (dig rates)

- Use of availability

- Equipment availability

Another interesting area is related to Tobin $Q$ analysis and data utilization. The continual advancement of the "internet of things" IOT will expand the data sources available to mine management. These new sources will only increase the need for tools to manage data utilization. Industry needs to be able to derive value from current data flows in order to prepare for the explosion of data arriving from the IOT (Burrus, 2014) and (Pal, 2015).

These additional data sources will require more advanced data analysis through data mining and big data analytics. The importance of sustained data utilization will only increase along with complication of management.

Continued technology innovation leads to a "redefinition" of professions. Mining engineering schools will be instrumental in producing engineers that are comfortable with the data aspects of modern operations management. Mining curriculum excluding mining operations technology and data utilization techniques would be like teaching medicine without including classes on nutrition.

Recommendations summary:

- Increased visualization and management through real-time system utilization

- Evolving definitions of utilization will be required

- Financial modeling using real options modeling linking technology ROI and managerial flexibility around data utilization 
- Isolation of direct and indirect benefits of data utilization

- Tobin $Q$ analysis of technology innovation and a company's market value

- Preparation and management of IOT in mining

- Implementation and management of advanced data mining

- Updating mining curriculum leading to the next generation of mining technologists and engineers

- Training centers on mining technologies will be required 


\section{Appendix:}

\subsection{DUVI Step definition and details:}

Table 7-1: Definition and details of the DUVI assessment

\begin{tabular}{|c|c|c|c|}
\hline Step & Name & Description & Outcome \\
\hline Step 1 & $\begin{array}{l}\text { Identify scope } \\
\text { of assessment }\end{array}$ & $\begin{array}{l}\text { Define limits of the } \\
\text { assessment or study: } \\
\text { Systems, departments, } \\
\text { people, etc. This can } \\
\text { be done through } \\
\text { identifying key reports } \\
\text { or processes the } \\
\text { organization wants to } \\
\text { implement and work } \\
\text { backward to the data } \\
\text { system. }\end{array}$ & $\begin{array}{l}\text { Key systems to focus on which will help drive } \\
\text { the factors for the assessment }\end{array}$ \\
\hline Step 2 & $\begin{array}{l}\text { Define BI } \\
\text { strategy }\end{array}$ & $\begin{array}{l}\text { having some context } \\
\text { behind the current } \\
\text { people, platform, and } \\
\text { process and where } \\
\text { they want to go in the } \\
\text { future. To get a } \\
\text { current }\end{array}$ & AHP weighting for each BI layer \\
\hline Step 3 & $\begin{array}{l}\text { Define factor } \\
\text { variables }\end{array}$ & $\begin{array}{l}\text { Each BI layer has key } \\
\text { factors. Each factor } \\
\text { can be made up of } \\
\text { custom variables based } \\
\text { upon the technology } \\
\text { platforms in the scope } \\
\text { of the assessment. } \\
\text { Variables will be } \\
\text { important to the } \\
\text { weighting of factors. }\end{array}$ & Factor variables and factor weighting process \\
\hline Step 4 & $\begin{array}{l}\text { AHP factor } \\
\text { weighting }\end{array}$ & $\begin{array}{l}\text { A formal process of } \\
\text { capturing the rank of } \\
\text { importance of the } \\
\text { factors based upon the } \\
\text { available variables of } \\
\text { the systems. }\end{array}$ & AHP weighting \\
\hline Step 5 & Assessment & $\begin{array}{l}\text { The variables of each } \\
\text { factor will be reviewed } \\
\text { and captured in a } \\
\text { formal source matrix } \\
\text { called the MISOM }\end{array}$ & Factor DUVI score \\
\hline
\end{tabular}




\begin{tabular}{|c|c|c|c|}
\hline & & $\begin{array}{l}\text { HOBI matrix. Each } \\
\text { factor will be scored. } \\
\text { Key variable } \\
\text { documentation will be } \\
\text { captured and stored in } \\
\text { will a scoping study } \\
\text { and HOBI matrix }\end{array}$ & \\
\hline Step 6 & DUVI review & $\begin{array}{l}\text { the final DUVI is } \\
\text { reviewed }\end{array}$ & Final DUVI score \\
\hline Step 7 & $\begin{array}{l}\text { Scoping study } \\
\text { report and } \\
\text { presentation }\end{array}$ & $\begin{array}{l}\text { Score is connected to } \\
\text { the scoping study and } \\
\text { presentation. The } \\
\text { Scoping study will be } \\
\text { centered on defining } \\
\text { and improving the } \\
\text { index. In some cases } \\
\text { the ROI calculations } \\
\text { can reference the } \\
\text { DUVI. The DUVI helps } \\
\text { improve two variables } \\
\text { that the schedule } \\
\text { reference; \% likelihood } \\
\text { and \% improvements. }\end{array}$ & $\begin{array}{l}\text { Scoping report, presentation, augmentation } \\
\text { plan, and ROI schedule all centered on driving } \\
\text { DUVI }\end{array}$ \\
\hline
\end{tabular}

\subsection{Analytical Hierarchy Process Calculations}

Matrix calculations:

\begin{tabular}{|c|c|c|c|c|c|}
\hline 4 & A & B & C & D & $\mathbf{E}$ \\
\hline 1 & Pairwise comparisons & & & & \\
\hline 2 & & $=\mathrm{A} 3$ & $=\mathrm{A} 4$ & $=\mathrm{A} 5$ & $=A 6$ \\
\hline 3 & ='DUtl Factor AHP'!B6 & 1 & 1 & 0.333333333333333 & 0.5 \\
\hline 4 & ='DUtI Factor AHP'!B11 & $=1 / \mathrm{C} 3$ & 1 & 1 & 1 \\
\hline 5 & ='DUtI Factor AHP'!B16 & $=1 / \mathrm{D} 3$ & $=1 / \mathrm{D} 4$ & 1 & 1 \\
\hline 6 & ='DUtI Factor AHP'!B20 & $=1 / \mathrm{E} 3$ & $=1 / \mathrm{E} 4$ & $=1 / \mathrm{E} 5$ & 1 \\
\hline 7 & & $=\mathrm{SUM}(\mathrm{B} 3: \mathrm{B} 6)$ & $=\operatorname{SUM}(\mathrm{C} 3: \mathrm{C} 6)$ & =SUM(D3:D6) & $=$ SUM(E3:E6) \\
\hline 8 & & & & & \\
\hline
\end{tabular}

Resulting in: 


\begin{tabular}{|c|c|c|c|c|}
\hline \multicolumn{4}{|c|}{ Pairwise comparisons among BI Layers } & \multirow[b]{2}{*}{ Action } \\
\hline & Data & Information & Knowledge & \\
\hline Data & 1 & 1 & $1 / 3$ & $1 / 2$ \\
\hline Information & 1 & 1 & 1 & 1 \\
\hline Knowledge & 3 & 1 & 1 & 1 \\
\hline \multirow[t]{2}{*}{ Action } & 2 & 1 & 1 & 1 \\
\hline & & 4.0 & 3.3 & 3.50 \\
\hline
\end{tabular}

Averaging out pairwise comparisons:

\begin{tabular}{|c|c|c|c|c|c|}
\hline$\Delta$ & $\mathrm{H}$ & 1 & J & K & L \\
\hline 1 & & & & & \\
\hline 2 & & $=\mathrm{B} 2$ & $=\mathrm{C} 2$ & $=\mathrm{D} 2$ & $=\mathrm{E} 2$ \\
\hline 3 & & $=\mathrm{B} 3 / \mathrm{B} \$ 7$ & $=\mathrm{C} 3 / \mathrm{C} \$ 7$ & $=\mathrm{D} 3 / \mathrm{D} \$ 7$ & $=E 3 / E \$ 7$ \\
\hline 4 & & $=\mathrm{B} 4 / \mathrm{B} \$ 7$ & $=\mathrm{C} 4 / \mathrm{C} \$ 7$ & $=D 4 / D \$ 7$ & $=\mathrm{E} 4 / \mathrm{E} \$ 7$ \\
\hline 5 & & $=\mathrm{B} 5 / \mathrm{B} \$ 7$ & $=\mathrm{C} 5 / \mathrm{C} \$ 7$ & $=\mathrm{D} 5 / \mathrm{D} \$ 7$ & $=\mathrm{E} 5 / \mathrm{E} \$ 7$ \\
\hline 6 & & $=\mathrm{B} 6 / \mathrm{B} \$ 7$ & $=\mathrm{C} 6 / \mathrm{C} \$ 7$ & $=\mathrm{D} 6 / \mathrm{D} \$ 7$ & $=E 6 / E \$ 7$ \\
\hline 7 & & & & & \\
\hline
\end{tabular}

Resulting in:

\begin{tabular}{|r|r|r|r|}
\hline Data & Information & Knowledge & Action \\
\hline 0.1429 & 0.2500 & 0.1000 & 0.1429 \\
\hline 0.1429 & 0.2500 & 0.3000 & 0.2857 \\
\hline 0.4286 & 0.2500 & 0.3000 & 0.2857 \\
\hline 0.2857 & 0.2500 & 0.3000 & 0.2857 \\
\hline
\end{tabular}

Key AHP indicator calculations: 


\begin{tabular}{|c|c|c|c|}
\hline 2 & $\mathrm{~N}$ & $\mathrm{O}$ & $\mathbf{P}$ \\
\hline 1 & & & \\
\hline 2 & Weighting & & Consistency measure \\
\hline 3 & =AVERAGE(I3:M3) & & $=$ MMULT(B3:E3,N3:N6)/N3 \\
\hline 4 & $=$ AVERAGE $(14: L 4)$ & & $=\operatorname{MMULT}(\mathrm{B} 4: \mathrm{E} 4, \$ \mathrm{~N} \$ 3: \$ \mathrm{~N} \$ 6) / \mathrm{N} 4$ \\
\hline 5 & $=$ AVERAGE(I5:L5) & & $=$ MMULT(B5:E5, $\$ \mathrm{~N} \$ 3: \$ N \$ 6) / \mathrm{N} 5$ \\
\hline 6 & =AVERAGE $(16:$ L6) & & $=$ MMULT $(\mathrm{B} 6: \mathrm{E} 6, \$ \mathrm{~N} \$ 3: \$ \mathrm{~N} \$ 6) / \mathrm{N} 6$ \\
\hline 7 & & $\mathrm{Cl}$ & $=($ AVERAGE $(\mathrm{P} 3: \mathrm{P} 6)-4) / 3$ \\
\hline 8 & & RI & 0.9 \\
\hline 9 & & C Ratio & $=\mathrm{P} 7 / \mathrm{P} 8$ \\
\hline
\end{tabular}

Resulting in:

\begin{tabular}{|r|r|r|}
\hline Weighting & Consistency measure \\
\hline 0.16 & 4.08 \\
\hline 0.24 & 4.09 \\
\hline 0.32 & 4.17 \\
\hline 0.28 & 4.13 \\
\hline $\mathrm{Cl}$ & 0.04 \\
\hline $\mathrm{Rl}$ & 0.90 \\
\hline C Ratio & 0.04 \\
\hline
\end{tabular}




\subsection{Excel calculations of DUVI showing sum product}

\begin{tabular}{|c|c|c|c|c|c|}
\hline & B & c & D & E & $\mathrm{F}$ \\
\hline 3 & \multicolumn{5}{|l|}{ Data Utilization Index (DUtI) } \\
\hline \multicolumn{6}{|l|}{4} \\
\hline 5 & Layer & Key Factors & Abbreviation & AHP Weight & Assessment Score \\
\hline 6 & Data & System Availability and Health & Sys Health & $=$ 'AHP Weighting!'N13 & ='Scoring worksheet'? 4 \\
\hline 7 & & Data connectivity & Connectivity & ='AHP Weighting!'N14 & "='Scoring worksheet'!F5 \\
\hline 8 & & Compliance to mine plan and TUM & Engr & ='AHP Weighting'!N15 & "='Scoring worksheet'!F6 \\
\hline 9 & & Change i support requests & Sup & = 'AHP W'eighting' N16 & '='Scoring worksheet!'F7 \\
\hline 10 & & Organizational ownership & Owner & ='AHP W'eighting'!N17 & ='Scoring worksheet'?F8 \\
\hline 11 & Information & Excel connections & Excel & ='AHP Weighting!'N24 & = 'Scoring worksheet'"F9 \\
\hline 12 & & Direct report linkage & Dir Link & = 'AHP Weighting!'N25 & ='Scoring worksheet!'F10 \\
\hline 13 & & Ease of querying & Ease & = 'AHP Weighting'N26 & ='Scoring worksheet'?F11 \\
\hline 14 & & Ratio of querying types & Query ratios & = 'AHP Weighting'!N27 & ='Scoring worksheet'!F12 \\
\hline 15 & & Level of system integration & Integration & ='AHP Weighting'!N28 & ='Scoring worksheet!'F13 \\
\hline 16 & Knowledge & Cognitive overload & Overload & ='AHP Weighting'!N35 & ='Scoring worksheet'!F14 \\
\hline 17 & & Reporting quality & Quality & ='AHP Weighting'N36 & ='Scoring worksheet'! 15 \\
\hline 18 & & Reporting functionality & Funct & = 'AHP Weighting'!N37 & ='Scoring worksheet'!F16 \\
\hline 19 & & Report utilization & Utiliz & = 'AHP W'eighting'!N38 & = 'Scoring worksheet'?F17 \\
\hline 20 & Action & Leading indicators & Leading Ind & = 'AHP Weighting'!N45 & ='Scoring worksheet'?F18 \\
\hline 21 & & Improvement initiatives & Initiatives & = 'AHP W'eighting'!N46 & ='Scoring worksheet!'F19 \\
\hline 22 & & Level of queries & Local queries & = 'AHP Weighting!'N47 & ='Scoring worksheet'!F20 \\
\hline 23 & & Frontline Engagement & Frontline & ='AHP Weighting'!N48 & ='Scoring worksheet!'F21 \\
\hline 24 & & Report turnover & Turnover & ='AHP W'eighting'!N49 & ='Scoring w orksheet'!F22 \\
\hline \multicolumn{6}{|l|}{25} \\
\hline \multicolumn{6}{|l|}{26} \\
\hline 27 & & & AHP Weight & & \\
\hline 28 & Data: $=$ & "=SUMPRODUCT(F6:F10,E6:E10) & = 'AHP Weighting!!N3 & & \\
\hline 29 & Information: = & =SUMPRODUCT(F11:F15,E11:E15) & ='AHP Weighting!!N4 & & \\
\hline 30 & Knowledge: = & =SUMPRODUCT(F16:F19,E16:E19) & ='AHP Weighting'!N5 & & \\
\hline 31 & Action: $=$ & =SUMPRODUCT(F20:F24,E20:E24) & ='AHP Weighting'!N6 & & \\
\hline \multicolumn{6}{|l|}{32} \\
\hline 33 & DVI: $=$ & =SUMPRODUCT(C28:C31,D28:D31) & & & \\
\hline 34 & & & & & \\
\hline
\end{tabular}

\subsection{Write up of short course survey on big data}

In February 2015 Sean Dessureault held a short course at the SME conference in Denver CO.

Some of the top industry expert's attended discussing key items about big data in mining. Pratt

Rogers presented and surveyed the attendees on key question related to data utilization. The following summarizes each of the questions and the responses.

\subsection{Justification NPV and Real Options Analysis}

At the start of the dissertation the author explored the possibility of using Real Option Analysis

ROA as part of the model. After realizing the complication of just measuring data utilization 
ROA was removed. When discussing $\mathrm{ROI}$ of technology ROA will be critical to correctly assess the impact of technology. There are many risk factors and ROA can account for these in justification.

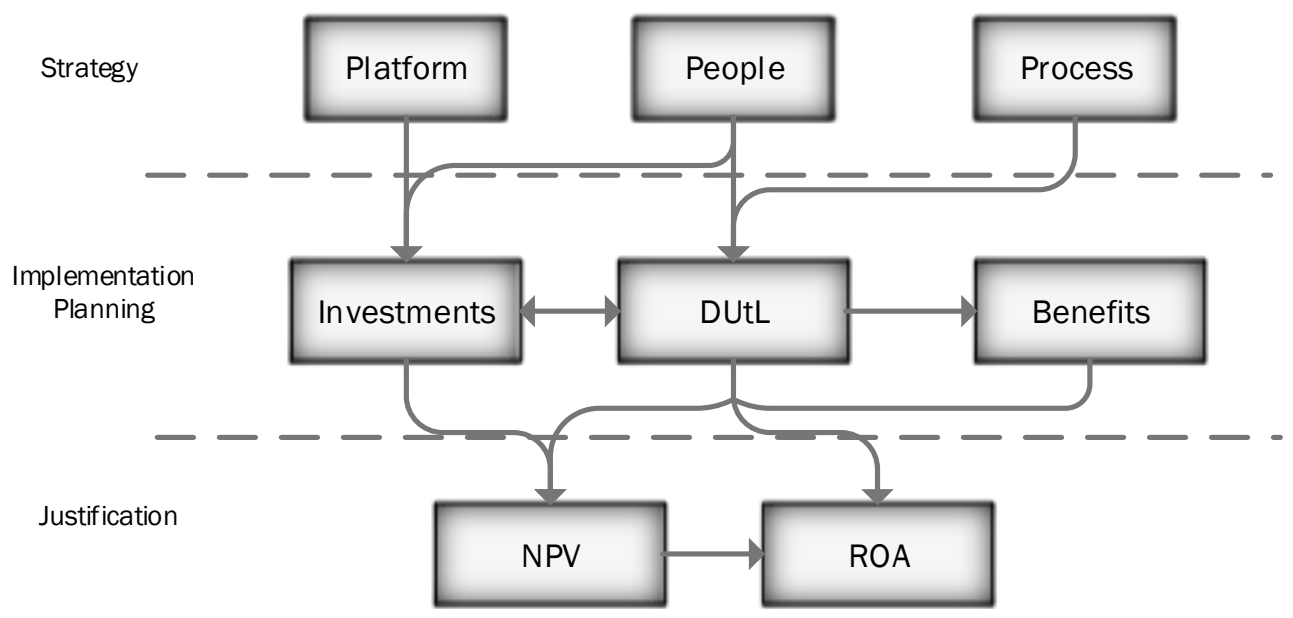

Figure 7-1: Methodology

\subsubsection{Conceptual Justification Model Introduction:}

The proposed methodology will extend current MIS models to and integrated IT and culture (data utilization) framework. The proposed model attempts to build upon the Datar-Mathews options pricing model by introducing the key variable of "Data Value Index" to the NPV calculations. The model will be introduced and each step defined in detail. The objectives, equations and output of each step will be reviewed. 
Table 7-2: Summary of ROA model framework

Step 1: NPV Schedules

Step 2: Data Value Index

Step 3: Monte Carlo Simulation

Step 4: Datar - Mathews RO pricing model

\begin{tabular}{|c|c|c|c|c|}
\hline Objectives & $\begin{array}{l}\text { Schedule all investments } \\
\text { and potential benefits } \\
\text { based on a clear strategy } \\
\text { framework }\end{array}$ & $\begin{array}{l}\text { An index used to weight the } \\
\text { potential benefits of a DW. }\end{array}$ & $\begin{array}{l}\text { What if analysis of key } \\
\text { parameters and variables }\end{array}$ & $\begin{array}{l}\text { Evaluation considering managerial } \\
\text { flexibility }\end{array}$ \\
\hline $\begin{array}{l}\text { Comments / } \\
\text { Equations }\end{array}$ & $\begin{array}{l}\text { Strategy framework based } \\
\text { Investments are isolated } \\
\text { and assumption scheduled } \\
\text { Potential benefits }\end{array}$ & $\begin{array}{l}\text { See Excel DUVI model } \\
\text { Case studies will be used to } \\
\text { develop a probability used in } \\
\text { estimating the potential } \\
\text { benefits of a DW initiative. } \\
\text { This probability will be a } \\
\text { function of the correlation } \\
\text { between Data Value Index } \\
\text { and positive operational } \\
\text { outcomes of three actual data } \\
\text { warehousing initiatives. }\end{array}$ & $\begin{array}{l}\text { This simulations adjust } \\
\text { key variables that will } \\
\text { predict the number of } \\
\text { occurrences o }\end{array}$ & \\
\hline Output & $\begin{array}{l}\text { Standard discounted cash } \\
\text { flow of investments }\end{array}$ & $\begin{array}{l}\text { A quantitative/qualitative } \\
\text { assessment of data } \\
\text { utilization. }\end{array}$ & & Risk adjusted NPV \\
\hline
\end{tabular}




\subsubsection{NPV and IT Investment classification and schedule}

All financial justification models start with a schedule of costs and anticipated returns on proposed investments. Our model of scheduling investments for a data warehousing initiatives will require some assumptions and discounts. Data warehouses our complex machines that are built upon existing IT infrastructure that has been in place for a significant period of time. Many of these costs can be considered "sunk" or out of the schedule as they are not an additional expenditure for the initiatives. This section will provide a detailed accounting of the methods used to classify investments (costs) and benefits (returns) used in the justification model.

\subsubsection{Strategy Definition:}

The first step in isolating investments and potential benefits is to determine a specific strategy for the proposed investment and improvement initiative. This strategy will be the guiding principles used to estimate the required investments and potential benefits of the initiative. The strategy will be based on the tiers presented in Figure 3-1Error! Reference source not found. The strategy must lay out management goals and allotment of resources for the people, platform and processes. As seem in upcoming section investment schedules are grouped according to these strategy buckets.

\subsubsection{Investment NPV Schedule:}

The literature describes the state of technology in the mining industry. Technology infrastructure requires investment across multiple departments and functions. Many of these technology are used for a variety of purposes which facilitate operating a modem mine. Many of the platforms used for a data warehousing initiatives are built upon existing infrastructure.

\subsection{Platforms -}

DW, additional hardware, source systems etc. 
7.5.2.2.2 People-

new $\mathrm{Cl}$ and $\mathrm{BI}$ people to support data utilization processes

A potential schedule of the NPV will look similar to what is shown in Figure 7-2. 


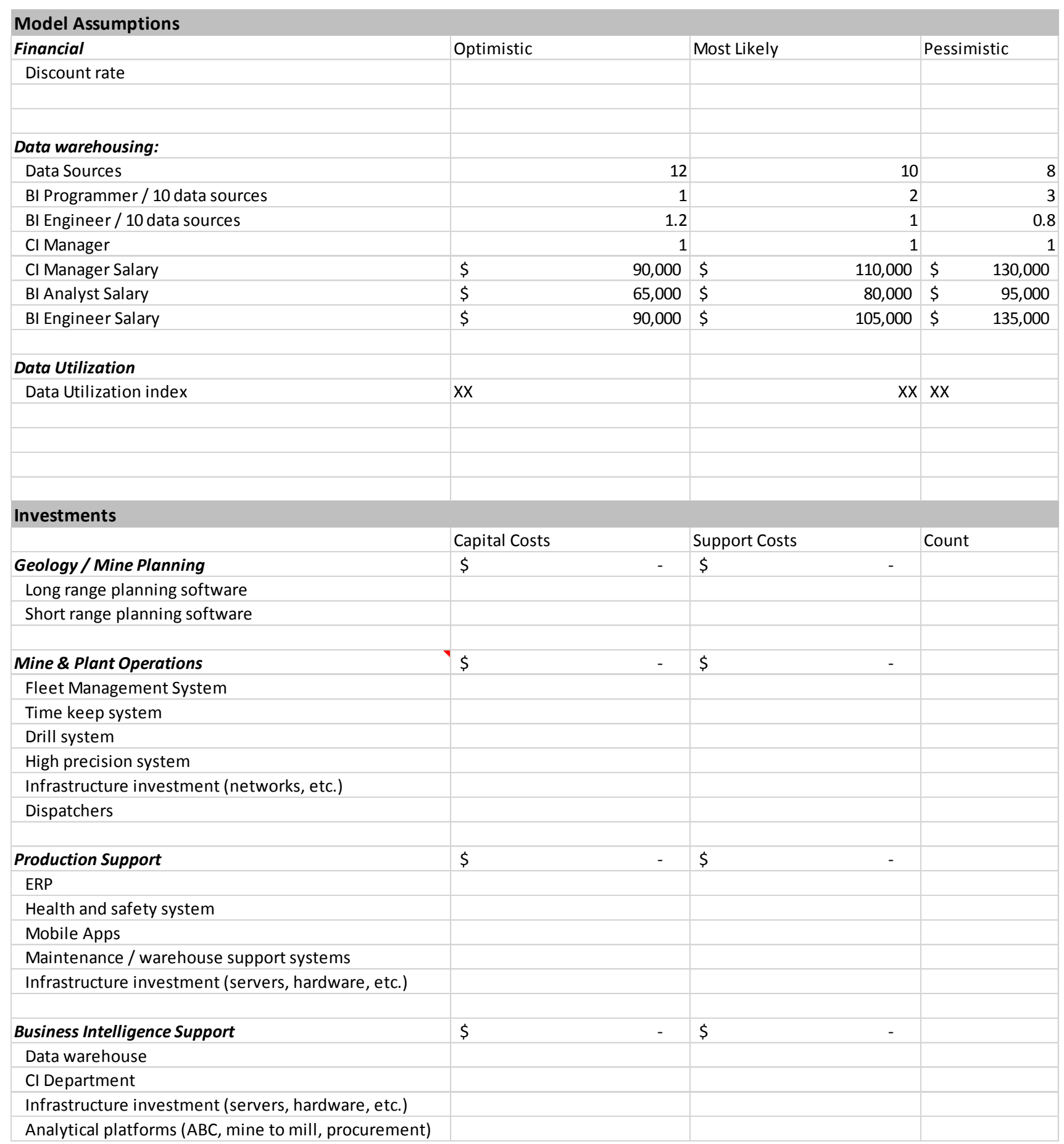

Figure 7-2: A typical investment assumptions and schedule 


\subsubsection{Benefit NPV Schedule:}

\subsection{Business Insight}

A key benefit of using data or business intelligence for an organization. Examples of business insight are high level monthly reports consumed in business meetings. Usually business insight is made of "Key Performance Indicators". They are usually "look backs" on the past performance of organizations. This level of data utilization usually guides long term capital expenditures or strategy decisions. Accurate business insight can have significant impact on mine planning and adherence to mine plan. Certain operations with complex geology and operational constraints require consistent adherence to mine plan even at the expense of equipment efficiency. General business insight ensures that normal decisions are based on accurate and timely data.

\subsection{Process improvement}

This category of benefit is related to initiatives that are used to change behavior of site management, front line supervision and operators. Process improvement will change behavior of management though prescribed process that create focus and pointed questions. These initiatives are supported and maintained by local entities. Process improvement focuses primarily on leading indicators with limited use of operational outcomes. Initiatives such as these required aggregatable data across multiple dimensions.

The typical benefit classification schedule will look similar to what is shown in Figure 7-3. 


\begin{tabular}{|c|c|c|c|}
\hline Benefits & & & \\
\hline Geology Mine Planning & Type & Definition & \\
\hline Budgeting and forecasting & $\begin{array}{l}\text { qualitative (difficult to } \\
\text { quantify) }\end{array}$ & $\begin{array}{l}\text { Improvements from improv } \\
\text { can be large and significant. }\end{array}$ & forecasting and budgeting. These \\
\hline Plant \& Mine Operations (source systems) & Insight & Only available it some level & DUl is seem from source systems \\
\hline Equipment efficiency (availability \& utilization) & Quantitative & $\begin{array}{l}\text { Investment in technology sh } \\
\text { equipment efficiency from } \\
\text { of equipment. }\end{array}$ & $\begin{array}{l}\text { uld lead to improvements in } \\
\text { proved availability and utilization }\end{array}$ \\
\hline Employee efficiency (operators and clerks) & $\begin{array}{l}\text { Quantitative (with companies } \\
\text { that have Kronos) }\end{array}$ & $\begin{array}{l}\text { Improvement in personnel } \\
\text { ton/man-hour will be used }\end{array}$ & $\begin{array}{l}\text { nagement such as overtime or } \\
\text { measure this KPI }\end{array}$ \\
\hline Production Support (source systems) & Insight & & \\
\hline Budgeting and forecasting & Qualitative & Only available it some level & DUl is seem from source systems \\
\hline Incident rate & Quantitative (not monetary) & While this may be hard to q & ntify for this area of research there \\
\hline Equipment health & Quantitative & Improvements in tires, and & uipment damage results in \\
\hline Maintenance & Quantitative & Available hours, improved $\mathrm{F}$ & planning or unplanned \\
\hline $\begin{array}{l}\text { Business Intelligence Support (Extra benefits from } \\
\text { improved DUI) }\end{array}$ & Process improvement & Only available if the option & invest in $\mathrm{Bl}$ is chosen in year $\mathrm{x}$. \\
\hline Shift coordination & Quantitative & Shift coordination through $\mathrm{p}$ & cess improvement activities such \\
\hline Reduced spending & Quantitative & measurement of spending & \\
\hline & & & \\
\hline & & & \\
\hline
\end{tabular}

Figure 7-3: Benefits schedule 


\subsubsection{Real option analysis:}

Real options justification methods are robust enough to model managerial flexibility and multiple sources of uncertainty related to data utilization.

- Datar Mathews approach using NPV, Monte Carlo Simulation, and unique datar Mathews real options valuing

\subsubsection{Option and Scenario Modeling}

\subsubsection{Probabilities calculations:}

- Scoping studies

- initial DUVI prior to DW

- Time series

- DUVI comparison after DUVI - expanded more fully in the case studies

Must account for multiple sources of uncertainty. Real options modeling with multiple sources of uncertainty has been done in the literature. The proposed model there takes into account managerial flexibility related to how data is incorporated into the organization.

Table 7-3: Data utilization options possibilities

\begin{tabular}{lll}
\hline Data Value Index & Probability & \multicolumn{1}{c}{ Strategy } \\
\hline High DUVI & XXX & $\begin{array}{l}\text { A high data utilization is an organization that has fully } \\
\text { absorbed the data warehouse into the reporting and process } \\
\text { improvement strategies. Granularity and integration of data } \\
\text { allows individual mines and corporate to report from same } \\
\text { systems }\end{array}$ \\
\hline Most likely DUVI & XXX & $\begin{array}{l}\text { The most likely scenario is when an individual mine has most } \\
\text { reports and improvement processes based on the granular } \\
\text { data of the DW. Some reports for site and corporate are based } \\
\text { on "outside" excel sheets. }\end{array}$
\end{tabular}




\section{Low DUVI}

$\mathrm{XXX}$

A low Data Value Index is usually depicted on a company that uses data in limited fashions for monthly reports. It is all done through very risky and difficult spreadsheets that are not connected to data tables.

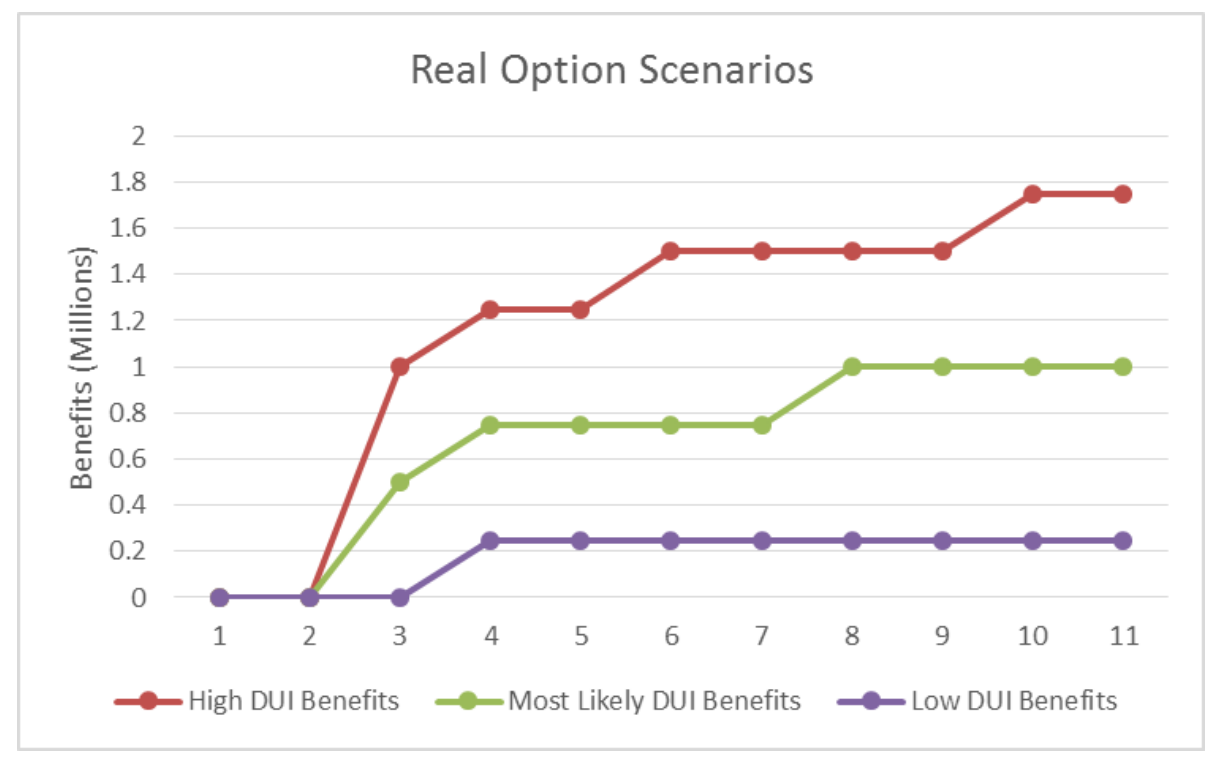

Figure 7-4: Real option scenarios

- Data utilization $=$ to impact

- Impact needs evaluation

- As impact evaluated get value of data

Table 7-4: Key NPV variable definitions

Variable Definition

Monte Carlo Simulation of what if analysis used to measure the impact of key variables on the overall risk adjusted NPV 


\begin{tabular}{|c|c|}
\hline Manager flexibility & $\begin{array}{l}\text { Managers at operation have the "option" to utilize data. Therefore manager flexibility } \\
\text { and data utilization (process) are linked. When a manger "exercises" the option to } \\
\text { utilize data there are expected returns on the investments. }\end{array}$ \\
\hline Investments & Proposed investments in People, Platform, and Process. \\
\hline Benefits & Return on investment scheduled under insight and process benefits \\
\hline Cash flows & $\begin{array}{l}\text { - } \text { Original sources }(\$, t) \\
\text { - } \quad \text { DW \& SOWs }(\$, t) \\
\text { - } \quad \text { Cl personnel }(\$, t) \\
\text { - } \quad \text { Interest rate }(i) \\
\text { - } \quad \text { Ongoing annuity (support costs) }\end{array}$ \\
\hline
\end{tabular}




\section{References}

Anon., 2012. Criteria for Accrediting Engineering Programs, Baltimore: s.n.

Anon., 2015. Colorado School of Mines: Engineering and Technology Management Program. [Online] Available at: http://inside.mines.edu/MS-Engineering-Technology-Management [Accessed 8 2015].

Anon., 2015. GRADUATE CERTIFICATE IN MINE PRODUCTION AND INFORMATION TECHNOLOGY. [Online]

Available at: http://online.engineering.arizona.edu/online-programs/mining-and-geological$\underline{\text { engineering/graduate-certificate-in-mine-production-and-information-technology/ }}$ [Accessed 8 2015].

Anon., 2015. South Dakota School of Mines and Technology. [Online]

Available at: http://www.sdsmt.edu/Academics/Departments/Mining-Engineering-andManagement/Mining-Engineering-and-Management/ [Accessed 8 2015].

Applegate, L. M., Austin, R. D. \& McFarlan, W. F., 2007. Corporate Information Strategy and Management. s.I.:McGraw-Hill/Irwin.

Bartos, P. J., 2007. Is mining a high-tech industry?: Investigations into innovation and productivity advance. Resources Policy, 12, 32(4), pp. 149-158.

Batini, C. \& Scannapieca, M., 2006. Data Quality: Concepts, Methodologies, and Techniques. Berlin: Springer.

Bearman, R. A., 2013. Step change in the context of comminution. Minerals Engineering, pp. 2-11.

Benito, R. \& Dessureault, S., 2008. Estimation of incremental haulage costs by mining historical data and their influence in final pit limit definition. Mining Engineering, 60(10), p. 10. 
Boudreau-Trudel, B., Nadeau, S., Zaras, K. \& Deschamps, I., 2014. Introduction of Innovative Equipment in Mining: Impact on Occupational Health and Safety. Open Journal of Safety Science and Technology.

Bradley, R. V., Pridmore, J. L. \& Byrd, T. A., 2006. Information Systems Success In the Context of Difference Corporate Cutlure Types: An Empirical Investigation. Journal of Managment Information Systems, 23(2), pp. 267-294.

Brandao, L., Dyer, J. S. \& Hahn, W. J., 2005. Using Binomial Decision Trees to Solve Real-Option Valuation Problems. Decision Analysis, June, 2(2), pp. 69-88.

Burrus, D., 2014. The Internet of Things Is Far Bigger Than Anyone Realizes. [Online] Available at: http://www.wired.com/insights/2014/11/the-internet-of-things-bigger/

Chen, T., Zhang, J. \& Lai, K.-K., 2009. An integraed real options evaluation model for information technology under multiple risks. International Journal of Project Management, 27(8), pp. 776786.

Coulson, M., 2012. The history of mining: The events, technology and people involved in the industry that forged the modern world. s.l.:Harriman House Limited.

Davis, F., 1989. Percieved Usefulness, Percieved Ease of Use, and User Acceptance of Information Technology. MIS Quarterly, 13(3), pp. 319-340.

De Lemos, D., 2013. Surface mining technology: Managing the paradigm shift.. Mining Engineering, December, 65(12), pp. 36-40.

DeLone, W. H. \& McLean, E. R., 1992. Information systems success: The quest for the dependent variable.. Information systems research, pp. 60-95.

DeLone, W. H. \& McLean, E. R., 2003. The DeLone and McLean Model of Information Systems Success: A Ten-Year Update. Journal of Managment Information Systems, 19(4), pp. 9-30. 
Dessurealt, S., Sinuhaji, A. \& Coleman, P., 2007. Data Mining Mine Saftey Data. Mining Engineering Magazine, 59(8), pp. 65-70.

Dessureault, S., 2002. Tactical mine management. [Online]

Available at: http://hdl.handle.net/2429/12942

Dessureault, S., 2007. Data Mining Mine Data: Energy Consumption Model. CIM Magazine, 2(6).

Dessureault, S., 2015. MISOM resources: Data warehouse. [Online]

Available at: http://www.misom.com/index.php/resources

[Accessed 2015].

Dessureault, S. \& Scoble, M., 2003. Data infrastructure for a tactical mine management system. Mine Technology, Volume 112, pp. 73-85.

Dutton, E. \& Afuang, A., 2015. Robotics, Control and Virtual Reality: Why Digital Transformation is Critical for Mining. [Online]

Available at: http://www.idc.com/getdoc.jsp?containerld=prSG25858815

[Accessed 258 2015].

Eppler, M. J. \& Mengis, J., 2004. The Concept of Information Overload: A Review of Literature from Organization Science, Accounting, Marketing, MIS, and Related Disciplines. The Information Society: An International Journal, 20(5), pp. 324-344.

Erkayauglu, M., 2015. A Data Driven Mine-to-Mill Framework for Modern Mines, University of Arizona: Dissertation.

Espinoza, R. M. R., 2013. REENGINEERING FRONTLINE SUPERVISION IN A LARGE COAL MINE THROUGH A CENTRALIZED CONTROL ROOM AND MOBILE COMPUTING, University of Arizona: Masters Thesis. 
Farooki, M., 2012. The diversification of the global mining equipment industry-Going new places?. Resources Policy, pp. 417-424.

Filippou, D. \& King, M., 2011. R\&D prospects in the mining and metals industry. Resources Policy, pp. 276-284.

Gutierrez, E. A., 2008. Integration of Data Sources for Optimizing the Drill-to-Leach/Mill Process through the Application of Data Warehousing and Data Mining Techniques, University of Arizona: Master Thesis.

Haug, A., Zachariassen, F. \& van Liempd, D., 2011. The costs of poor data quality. Journal, 4(2).

Hitzman, M. W., 2002. R\&D in a "declining" industry (mining): support for the development of revolutionary technologies?. Technology in Society, pp. 63-68.

Janseen, R. \& de Poot, H., 2006. Information overload: why some people seem to suffer more than others. s.I., NordiCHI '06.

Jerry, C.-J. C. \& RKING, W., 2005. Measuring the Performance of Information Systems: a Functional Scorecard. Journal of Managment Information Systems, 22(1), pp. 85-115.

Kahraman, M., 2011. Real-time adherence to mine plan screen for integrated control rooms.. The University of Arizona: Thesis.

Kahraman, M., 2015. HOLISTIC MINE MANAGEMENT BY IDENTIFICATION OF REAL-TIME AND HISTORICAL PRODUCTION BOTTLENECKS. The University of Arizona: Dissertation.

Kaplan, R., Kaplan, R. S. \& Norton, D. P., 1996. The balanced scorecard: translating strategy into action. s.I.:Harvard Business Press.

Kaplan, R. S. \& Norton, D. P., 2004. Measuring the Strategic Readiness of Intangible Assets. Harvard business review, 82(2), pp. 52-63. 
Klippel, A. F., Petter, C. O. \& Antunes, J. A. V. J., 2008. Management Innovation, a way for mining companies to survive in a globalized world. Utilities Policy, p. 332-333.

LaValle, S. et al., 2013. Big Data, Analytics and the Path From Insights to Value. MIT Sloan Management Review, December.

Lopez, R. B., 2008. MINE EQUIPMENT REPLACEMENT ANALYSIS THROUGH DATAMINING AND ACTIVITY BASED COSTING, University of Arizona: Masters Thesis.

MacDonald, J., 2013. Managing a mining operation requires actionable production intelligence. Mining Engineering, March, 65(3), pp. 55-56.

Mathews, S., 2009. VALUING RISKY PROJECTS WITH REAL OPTIONS.. Research Technology Management, 52(5), pp. 32-41.

Mathews, S., Datar, V. \& Johnson, B., 2007. A Practical Method for Valuing Real Options: The Boeing Approach. Journal of Applied Corporate Finance, pp. 95-101.

Miles, R., n.d. History of Mining Innovations. [Online] Available at: https://magic.piktochart.com/output/6118356-history-of-mining-innovations [Accessed 258 2015].

Mottola, L. \& Payton, R., n.d. Information Technology for Mining - A Strategic Approach. s.I.s.n.

Nelson, R., P, T. \& B, W., 2005. Antecedents of Information and System Quality: An Empirical Examination Within the Context of Data Warehousing. Journal of Management Information Systems, 21(4), pp. 199-235.

Nikulin, C., Graziosi, S., Cascini, G. \& Stegmaier, R., 2013. Integrated Model for Technology Assessment and Expected Evolution: A Case Study in the Chilean Mining Industry. Journal of Integrated Design \& Process Science, pp. 53-80. 
Nusca, . A., 2015. Fortune. [Online]

Available at: http://fortune.com/2015/08/25/internet-things-mining-industry/

[Accessed 258 2015].

Pal, T., 2015. Wearable and Big Data: Potential Challenges, Potential Rewards. [Online]

Available at: http://electronicsofthings.com/2015/08/wearable-and-big-data-potential-challengespotential-rewards/

Ramamurthy , K. R., Sen, A. \& Sinha, A. P., 2008. An empirical investigation of the key determinants of data warehouse adoption.. Decision Support Systems, pp. 817-841.

Rogers, W. P., 2012. Using Data Warehousing to Develop a Social Intelligence Suite for the American Coal Mining Industry, University of Arizona: Master Thesis.

Sadiq, S., 2013. Handbook of Data Quality: Research and Practice. Berlin: Springer-Verlag.

Salcedo, M. A. A., 2012. REAL TIME COST ESTIMATION FOR EQUIPMENT ASSIGNATION IN MINING OPERATIONS, University of Arizona: Master Thesis.

Shin, N., 2006. The impact of information technology on the financial performance of diversified firms.. Decision Support Systems, 41(4).

Sinuhaji, A., 2007. IMPROVING BLOCK CAVING PRODUCTION PLANNING TRHOUGH THE USE OF DATA WAREHOUSING AND DATA MINING, University of Arizona: Masters Thesis.

Tenorio, V. O., 2012. MEASUREMENT OF THE EFFECTIVENESS OF A DECISION SUPPORT SYSTEM FOR BLENDING CONTROL OF LARGE SCALE COAL MINES, University of Arizona: Masters Thesis.

Tilton, J. E., 2003. Creating wealth and competitiveness in mining. Mining Engineering, pp. 15-22. 
Tilton, J. E. \& Landsburg, H. H., 1999. Innovation Productivity Growth, and the survival of the U.S. copper industry. Productivity in Natural Resource Industries; Improvement through Innovation, pp. 109-139.

Upstill, G. \& Hall, P., 2006. Innovation of the mineral industry: Australia in a global context. Resources Policy, pp. 137-145.

Venkatesh, V., Morris, M., Davis, G. \& Davis, F., 2003. User acceptance of information technology: Toward a unified view. MIS Quarterly, pp. 425-478.

Williams, S. \& Williams, N., 2010. The profit impact of business intelligence. s.I.:Morgan Kaufmann.

Witchalls, C., 2013. The internet of things business index. The Economist.

Yeo, K. T. \& Qui, F., 2003. The value of management flexibility-a real option approach to investment evaluation. International Journal of Project Management, 21(4), pp. 243-250.

Yildirim, M., 2005. Data Mining in Pit Production Management System, University of Arizona: Masters Thesis.

Zammit-Lucia, J., 2013. Rosia Montana and misguided activism. [Online] Available at: http://www.mining.com/web/rosia-montana-and-misguided-activism/ 